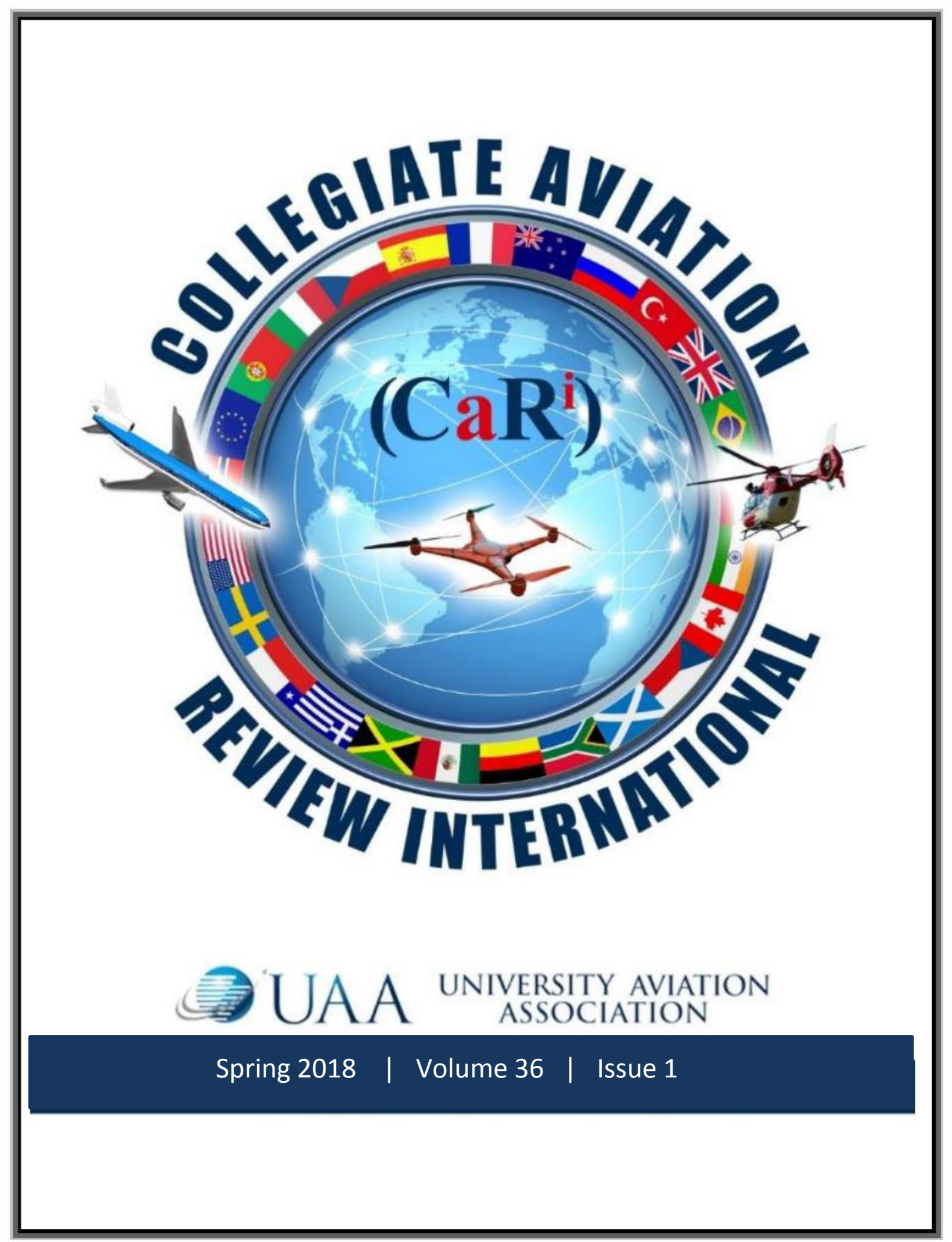


This page intentionally left blank 


\section{COLLEGIATE AVIATION REVIEW INTERNATIONAL}

A PEER REVIEWED JOURNAL OF THE

\section{UNIVERSITY AVIATION ASSOCIATION}

Todd P. Hubbard

Editor-in-Chief 
COLLEGIATE AVIATION REVIEW INTERNATIONAL

YEAR 2018 VOLUME $36 \quad$ ISSUE NUMBER 1

Todd P. Hubbard, Editor-in-Chief

Copyright C 2018 University Aviation Association

ISSN Number: 1523-5955

Electronic delivery: uaa.aero

Managed by: Todd P. Hubbard

All correspondence and inquiries

\section{For Content:}

University Aviation Association

c/o Todd P. Hubbard

1700 Lexington Ave.

Norman, OK 73069

Tel. (405) 474-5199

E-mail: thubbard@ou.edu 


\section{Editorial Board \\ of the \\ Collegiate Aviation Review International}

\section{Todd P. Hubbard}

University of Oklahoma Editor-in-Chief

\section{Timm J. Bliss}

Oklahoma State University

Guest Editor 
This page intentionally left blank 


\section{Publication Committee at Large}

This is a list of past and present committee members. The CARI has been a work in progress over the years. List many journals, it has migrated from hard copy to disc to digital copy, but not without much debate. The editorial staff wishes to express their thanks to everyone who has made this journal what it is today.

\author{
Wendy Beckman \\ Elizabeth Bjerke \\ Elizabeth Blickensderfer \\ Timm J. Bliss \\ Nate Callender \\ Thomas Carney \\ Gerald Chubb \\ Patti Clark \\ Pablo De Leon \\ Chad Depperschmidt \\ Peter Dittmer \\ Wayne Dorman \\ Richard Fanjoy \\ Ramon-Osvaldo Gonzalez \\ Mavis Green \\ Terrence Kelly \\ Jacqueline Luedtke \\ John H. Mott \\ David NewMyer \\ Mary Niemczyk \\ Gary Northam \\ Marc O'Brien \\ Samuel Pavel \\ Robin O'Donnell \\ Matthew Romero \\ Lorelei Ruiz \\ James Simmons \\ Matt Vance \\ Ryan Wallace \\ Anthony Wende \\ Scott Winter
}

\author{
Middle Tennessee State University \\ University of North Dakota \\ Embry-Riddle Aeronautical University \\ Oklahoma State University \\ Middle Tennessee State University \\ Purdue University \\ Ohio State University \\ Embry-Riddle Aeronautical University-Worldwide \\ University of North Dakota \\ Oklahoma State University \\ Utah Valley University \\ Utah Valley University \\ Purdue University \\ Farmingdale State College \\ CUNY Aviation Institute at York College \\ Saint Louis University \\ Embry-Riddle Aeronautical University—Prescott \\ Purdue University \\ Southern Illinois University at Carbondale \\ Arizona State University \\ Embry-Riddle Aeronautical University-Prescott \\ Arizona State University \\ Southern Illinois University \\ The Ohio State University \\ Southern Illinois University at Carbondale \\ Southern Illinois University at Carbondale \\ Metropolitan State University of Denver \\ Oklahoma State University \\ Polk State College \\ Arizona State University \\ Embry-Riddle Aeronautical University
}




\section{ACKNOWLEDGEMENTS}

No juried publications can excel without the tireless efforts of experts from all aerospace disciplines who volunteer their time to serve as anonymous reviewers. Indeed, the ultimate guarantors of quality and appropriateness of scholarly materials for a professional journal are the knowledge, integrity, and thoroughness of those who serve in this capacity. The thoughtful, careful, and timely work of Drs. Bliss and Wallace, and the issue reviewers, add substantively to the quality of the journal. On behalf of University Aviation Association, we extend our thanks. 


\section{STATEMENT OF OBJECTIVES}

The University Aviation Association publishes the Collegiate Aviation Review International throughout each calendar year. Papers published in each volume and issue are selected from submissions that were subjected to a double blind peer review process.

The University Aviation Association is the only professional organization representing all levels of the non-engineering/technology element in collegiate aviation education and research. Working through its officers, trustees, committees, and professional staff, the University Aviation Association plays a vital role in collegiate aviation and in the aerospace industry.

The University Aviation Association accomplishes its goals through a number of objectives:

To encourage and promote the attainment of the highest standards in aviation education at the college level

To provide a means of developing a cadre of aviation experts who make themselves available for such activities as consultation, aviation program evaluation, speaking assignment, and other professional contributions that stimulate and develop aviation education

To furnish an international vehicle for the dissemination of knowledge relative to aviation among institutions of higher learning and governmental and industrial organizations in the aviation/aerospace field

To foster the interchange of information among institutions that offer non-engineering oriented aviation programs including business technology, transportation, and education

To actively support aviation/aerospace oriented teacher education with particular emphasis on the presentation of educational workshops and the development of educational materials covering all disciplines within the aviation and aerospace field

\section{University Aviation Association}




\section{Editor's Commentary}

This is a special issue of the Collegiate Aviation Review International. Featured first is Lutte's research article, Aviation Outreach Model and Gap Analysis: Examining Solutions to Address Workforce Shortages. The purpose of this research was to examine aviation outreach programs to identify best practices and areas for improvement in the endeavor to recruit youth to the aviation industry. The research includes creation of a model of aviation outreach and development and application of an aviation outreach gap analysis design.

This second featured work is a reprint of the UAS Pilots Code, a product of the ACI Aviators Code Initiative by Baum, Kiernan, Steinman, and Wallace. The UAS Pilots Code (UASPC) offers recommendations to advance flight safety, ground safety, and professionalism. It presents a vision of excellence for UAS pilots and operators, and includes general guidance for all types of UAS. The UASPC offers broad guidance — a set of values — to help a pilot interpret and apply standards and regulations, and to confront real world challenges to avoid incidents and accidents. It is designed to help UAS pilots develop standard operating procedures (SOPs), effective risk management, safety management systems (SMS), and to encourage UAS pilots to consider themselves aviators and participants in the broader aviation community. The reprinting of the UAS Pilots Code was by permission from the authors and organization.

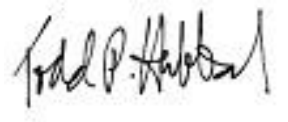

Todd P. Hubbard, Ed.D

Timm J. Bliss, Ed.D 


\section{Table of Contents}

Aviation Outreach Model and Gap Analysis: Examining Solutions to Address Workforce Shortages.13

UAS Pilots Code

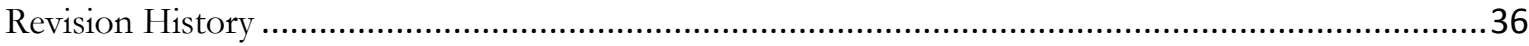

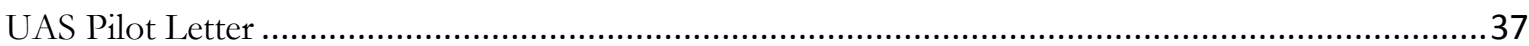

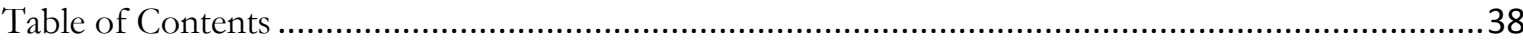

Preface

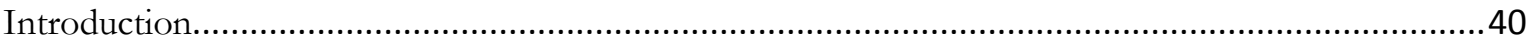

UAS Pilots Code

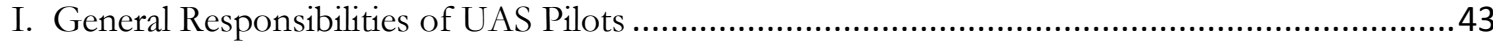

II. Manned Aircraft and People on the Surface …........................................................................49

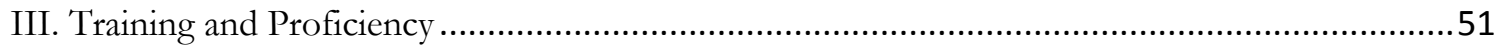

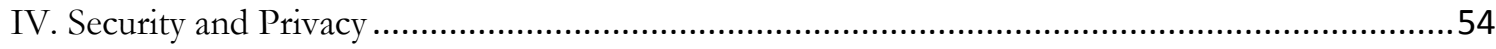

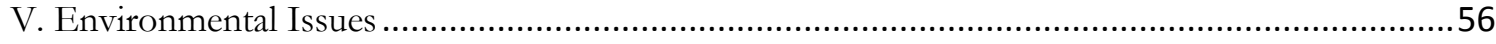

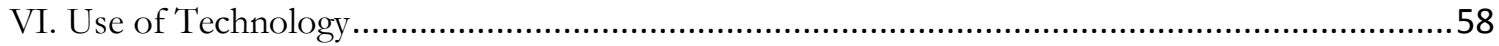

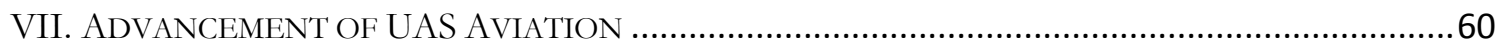

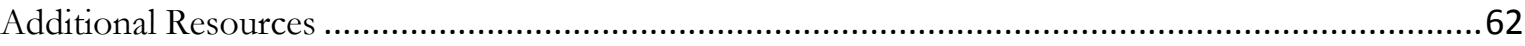

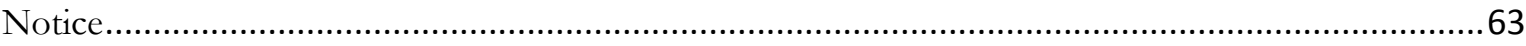

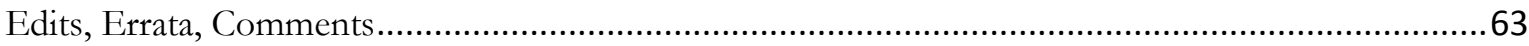

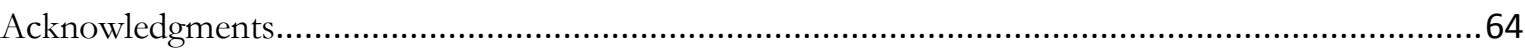

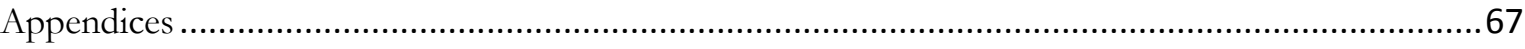

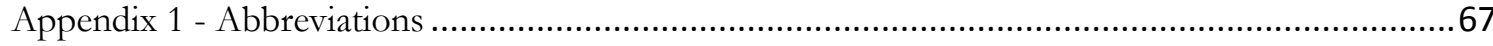

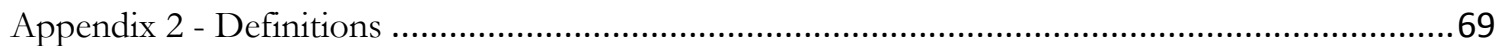

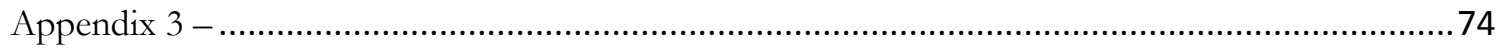

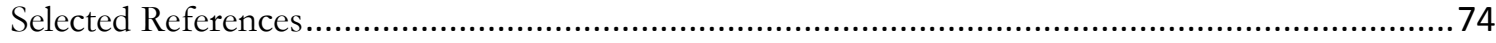

Appendix 4 - UASPC Condensed Version ...............................................................................

Appendix 5 - UASPC Abbreviated Version ...................................................................... 77

Index 
Collegiate Aviation Review International, Volume 36, Issue 1 (C) 2018

Professional Paper 


\title{
Aviation Outreach Model and Gap Analysis: Examining Solutions to Address Workforce Shortages
}

\author{
Rebecca K. Lutte \\ University of Nebraska at Omaha Aviation Institute
}

\begin{abstract}
The purpose of this research is to examine aviation outreach programs to identify best practices and areas for improvement in the endeavor to recruit youth to the aviation industry. The research includes creation of a model of aviation outreach and development and application of an aviation outreach gap analysis design. Three programs are analyzed, Women in Aviation Girls in Aviation Day, Experimental Aviation Association Young Eagles, and Aircraft Owners and Pilots Association High School Aviation Initiative. Each program takes a unique approach to recruiting youth and the strengths and weaknesses, based on the aviation outreach model, are discussed. Results of the research reveal that each of the three outreach programs should be considered a best practice. Recommendations for aviation outreach are provided with emphasis on increased attention to outcome measures. This research contributes a new method to assess outreach programs, a critical task in the effort to create solutions to the global aviation workforce challenges.
\end{abstract}

One of the most pressing issues facing the aviation community is the need to address the growing shortage of qualified personnel throughout the industry. The industry is facing shortages in many areas and it is a global concern. Outreach programs will play a vital role in the ability to fill the workforce pipeline with qualified professionals in the industry. Many aviation organizations, including large nonprofit organizations, have developed programs to try to introduce youth to opportunities in the aviation industry. The purpose of this research is to develop a model of aviation outreach program delivery and to analyze programs to identify best practices and determine areas for improvement.

\section{Aviation Global Workforce Shortages}

Aviation is facing global shortages of qualified personnel in many key areas of the industry. According to the Boeing Pilot and Technician Outlook, global demand is high for technicians, cabin crew, and pilots. Between 2017 and 2016, the global aviation industry will require 648,000 new airline technicians, 839,000 new cabin crew members, and 637,000 new commercial airline pilots (Boeing, 2017). The regions with greatest demand are Asia, followed by North America and Europe (Boeing, 2017). In 2011, the International Civil Aviation Organization (ICAO) published a 20-year forecast to examine the global needs for pilots, technicians, and air traffic controllers. The ICAO forecast a shortage in all three areas of aviation and again noted North America, Asia, and Europe as the most effected regions (ICAO, 2011). Shortages are expected as demand for air transport continues to rise. The International Air Transport Association (IATA) in their most recent forecast, predicted a near doubling of passengers in the next twenty years, leading to 7.8 billion passengers traveling in 2036 compared to 4 billion in 2017 (IATA, 2017). The forecast also supports the growth in the Asia market 
predicting that the China domestic air transport market will surpass the US to become the largest such market in the world by 2022 (IATA, 2017).

The global shortage of pilots has captured the attention of the industry. Given the Boeing estimate for 41,000 new aircraft entering service globally in the next 20 years, the industry will need 87 new pilots each day to meet that need, one every 15 minutes (Ostrower, 2017). The shortage is impacted by a variety of factors including cost of training, airline pilot retirement rates, demand for air travel, and reduced number of pilots coming from the military to supply the airlines (Higgins et al., 2014). The US Air Force was recently authorized to recall as many as 1,000 retired pilots back to active duty service to address the severe military pilot shortage (Winsor, 2017). In the US, the pilot supply challenges have primarily impacted the regional airline industry. The recent FAA forecast notes "the regional airlines are facing pilot shortages and tighter regulations regarding pilot training"

(Administration, 2017, p. 11). In 2015 the Regional Airline Association (RAA) estimated that regional airlines were only able to meet $62.7 \%$ of their hiring goals (RAA, 2016). At the most recent RAA annual conference, the RAA President and Chairman stated, "our industry faces a critical shortage of qualified pilots that, unless addressed, will continue to have a dramatic effect on our nation. The shortage will translate into fewer jobs, less economic activity, reduced aircraft orders, less service to some communities and no service at all to others" (RAA, 2017, p. 4).

Research on the pilot shortage has primarily focused on causes such as the impact of regulatory change on the pilot supply (Bjerke \& Malott, 2011; Lutte \& Lovelace, 2016), impact of pilot pay on pilot supply (Byrnes, 2015; Lutte, 2017), and analysis of supply and demand (Higgins et al., 2014). In a recent study which explored the hiring challenges at regional airlines, aviation outreach was identified as an essential tool to address the pilot shortage (Lutte, 2017).

\section{Understanding Outreach}

Outreach research is often focused within the area of social work. Within that literature, outreach has been defined as the "process of locating, contacting, and recruiting groups that are invisible, hidden, or otherwise difficult to engage in a program" (Ford, Miller, Smurzynski, \& Leone, 2007 , p. 174). Outreach is viewed as serving one of three purposes, 1) to reach and engage customers who do not readily use services, 2) to deliver services, or 3) to raise awareness of opportunities (Dewson, Davis, \& Casebourne, 2006). Dewson, et al. (2006) also describes the use of outreach as a tool for recruitment.

Outreach definitions are often framed in terms of taking services to people or making target groups aware of what organizations can offer. The definition generally includes the elements of making contact and providing services or resources to a targeted group (Andersson, 2013). Outreach applies to a variety of fields and generally involves action taken out of the "mainstream institutional setting" ( $\mathrm{p}$. 1) to "raise the profile" (p. 2) of available services (Dewson et al., 2006). The overall goal is to initiate change in the target group (Andersson, 2013).

Andersson (2013) notes three components to outreach, making initial contact, initiating change, and providing support to keep the process going. The process has been described as influenced by three factors: person factors, process factors, and environment factors (Ford et al., 2007). Person factors focus on outreach staff and include elements such as training and personality (Ford et al., 2007). Cheney and Merwin (1996) note that training should include attention to having the appropriate attitude, safety and conflict resolution, and the ability to provide accurate information. Additionally, Dewson et al. (2006) noted that it is important that volunteers for outreach be recruited from the communities that outreach serves. Those who participate in this activity should possess the following characteristics: 
- Enthusiastic, friendly, outgoing

- Passion for the job

- Empathy towards targeted group

- Shared characteristics with targeted group

- Good communication and organizational skills

- Flexible and prepared to work out of hours (Dewson et al., 2006, pp. 28-29)

Process factors are defined as "how populations are selected for outreach and the activities used to facilitate interactions" (Ford et al., 2007, p. 174). An important element to outreach is defining the target group and making initial contact. The key to making contact is "there has to be a purposeful attempt at getting in touch with members of a target group" (Andersson, 2013, p. 177). While that may seem obvious on the surface, one could argue that a purposeful attempt to get in touch with a specific target group would involve more than a general internet or social media posting. By contrast, this definition implies a specific action targeted to a specific group. Another key element is to come to agreement on defining the problem that needs to be addressed (Andersson, 2013). A greater challenge is the ability to contact those considered underrepresented or "hard to reach" (Andersson, 2013; Dewson et al., 2006). This group may have little knowledge of the information provided. In the case of aviation, there are certain underrepresented groups in the profession, such as women and minorities, who may constitute a hard to reach group. In the STEM recruitment world, one author notes the key to success to recruiting young women. "It is no secret at all. Women and girls need to see female role models in the workplace that look like them - over and over and over again" (Milgram, 2011, p. 5).

Environment factors address the place and overall environment where the contact or interaction occurs. This may occur in public, private, or in an environment where safety may be a concern. Safety concerns related to the specific environment should be included in training (Cheney \& Merwin, 1996). Additional considerations for location of outreach activity include 1) location close to where the target groups live, 2) location close to where the target group spends time, and 3) location where the target group is comfortable (familiar \& non-threatening) (Dewson et al., 2006).

Engaging the target group through interaction requires a strategy for activity implementation. Outreach may involve a variety of activities. Generally, there are two options, either acting as a link to connect target groups with resources, a process referred to as "linkage", or providing a direct interaction to initiate change (Andersson, 2013, p. 176). Linkage activities may range from advertising and marketing to having a presence at employment fairs or other key venues (Dewson et al., 2006). Providing a direct interaction can include in school outreach, public events, establishing clubs, providing a camp or workshop experience, or establishing mentoring programs (Castner \& Stowell, 2012). It should also be noted that there is often a limited opportunity to engage during a direct interaction event due to interactions in outreach activities generally characterized by brief encounters in busy and often noisy environments (Cheney \& Merwin, 1996). The ability to interact with target groups may also be impacted by gatekeepers. Gatekeepers are "influential individuals who can either facilitate or impede access to a community" (Ford et al., 2007, p. 176).

Some argue that it is not enough to provide an event or opportunity for direct interaction. There must also be continued, sustained involvement and support to keep the process for change moving forward (Andersson, 2013; Ford et al., 2007). Given the limitations noted for direct interactions, providing a means for sustained support prove to be beneficial. The purpose of sustained involvement is to avoid being a "random act of outreach" that lacks connections to additional steps (Castner \& Stowell, 2012, p. 18). According to Castner and Stowell (2012), "outreach is most effective when viewed as a continuous process" (p. 18).

Providing activities to facilitate interactions may also result in opportunities to collaborate with other organizations. This collaboration, when it works, can be useful for building relationships with 
other organizations and may enhance outreach (Dewson et al., 2006; Klemm, Rempusheski, \& Teixeira, 2013). Scull and Cuthill (2010) recommend the following steps for collaborative response in outreach 1) "identification of stakeholder groups, 2) action planning, 3) establishment of working groups to progress strategy implementation, and 4) implementation monitoring, and potential revisions of identified strategies" (p. 71). The authors provide a model of engaged research that incorporates the idea that all stakeholders who influence the decision to participate should be involved in the outreach efforts (Scull \& Cuthill, 2010). A word of caution must be included as collaboration may also result in conflict amongst organizations.

Creating a way to measure outcomes is an ongoing challenge for outreach programs (Dewson et al., 2006; Dickey, 2000; Whitney, Dutcher, \& Keselman, 2013). Challenges include defining outcome measures and the fact that outcomes from the outreach activity often take an extended amount of time to materialize (Dewson et al., 2006). It is more common in nonprofits to measure outputs vs outcomes. Outputs can be measured by examining areas such as number of events provided or number of people attending, whereas outcomes are designed to measure change such as change in behavior or skills based on the outreach experience (Lee \& Clerkin, 2017). Short term options for evaluation may include observations of outreach personnel/volunteers and audience interaction or debriefings with outreach personnel/volunteers (Cheney \& Merwin, 1996). With either method, documentation is an important element. Surveys of participants are also a common measure (Cheney \& Merwin, 1996). Additional barriers to creating a successful outreach program addressed in the literature include lack of clear goals, lack of support from mainstream organizations, and lack of funding (Dewson et al., 2006; Ford et al., 2007).

\section{Purpose of the Research}

The purpose of this research is to analyze aviation youth outreach programs through development of a model of aviation outreach programs and development and application of an aviation outreach gap analysis.

Research Questions:

1. What are the key elements to an aviation outreach program?

2. What types of aviation youth outreach programs are currently being offered by large aviation nonprofit organizations?

3. What are large aviation nonprofit organizations doing well regarding youth outreach and what areas can be improved upon?

\section{Model of Aviation Outreach}

Dewson et al. (2006) note that the "definition of outreach is often shaped by the type of activity that is being undertaken" (p. 11). The following definition of aviation outreach is presented for the purpose of this research:

Outreach in aviation involves contacting and engaging targeted groups to bring awareness of the career opportunities in the field to recruit the next generation of aviation professionals.

The review of the literature on outreach resulted in development of the aviation outreach model (Figure 1). 
Figure 1. Model of Aviation Outreach

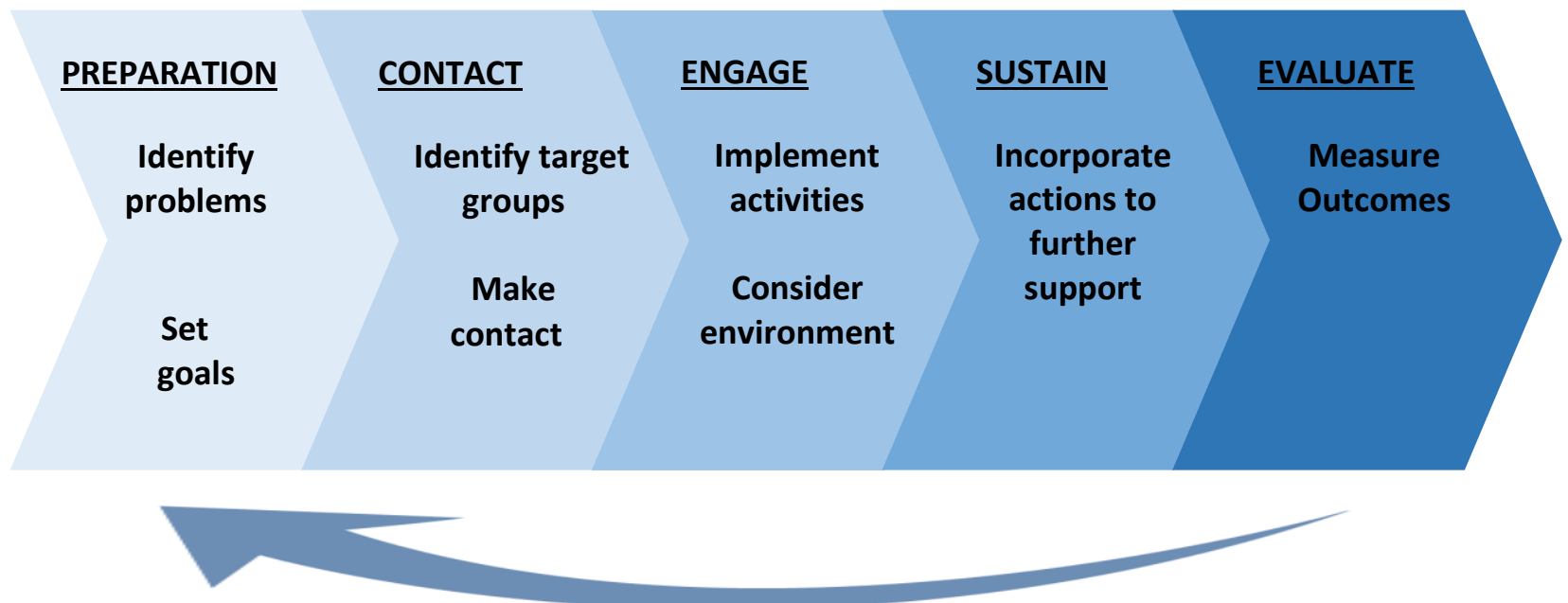

The first step in the model is preparation and pre-outreach planning. These actions include identifying goals. To identify goals, stakeholders should first agree on the problem(s) to be addressed. For example, when targeting youth for raising awareness of careers as airline pilots, problems to address may be declining allure of the career due to negative perceptions of lifestyle and pay, cost of training, and overall lack of awareness of career opportunities (Lutte \& Lovelace, 2016). Once the problem(s) to address is agreed upon, goals should be established that relate to those specified problems. Additional areas to consider in the preparation stage include timeline, budget, and identification of additional stakeholders and gatekeepers.

The next step, initiating contact, consists of actions such as identifying the specific target groups and a means to establish initial contact. Organizations may choose to target a specific age group or level of education (Grades 9 - 12 for example). Making initial contact can include direct contact options, use of social media, or a combination of methods. Large organizations may also use the organization's chapter network for reaching out to local communities. A strategy for contacting hard to reach or underrepresented groups should also be considered. Knowledge of the identified gatekeepers, those who can facilitate or impede outreach such as school counselors or corporate sponsors, will result in an ability to develop a strategy for utilizing gatekeepers to enhance outreach.

Engagement steps include implementing the activities for interaction with the target group. Activities that are tied to the identified goals are developed and implemented. Factors to consider include the environment in which the activity will take place and identification of potential threats to safety. For example, if flight operations are a part of the activity, additional environmental concerns are to identify any threats to safety that will need to be considered. When working with youth, additional threats to be managed may include the need for background checks or other oversight measures for volunteers. Another consideration is to address the training needs for those who are directly involved in providing the outreach activity.

Once the outreach has taken place, the next step in the model is to sustain the momentum that has started. In this phase, organizations should consider additional actions such as providing materials for "next steps" for participants to continue a path for an aviation career. This may include providing additional information and activities. Having the ability to capture contact information for participants will enhance the ability to reach out and assist in sustaining the momentum of participants.

In the final step, evaluation, organizations should develop a means to measure the results of the outreach initiative. Identifying outcome measures is a primary, yet challenging, means to evaluate a 
program. Collecting data on outcome measures and then comparing those results to the organizational goals will allow for evaluation of the program. As establishing outcome measures can be difficult, alternative evaluation techniques such as direct observations of activities and/or event debriefs may also prove useful. Regardless of what technique is utilized, the results should be compared back to the original goals, making this process a cyclical process that then feeds back to preparation for future outreach events.

\section{Aviation Outreach Gap Analysis}

This study is qualitative in nature and incorporates development and implementation of a gap analysis design. Gap analysis has been defined as a method for comparing desired outcomes or performance to actual outcomes or levels of performance (FAA, 2010; Stolzer, Halford, \& Goglia, 2011). The analysis allows for identification of possible deficiencies in programs so that strategies can be developed to correct those deficiencies. Gap analysis has been described as a self-audit against industry best practices (Pro, 2017). This methodology is widely used in aviation (Hudy \& Woolford, 2007; Lutte, 2015; Malm, Fredriksson, \& Johansen, 2016; Plioutsias, Karanikas, \& Chatzimihailidou, 2017), particularly in the area of Safety Management Systems (FAA, 2010; ICAO, 2013; Leib \& Lu, 2013; Ostrowski, Valha, \& Ostrowski, 2014; TRB, 2009).

An aviation outreach program gap analysis was designed to incorporate the five elements of the model to analyze outreach programs based on those elements. When developing a gap analysis, several options exist. The researcher can adopt a previously developed gap analysis design, revise an existing gap analysis, or develop a new gap analysis. As this is a new line of research not previously explored, the researcher developed a new gap analysis for this study. The development was influenced by a review of many types of gap designs developed for aviation. The final gap analysis developed for this research (Appendix) is modeled after the ICAO SMS gap analysis (ICAO, 2013) and the ASBU training gap analysis (Lutte, 2015).

The gap analysis was applied to a purposive sample of nonprofit organizations with youth aviation outreach programs. The nonprofit organizations were selected based on size and reputation. Organizations with large membership and those that are well known within the aviation community were targeted. The gap analysis was applied using a review of documents and publicly available information regarding the targeted programs. When able, interviews were conducted with members of the organization involved in management of the programs to fill in missing information. A limitation to this approach is that not all components of the gap analysis (example: budget) had information publicly available to an external party. The three programs selected are described below.

\section{Experimental Aircraft Association Young Eagles}

The Experimental Aircraft Association (EAA), a nonprofit organization with over 200,000 members, focuses on promoting and supporting recreational flying (EAA, 2017a). The mission of EAA is "to grow participation in aviation by promoting the spirit of aviation" (EAA, 2017b). EAA has multiple programs to promote aviation. The program selected for this research is the Young Eagles program. According to EAA, "inspiring young people to experience the freedom of flight is one of EAA's greatest obligations to assure a strong future for aviation" (EAA, 2017d). The Young Eagles program, started in 1992, provides a first free ride on an airplane to youth between ages 8 and 17. Through a network of 43,000 EAA member volunteer pilots, the EAA has provided flights for over 2,000,000 kids (EAA, 2017c). At the EAA annual Air Venture in Oshkosh, Wisconsin in 2016, Harrison Ford flew the 2 millionth Young Eagle flight (Pope, 2016). Multiple requirements must be met to volunteer as a Young Eagles pilot including training requirements, background check, and insurance requirements. Workshops for Young Eagles volunteers and leaders are provided at Air Venture each year. The youth participant also completes a registration form with parental approval 
and waiver which also allows EAA to capture participant information. The Young Eagles is the first step in a five-step program for young people. With the capture of participant information, the EAA can follow up with the offer of an EAA student membership, access to a learn to fly course, an opportunity for a free first flight lesson, and potential for flight training scholarships (EAA, 2017c). In 2011, the EAA conducted a study to identify the participants in the program who continued on and earned a pilot certificate. The results indicated that Young Eagles participants are 5.4\% more likely to earn a pilot's certificate than youth of the same age who did not participate in the program. The study also revealed that $9 \%$ of the Young Eagles who earned pilot certificates were female, higher than the $6 \%$ female representation for the total pilot population (Tallman, 2011).

\section{Women in Aviation Girls in Aviation Day}

The nonprofit organization, Women in Aviation, International (WAI), has a membership of over 12,000 (WAI, 2017a). The organization is "dedicated to the encouragement and advancement of women in all aviation career fields and interests" (WAI, 2017a). A primary outreach program of WAI is the annual Girls in Aviation Day (GIAD), targeted at girls ages 8 to 17. WAI delivers this program through implementing events throughout many of the 114 chapters and some corporate members of the organization. The goals of the program, as listed on the organization's web site are to "connect with other girls and women who are excited about aviation, explore the opportunities for working in the aviation and aerospace industry, and experience the high flying fun aviation offers" (WAI, 2017b). A variety of events are implemented by the various chapters and sponsors. Chapters are provided with a chapter kit from WAI that includes information such as potential activities, how to schedule volunteers, volunteer training, fundraising suggestions, liability release form, guidance on obtaining insurance, and general guidelines for events (Bosco, C, personal communication, October 19, 2017). The guidelines include activities that are not allowed (flights) and the need for parent participation. To participate as a volunteer, one must be a member of a WAI chapter. Background checks for volunteers are not required (Bosco, C, personal communication, October 19, 2017). Some examples of chapter events include the University of Nebraska at Omaha Maverick chapter with support from the NASA Nebraska Space Grant conducted an event that included activities such as flight planning and career presentations and the participants were provided information on future EAA Young Eagles flights in the area. The Houston Texas WAI chapter hosted an event for 100 girls at the Lone Star Flight Museum with hands on activities to learn about aviation concepts. United Airlines hosted events at five different airport locations with activities that ranged from tours of flight operations to panel presentations on career opportunities for women in aviation. The GIAD has grown at a rapid pace since the first GIAD in 2015. The first year there were approximately 3,200 participants. In 2016, the numbers grew to approximately 7,000 participants (M. Martin, personal communication, October 19, 2017). On September 23, 2017, there were 74 events held in 12 different countries by chapters and corporate members with approximately 9,700 attendees (WAI, 2017b). While WAI does not capture participant information, they do conduct follow up surveys with chapters for evaluation and review and use those results to make potential changes to the program and to share best practices (M. Martin, personal communication, October 19, 2017). 


\section{Aircraft Owners and Pilots Association High School Aviation Initiative}

The largest nonprofit aviation organization in the US, the Aircraft Owners and Pilots Association (AOPA), has a membership of over 400,000 (AOPA, 2017d). The mission of the AOPA is "to protect your freedom to fly by advocating on behalf of our members; educating pilots, nonpilots, and policymakers alike; supporting activities that ensure the long-term health of General Aviation; fighting to keep General Aviation accessible to all; and securing sufficient resources to ensure our success" (AOPA, 2017b). To assist in meeting their mission, AOPA has created an umbrella program called You Can Fly to build the pilot community. The program includes several initiatives such as a program to build and support flying clubs and programs to provide flight training resources for both new pilots and pilots who have been inactive for an extended period. As a part of the You Can Fly programs, the organization has launched the AOPA High School Aviation Initiative to address the identified problem of "a gap in aviation youth education" (AOPA, 2017e). The mission of this initiative "is to help build and sustain aviation STEM programs in high schools in order to provide a quality workforce to the aviation industry" (AOPA, 2017a). Through the High School Aviation Initiative, AOPA works with high schools and other education programs to share resources and best practices for implementing aviation related programs and aviation STEM curriculum. The program primarily targets principals, guidance counselors, and teachers. There are also provisions for scholarships and grant support. As a part of these efforts, AOPA hosts an annual AOPA High School Aviation STEM Symposium to bring educators together for further collaboration. The Symposium is in its third year. Previous years were a one day event with participation levels of 160 in 2015 and 200 in 2016 (Tulis, 2017). The Symposium for 2017 was a two-day event with 258 attendees from 40 states (Hasselbring, C, personal communication, November 9, 2017). The 2017 event presented the curriculum and information related to implementing a $9^{\text {th }}$ grade aviation course which has been field tested by 29 teachers and will be available for high schools starting in the Fall of 2018 (Tulis, 2017). Additional courses for grades 10, 11, and 12 will be added culminating in a four-year aviation high school program in three available tracks, pilot, unmanned aircraft systems, and aerospace engineering. The curriculum includes units on industry workforce needs; career options such as military, airlines, maintenance, and air traffic control; professional development such as resume writing, interview skills, and professionalism; and guidance on pathways including universities, technical colleges, and the military (Hasselbring, C, personal communication, November 9, 2017). To participate in the high school initiative, high schools must apply to AOPA and are selected based on factors such as administrative support and qualifications and dedication of the proposed teachers who will implement the curriculum (Hasselbring, C, personal communication, November 9, 2017). The program is funded by donations to the AOPA foundation and all courses will be offered at no charge to high schools (AOPA, 2017c). To evaluate the program and gain feedback, AOPA conducts surveys and on-site visits. Teachers in the program complete 12 surveys a year and students complete two. The surveys and site visit results are analyzed by external evaluators and results are submitted to AOPA to explore potential program improvements (Hasselbring, C, personal communication, November 9, 2017).

\section{Gap Analysis Results}

The aviation outreach gap analysis was applied to all three outreach programs. The results of the gap analysis application are described by summarizing the information related to the five areas of the aviation outreach model. For each area, a summary table is provided to present the gap analysis results for the three cases. Each question in the gap analysis is designed for a "yes" or "no" response. A "no" indicates a gap exists. A response of "NA" indicates that there is not enough evidence available to determine whether the outreach component has been met. It should not be assumed that gap elements are not met simply because information for the gap element was not publicly available. 


\section{Outreach Preparation}

All three organizations have a positive response to all items under the outreach preparation segment of the gap analysis (Table 1). The problems related to the shortage of qualified personnel are well understood and goals to address the problem are described on the program websites. The timelines for each of the programs vary. While two events are offered at specific times, such as Girls in Aviation Day and the AOPA High School STEM Symposium, the EAA Young Eagles program is ongoing and occurs year-round. Budget information and financial statements are available for all three organizations. Two of the three (AOPA and EAA) make some financial statements publically available on their web sites that indicate expenses for programs in general. WAI provides a financial statement within the WAI State of the Organization document available through member login to the web site. The financial statement includes specific expenses for Girls in Aviation Day. That exact amount is not presented here as it is membership protected. All three organizations appear to have a solid understanding of the use of gatekeepers. The AOPA program makes use of school counselors and principals as access points and use teachers in K-12 schools for implementation of the high school curriculum. EAA and WAI use their chapters as gatekeepers as the chapter volunteers provide the actual engagement activity on behalf of the organization. This allows for excellent coverage and an ability to reach a much wider audience. Using chapters also allows for greater flexibility. For example, Young Eagles chapters can schedule flight days based on regional weather, availability of volunteers, etc. In the case of WAI, allowing chapters to determine the specific type of activity provided for Girls in Aviation Day, with guidance from WAI, allows for greater creativity and the ability to respond to the size and needs of the specific target market.

Table 1. Aviation outreach gap analysis results: Outreach preparation

\begin{tabular}{|c|c|c|c|}
\hline & $\begin{array}{l}\text { WAI } \\
\text { GIAD }\end{array}$ & $\begin{array}{c}\text { EAA } \\
\text { Young Eagles }\end{array}$ & $\begin{array}{c}\text { AOPA } \\
\text { High School } \\
\text { Initiative }\end{array}$ \\
\hline $\begin{array}{l}\text { Has the problem } \\
\text { statement been clearly } \\
\text { identified? }\end{array}$ & Yes & Yes & Yes \\
\hline $\begin{array}{l}\text { Have clear goals for } \\
\text { the outreach effort } \\
\text { been identified? }\end{array}$ & Yes & Yes & Yes \\
\hline $\begin{array}{l}\text { Has a timeline been } \\
\text { established? } \\
\text { Has a budget been }\end{array}$ & Yes & Yes & Yes \\
\hline $\begin{array}{l}\text { agreed upon? } \\
\text { Have *gatekeepers }\end{array}$ & Yes & Yes & Yes \\
\hline $\begin{array}{l}\text { been identified? } \\
\text { Has a strategy been }\end{array}$ & Yes & Yes & Yes \\
\hline $\begin{array}{l}\text { developed for } \\
\text { working with } \\
\text { gatekeepers? }\end{array}$ & Yes & Yes & Yes \\
\hline
\end{tabular}

*Gatekeepers are defined as stakeholders who can facilitate or impede outreach (example, school counselors, corporate sponsors). 


\section{Initiate Contact}

There are mixed results for the second component of the gap analysis, initiate contact (Table 2). All three groups have identified their respective target groups and use a variety of means including social media and direct contact for initiating contact. In the chapter kit, WAI provides specific suggestions for contacting key groups such as other local aviation groups and schools to enhance participation. The kit also provides guidance on contacting media and the use of social media. While WAI clearly has set a strategy for targeting underrepresented groups in aviation through their focus on women, it is not as clear whether EAA has established a specific strategy for contacting underrepresented groups. Although there is no evidence of a specific strategy to contact underrepresented groups, it appears that the EAA Young Eagles program has had some success in outreach to young women as indicated in the results of the EAA study. AOPA does note that a diverse group of students can be reached (AOPA, 2017e) through the High School Aviation Initiative.

Diversity of the student population is a factor when reviewing high school applications (Hasselbring, C, personal communication, November 9, 2017). A focus on diversity is also included in the curriculum to highlight the accomplishments of people in aviation in underrepresented groups such as Katherine Johnson, the WASPs, and the Mercury 13 group (Hasselbring, C, personal communication, November 9, 2017).

Table 2. Aviation outreach gap analysis results: Initiate contact

\begin{tabular}{lccc}
\hline & $\begin{array}{c}\text { WAI } \\
\text { GIAD }\end{array}$ & $\begin{array}{c}\text { EAA } \\
\text { Young Eagles }\end{array}$ & $\begin{array}{c}\text { AOPA } \\
\text { High School } \\
\text { Initiative }\end{array}$ \\
\hline $\begin{array}{l}\text { Has the target group(s) } \\
\text { been identified? }\end{array}$ & Yes & Yes & Yes \\
\hline $\begin{array}{l}\text { Have potential hard to } \\
\text { reach or } \\
\text { underrepresented groups } \\
\text { been identified? }\end{array}$ & Yes & NA & Yes \\
\hline $\begin{array}{l}\text { Has a plan for initial } \\
\text { contact been developed? }\end{array}$ & Yes & Yes & Yes \\
\hline $\begin{array}{l}\text { Has contact using social } \\
\text { media been considered? }\end{array}$ & Yes & Yes & Yes \\
\hline $\begin{array}{l}\text { Has contact using direct } \\
\text { communication been } \\
\text { considered? }\end{array}$ & Yes & Yes & Yes \\
\hline $\begin{array}{l}\text { Has a plan for } \\
\text { contacting gatekeepers } \\
\text { been established? }\end{array}$ & Yes & Yes & Yes \\
$\begin{array}{l}\text { Does the contact plan } \\
\text { include a strategy to } \\
\text { reach out to } \\
\begin{array}{l}\text { underrepresented or } \\
\text { hard to reach groups? }\end{array}\end{array}$ & Yes & NA & Yes \\
\hline
\end{tabular}




\section{Engage}

In the area of engagement, all three organizations implement activities to meet identified goals (Table 3). As previously noted, two of the three organizations, the EAA and WAI, use their vast chapter networks for implementation of activities. In the case of EAA, chapter volunteers schedule and organize Young Eagles events and members volunteer to fly. The program is centrally administered with specific training and event requirements such as background checks for volunteers and required insurance for participating pilots. All Young Eagles events must comply with the EAA program guidelines. Given the nature of the events, a free flight experience, this approach is an excellent means for EAA to identify potential safety threats and the organization shows evidence of strategies to address those safety concerns. For Women in Aviation, the chapters participating in Girls in Aviation Day develop their own programs which allows them to tailor the programs to their specific target audience. While this approach provides for creativity and flexibility, it also results in less control by the central organization over the events conducted. Using the program chapter kit with specific guidelines for activities assists in addressing that concern. All three programs show evidence of identifying and addressing safety threats. This is clearly an essential task for the EAA, considering that flight activities are the focus. Efforts of the EAA in this area include parental consent on a liability release form, background checks for volunteers, and requirements related to flight currency, aircraft condition, and insurance. While the other organizations are not directly involved in flight activities, a review of any safety concerns, particularly for programs that work with youth, is warranted. WAI has identified and addressed safety concerns to include having a parent or other responsible adult with the participant throughout the activity, requiring a parent to sign a liability release and use of photo release. In addition, the organization provides guidance for the chapters to obtain insurance for the event. AOPA has identified safety threats related to curriculum activities and strategies to address those concerns are included in the curriculum design (Hasselbring, C, personal communication, November 9, 2017). Since the AOPA program targets educators in K-12 schools, it is suggested that those teachers who are implementing the program have been vetted by the schools and appropriate safety strategies for the school environment have been addressed by the school. Training is provided in all three programs for those involved in implementing the programs. All organizations provide training resources. Excellent examples of training resources include the WAI GIAD chapter kit and the AOPA High School Symposium.

Table 3. Aviation outreach gap analysis results: Engage

\begin{tabular}{lccc}
\hline & $\begin{array}{c}\text { WAI } \\
\text { GIAD }\end{array}$ & $\begin{array}{c}\text { EAA } \\
\text { Young Eagles }\end{array}$ & $\begin{array}{c}\text { AOPA } \\
\text { High School } \\
\text { Initiative }\end{array}$ \\
\hline $\begin{array}{l}\text { Have activities been } \\
\text { implemented to meet the } \\
\text { goals identified? }\end{array}$ & Yes & Yes & Yes \\
\hline $\begin{array}{l}\text { Have threats to safety related } \\
\text { to the specific activity } \\
\text { environment been identified? }\end{array}$ & Yes & Yes & Yes \\
\hline $\begin{array}{l}\text { Have strategies to address } \\
\text { specific safety threats been } \\
\text { implemented? }\end{array}$ & Yes & Yes & Yes \\
$\begin{array}{l}\text { Has appropriate training } \\
\text { been developed and } \\
\text { provided to those engaged in } \\
\text { the outreach activity? }\end{array}$ & Yes & Yes & Yes \\
\hline
\end{tabular}




\section{Sustain}

All three programs provide information to targeted groups to sustain momentum and continue forward progress towards next steps (Table 4). As previously noted, the EAA has laid out a five-step process allowing for the participant to progress from that first flight experience to a certificated pilot. The WAI organization offers a 6-month free digital membership to all who participate in GIAD. Attendees who fill out a form which captures name, age, address, and email will receive the membership. Additional information for next steps may be provided at the various events. For example, the University of Nebraska at Omaha Maverick chapter provided EAA Young Eagles information to their participants. The AOPA High School Initiative provides valuable next step information for educators and others who attend the Symposium. Participants learn about the state of hiring in the industry and postsecondary opportunities for their students through panel presenters. Information on career progression is also targeted directly to students through the curriculum design. Students in the High School Initiative program build a career portfolio based on the professional development activities and receive information on career options and pathways to achieve those goals.

Table 4. Aviation outreach gap analysis results: Sustain

\begin{tabular}{lccc}
\hline & WAI & $\begin{array}{c}\text { EAA } \\
\text { Young Eagles }\end{array}$ & $\begin{array}{c}\text { AOPA } \\
\text { High School } \\
\text { Initiative }\end{array}$ \\
\hline $\begin{array}{l}\text { Is information provided } \\
\text { to the target group to } \\
\text { provide "next step" } \\
\text { actions to sustain the } \\
\text { momentum? }\end{array}$ & Yes & Yes & Yes \\
\hline
\end{tabular}

\section{Evaluate}

As noted in the literature, evaluation is a common challenge for outreach programs. The gap analysis explores the use of output measures, outcome measures, and alternative options such as direct observation of the program or some type of debrief following the event to gain feedback (Table 5). All three organizations track output measures such as numbers of participants and events. These measures allow programs to compare year to year data to track trends and growth. Outcome measures have been collected and analyzed by one organization, the EAA. The outcome measure identified was pilot certification. This allowed the organization to examine which participants in the Young Eagles program went on to earn a private pilot certification. This is not an ongoing process but was a onetime review in 2011 using FAA and EAA data. The WAI organization does not measure outcomes due to the challenge that outcomes are not immediate but are years in the making (Martin, M, personal communication, October 19, 2017). WAI does use other measures for evaluation. A survey is distributed to all participant chapters to gather feedback to continuously improve the program and share best practices. There is evidence of capturing output measures and alternative techniques (site visits, surveys) for the AOPA program but no evidence was located showing identification or analysis of outcome measures, not surprising given the long lead time for outcome measures to materialize and the relative newness of the program. 
Table 5. Aviation outreach gap analysis results: Evaluate

\begin{tabular}{|c|c|c|c|}
\hline & $\begin{array}{l}\text { WAI } \\
\text { GIAD }\end{array}$ & $\begin{array}{c}\text { EAA } \\
\text { Young Eagles }\end{array}$ & $\begin{array}{c}\text { AOPA } \\
\text { High School } \\
\text { Initiative }\end{array}$ \\
\hline $\begin{array}{l}\text { Has *output data been } \\
\text { collected? }\end{array}$ & Yes & Yes & Yes \\
\hline $\begin{array}{l}\text { Have outcome measures } \\
\text { been identified? }\end{array}$ & No & Yes & No \\
\hline $\begin{array}{l}\text { Has data on the } \\
\text { outcome measures been } \\
\text { collected? }\end{array}$ & No & Yes & No \\
\hline $\begin{array}{l}\text { Has data been analyzed } \\
\text { and compared to } \\
\text { original goals? }\end{array}$ & Yes & Yes & Yes \\
\hline $\begin{array}{l}\text { Have alternative } \\
\text { evaluation techniques } \\
\text { other than outcome } \\
\text { measures been } \\
\text { implemented (exp: event } \\
\text { debrief, observations, } \\
\text { etc)? }\end{array}$ & Yes & NA & Yes \\
\hline $\begin{array}{l}\text { Has assessment data } \\
\text { been collected for } \\
\text { alternative evaluation } \\
\text { techniques? }\end{array}$ & Yes & NA & Yes \\
\hline $\begin{array}{l}\text { Has assessment data } \\
\text { been analyzed and } \\
\text { compared to original } \\
\text { goals? }\end{array}$ & Yes & NA & Yes \\
\hline
\end{tabular}

\section{Analysis of Results}

The research provided a means to examine and ultimately assess outreach activities by large aviation nonprofit organizations. Given the importance of the task, the resources required, and the significant amount of time associated with engaging in outreach activities, it is important that we get it right. The application of the gap analysis shows the aviation outreach programs examined are doing just that. The strengths of the three programs examined include the following. The programs reflect a broad range of creative solutions to address the aviation workforce shortage. The programs make excellent use of extensive networks of chapters, volunteers, and identified gatekeepers to broaden the reach. Additionally, Women in Aviation serves as a primary example of a nonprofit organization implementing outreach that is aimed at underrepresented groups. The weaknesses are those that routinely plague outreach activities. While the three organizations are effective in measuring outputs of the programs, most do not measure outcomes. This is not uncommon in outreach programs and is particularly challenging in youth outreach programs due to the long gap in time between activity and desired outcome. A leader in measuring outcomes is the EAA Young Eagles program. An additional 
area that could be improved is a thorough and comprehensive review of potential safety threats. While some of the organizations do take measures to address some concerns, evidence of a comprehensive review of safety concerns would enhance the programs. Again, the EAA Young Eagles program is the stand out program example of identifying and addressing safety threats, an essential task given the flight activities of the program. A final recommendation is to develop a strategy for identifying, targeting, and including underrepresented groups in outreach efforts. WAI is a stand out example of successfully meeting this goal.

Based on the review, the following specific recommendations are provided for each of the three programs. It is recommended that the EAA update the 2011 study. Given the amount of data to review, it would be challenging to conduct the review on an ongoing basis but having a set time, such as every five years, would allow for trends to be established. To explore the best of use of resources, it may also be beneficial to track whether the participants utilized the five-step approach EAA offers The AOPA program is just launching the first high school courses with more on the way. Capturing participant data may be stifled due to the environment in which the program operates and restrictions on sharing of information of high school students. If the organization can capture participant information through an alternate means, such as participant sign up for a specifically designed High School Initiative student membership with AOPA, that would allow for the opportunity to capture participant information. AOPA could then identify and analyze outcome measures such as enrollment in an aviation university program or pilot certification through follow up surveys or additional research. It is recommended that AOPA work with universities to explore the option of delivering the AOPA curriculum as dual credit coursework, allowing the high school students to also gain college credits at a local university aviation program. For the Women in Aviation GIAD program, capturing contact information for participants is recommended. This could be done by adding parameters to the event registration or sign in sheet. Alternatively, WAI can create a database using the existing sign-up data for the 6-month free digital membership which currently captures contact information. A database of participants would allow WAI to conduct a variety of follow up assessment actions such as track the number of participants who become full members or conduct a survey at set intervals to assess whether the girls who participated in GIAD continued on a path to an aviation career. By conducting a periodic assessment, the organization could establish trends and gather information to update the database of participants. After all, today's Girls in Aviation Day participants, will be tomorrow's Women in Aviation mentors. One of the many strengths of WAI is the scholarship program. For 2018, the WAI available scholarships are estimated at $\$ 634,000$ (WAI, 2017c). It is also suggested that WAI consider a scholarship earmarked specifically for former GIAD participants to further sustain the momentum of the program. While recommendations related to outcomes and evaluations were provided, it is understood that organizations must balance their resources against the perceived value of such efforts.

\section{Conclusions}

Aviation outreach programs play an important role in addressing the needs of the aviation workforce. Recruiting the next generation of aviation professionals is a high priority for the industry. This task should remain a constant focus. As one director observed, when times are lean in the industry, less of these programs exist and it is vital to keep a consistent focus on recruitment (Bosco, C, personal communication, October 19, 2017). The research shows the three programs provided by EAA, AOPA, and WAI are exemplary examples of aviation outreach and should be considered best practices for aviation organizations. Further research should be conducted to expand the number of programs examined and to further identify and explore outcome measures to determine the impact of the programs on the workforce pipeline. 


\section{References}

Administration, F. A. (2017). FAA aerospace forecast: 2017 - 2037. Retrieved from https://www.faa.gov/data_research/aviation/aerospace_forecasts/media/FY201737_FAA_Aerospace_Forecast.pdf

Andersson, B. (2013). Finding ways to the hard to reach: Considerations on the content and concept ot outreach work. European Journal of Social Work, 16(2), 171-186. doi:10.1080/13691457.2011.618118

AOPA. (2017a). About the high school initiative. Retrieved from https://youcanfly.aopa.org/highschool/about

AOPA. (2017b). AOPA's mission, vision and values. Retrieved from https:/ / www.aopa.org/about/mission-vision-and-values

AOPA. (2017c). High school aviation STEM curriculum: Coming Fall 2018. Retrieved from https://youcanfly.aopa.org/high-school/high-school-curriculum

AOPA. (2017d). History of AOP A. Retrieved from https://www.aopa.org/about/history-ofaopa

AOPA. (2017e). You can fly. Retrieved from https://youcanfly.aopa.org/high-school

Bjerke, E., \& Malott, D. (2011). Impacts of Public Law 111- 216: Will the flight instructor career path remain a viable option for aspiring airline pilots? Collegiate Aviation Review, 29(1), 1-9.

Boeing. (2017). Pilot and technician outlook 2017 - 2036. Retrieved from http://www.boeing.com/commercial/market/pilot-technician-outlook/ - /pilottechnician-outlook

Byrnes, K. (2015). ATP motivation. Paper presented at the ALPA Airline Pilot Shortage? Myths, Facts, and Solutions Conference, Washington, DC.

Castner, L., \& Stowell, R. (2012). Effective outreach: Preserving general aviation by putting the "public"in public-use airports. Paper presented at the Department of Transportation National Workforce Summit, Washington, DC.

Cheney, R., \& Merwin, A. (1996). Intergrating a theoretical framework with street outreach services: Issues for successful training. Public Health Reports, 111(1), 83-88.

Dewson, S., Davis, S., \& Casebourne, J. (2006). Maximising the role of outreach in client engagement (326). Retrieved from http://webarchive.nationalarchives.gov.uk/20130125094156/http:/ / research.dwp.gov .uk/asd/asd5/report_abstracts/rr_abstracts/rra_326.asp

Dickey, B. (2000). Review of programs for persons who are homeless and mentally ill. Harvard Review of Psychiatry, 8(5), 242-250.

EAA. (2017a). About EAA. Retrieved from https://www.eaa.org/en/eaa/reneweaa/membership-thanks

EAA. (2017b). Who we are. Retrieved from https://www.eaa.org/en/eaa/about-eaa/who-weare

EAA. (2017c). Young eagles. Retrieved from https://www.eaa.org/en/eaa/aviation-educationand-resources/eaa-youth-education/eaa-young-eagles-program

EAA. (2017d). Youth education. Retrieved from https://www.eaa.org/en/eaa/aviationeducation-and-resources/eaa-youth-education

FAA. (2010). Safety management system (SMS) implementation guide. Retrieved from https://www.faa.gov/about/initiatives/sms/specifics_by_aviation_industry_type/air_ operators/media/sms_implementation_guide.pdf 
Ford, C. L., Miller, W. C., Smurzynski, M., \& Leone, P. A. (2007). Key components of a theory-guided HIV prevention outreach model: Pre-outreach preparation, community assessment, and a network of key informants. AIDS Education and Prevention, 19(2), 173-186.

Higgins, J., Lovelace, K., Bjerke, E., Lounsberry, N., Lutte, R., Friedenzohn, D., Pavel, S., Chase, B., \& Craig, P. (2014). An investigation of the United States airline pilot labour supply. Journal of Air Transport Studies, 5(2), 53-83.

Hudy, C., \& Woolford, B. (2007). Space human factors engineering gap analysis project final report (NASA/TP-2007-213739). Houston, TX: Johnson Space Center.

IATA. (2017). 2036 forecast reveals air passengers will nearly double to 7.8 billion [Press release]. Retrieved from http://www.iata.org/pressroom/pr/Pages/2017-10-24-01.aspx

ICAO. (2011). Global and regional 20-year forecasts (ICAO Doc 9956). Montreal, Canada: ICAO.

ICAO. (2013). Safety management manual (ICAO Doc 9859-AN-474). Montreal, Canada: ICAO

Klemm, P., Rempusheski, V., \& Teixeira, J. (2013). A nonprofit community service and academic collaboration to increase outreach to older adults with cancer: Lesson learned. Journal of Gerontological Social Work, 56(6), 554-568. doi:10.1080/01634372.2013.793222

Lee, C., \& Clerkin, R. (2017). The adoption of outcome measurement in human service nonprofits. Journal of Public and Nonprofit Affairs, 3(2), 111-134. doi:10.20899/jpna.3.2.111- 134

Leib, S., \& Lu, C.-t. (2013). A gap analysis of airport safety using ICAO SMS perspectives: A field study of Taiwan. Journal of Aviation Technology and Engineering, 2(2), 63-70. doi:10.7771/2159-6670.1078

Lutte, R. (2015). ICAO aviation system block upgrades: A method for identifying training needs. International Journal of Aviation, Aeronautics, and Aerospace, 2(4), 1-15. doi:10.15394/ijaaa.2015.1090

Lutte, R. (2017). Pilot supply at the regional airlines: Airline response to the changing environment and the impact on pilot hiring. Paper presented at the National Training Aircraft Symposium, Daytona Beach, FL.

Lutte, R., \& Lovelace, K. (2016). Airline pilot supply in the US: Factors influencing the collegiate pilot pipeline. Journal of Aviation Technology and Engineering, 6(1), 53-63. doi:10.7771/2159-6670.1148

Malm, A. M., Fredriksson, A., \& Johansen, K. (2016). Bridging capability gaps in technology transfers within related offsets. Journal of Manufacturing Technology and Management, 27(5), 640-661. doi:10.1108/JMTM-11-2015-0101

Milgram, D. (2011). How to recruit women and girls to the science, technology, engineering, and math (STEM) classroom. Technology and Engineering Teacher, 71(3), 4-11.

Ostrower, J. (2017). The U.S. will face a staggering shortage of pilots. CNN Money. Retrieved from http://money.cnn.com/2017/07/27/news/companies/pilot-shortagefigures/index.html

Ostrowski, K., Valha, D., \& Ostrowski, K. (2014). USAF aviation safety program: Gap analysis using ICAO. Professional Safety, 59(7), 26-32.

Plioutsias, A., Karanikas, N., \& Chatzimihailidou, M. (2017). Hazard analysis and safety requirements for small drone operations: To what extent do popular drones embed safety? Risk Analysis. doi:10.1111/risa.12867

Pope, S. (2016). Harrison Ford flies 2 millionth young eagle. Flying. Retrieved from https:/ / www.flyingmag.com/harrison-ford-flies-2-millionth-young-eagle 
Pro, S. (2017). Aviation gap analysis tool for FAA, ICAO, Transport Canada. Retrieved from http://www.asms-pro.com/Modules/SafetyAssurance/GapAnalysis.aspx

RAA. (2016). Pilot work.force and training update: Issue Briefing. Retrieved from http://c.ymcdn.com/sites/www.raa.org/resource/resmgr/2016docs/RAA_pilot_wor kforce_update_O.pdf

RAA. (2017). Regional horizons. Retrieved from http://c.ymcdn.com/sites/www.raa.org/resource/resmgr/2017ac/RAA_FullLayout_ Day1_vF_App.pdf

Scull, S., \& Cuthill, M. (2010). Engaged outreach: Using community engagement to facilitate access to higher education for people from low socio-economic backgrounds. Higher Education Research \& Development, 29(1), 59-74. doi:10.1080/07294360903421368

Stolzer, A., Halford, C., \& Goglia, J. (2011). Implementing Safety Management Systems in Aviation. Farnham: Ashgate.

Tallman, J. (2011). Young eagles more likely to become pilots. AOP A. Retrieved from https://www.aopa.org/news-and-media/all-news/2011/march/09/young-eaglesmore-likely-to-become-pilots

TRB. (2009). Safety management systems for airports: Volume 2: Guidebook (ACRP Report 1). Washington, DC: National Academy of Sciences.

Tulis, D. (2017). AOP A high school aviation program expands. Retrieved from https://www.aopa.org/news-and-media/all-news/2017/october/20/aopa-highschool-aviation-program-expands

WAI. (2017a). About WAI. Retrieved from https://www.wai.org/about-wai

WAI. (2017b). Girls in aviation day. Retrieved from https://www.wai.org/giad

WAI. (2017c). WAI connect. Retrieved from https://www.wai.org/news

Whitney, W., Dutcher, G., \& Keselman, A. (2013). Evaluation of health information outreach: Theory, practice, and future direction. Journal of the Medical Library Association, 101(2), 138-146. doi:10.3163/1536-5050.101.2.009

Winsor, M. (2017, October 21). Air Force authorized to recall up to 1,000 retired military pilots. $A B C$ News. Retrived from http://abcnews.go.com/US/air-force-recall-1000retired-military-pilots-address $/$ story? $\mathrm{id}=50629597$ 
Collegiate Aviation Review International, Volume 36, Issue 1 (c) 2018

Appendix

Aviation Outreach Programs Gap Analysis 
Each question is designed for a "yes" or "no" response. A "no" indicates a gap exists. If the response is "no", indicate under "Suggested action" how the element could/should be addressed. A response of "NA" indicates that there is not enough evidence available to determine whether the outreach component has been met.

\begin{tabular}{|c|c|c|c|}
\hline $\begin{array}{l}\text { Outreach component to } \\
\text { be analyzed }\end{array}$ & Answer & Comments & $\begin{array}{c}\text { Suggested } \\
\text { Actions }\end{array}$ \\
\hline \multicolumn{4}{|c|}{ Outreach Preparation } \\
\hline $\begin{array}{l}\text { Has the problem } \\
\text { statement been clearly } \\
\text { identified? }\end{array}$ & $\begin{array}{ll}\mathrm{O} & \text { Yes } \\
0 & \mathrm{No} \\
\mathrm{0} & \mathrm{NA}\end{array}$ & & \\
\hline $\begin{array}{l}\text { Have clear goals for the } \\
\text { outreach effort been } \\
\text { identified? }\end{array}$ & $\begin{array}{ll}\circ & \text { Yes } \\
\circ & \text { No } \\
\circ & \text { NA }\end{array}$ & & \\
\hline $\begin{array}{l}\text { Has a timeline been } \\
\text { established? }\end{array}$ & $\begin{array}{ll} & \text { Yes } \\
0 & \text { No } \\
0 & \text { NA }\end{array}$ & & \\
\hline $\begin{array}{l}\text { Has a budget been agreed } \\
\text { upon? }\end{array}$ & $\begin{array}{ll}\circ & \text { Yes } \\
\circ & \text { No } \\
\circ & \text { NA }\end{array}$ & & \\
\hline $\begin{array}{l}\text { Have *gatekeepers been } \\
\text { identified? }\end{array}$ & $\begin{array}{ll} & \text { Yes } \\
0 & \text { No } \\
0 & \text { NA }\end{array}$ & & \\
\hline $\begin{array}{l}\text { Has a strategy been } \\
\text { developed for working } \\
\text { with gatekeepers? }\end{array}$ & $\begin{array}{ll}\circ & \text { Yes } \\
\circ & \text { No } \\
0 & \text { NA }\end{array}$ & & \\
\hline \multicolumn{4}{|c|}{ Initiate Contact } \\
\hline $\begin{array}{l}\text { Has the target group(s) } \\
\text { been identified? }\end{array}$ & $\begin{array}{ll} & \text { Yes } \\
0 & \text { No } \\
0 & \text { NA }\end{array}$ & & \\
\hline $\begin{array}{l}\text { Have potential hard to } \\
\text { reach or underrepresented } \\
\text { groups been identified? }\end{array}$ & $\begin{array}{ll}\circ & \text { Yes } \\
\circ & \text { No } \\
\circ & \text { NA }\end{array}$ & & \\
\hline $\begin{array}{l}\text { Has a plan for initial } \\
\text { contact been developed? }\end{array}$ & $\begin{array}{ll}\mathrm{O} & \text { Yes } \\
0 & \mathrm{No} \\
\mathrm{O} & \mathrm{NA}\end{array}$ & & \\
\hline $\begin{array}{l}\text { Has contact using social } \\
\text { media been considered? }\end{array}$ & $\begin{array}{ll}\text { O } & \text { Yes } \\
0 & \text { No } \\
0 & \text { NA }\end{array}$ & & \\
\hline $\begin{array}{l}\text { Has contact using direct } \\
\text { communication been } \\
\text { considered? }\end{array}$ & $\begin{array}{ll} & \text { Yes } \\
0 & \text { No } \\
0 & \text { NA }\end{array}$ & & \\
\hline
\end{tabular}




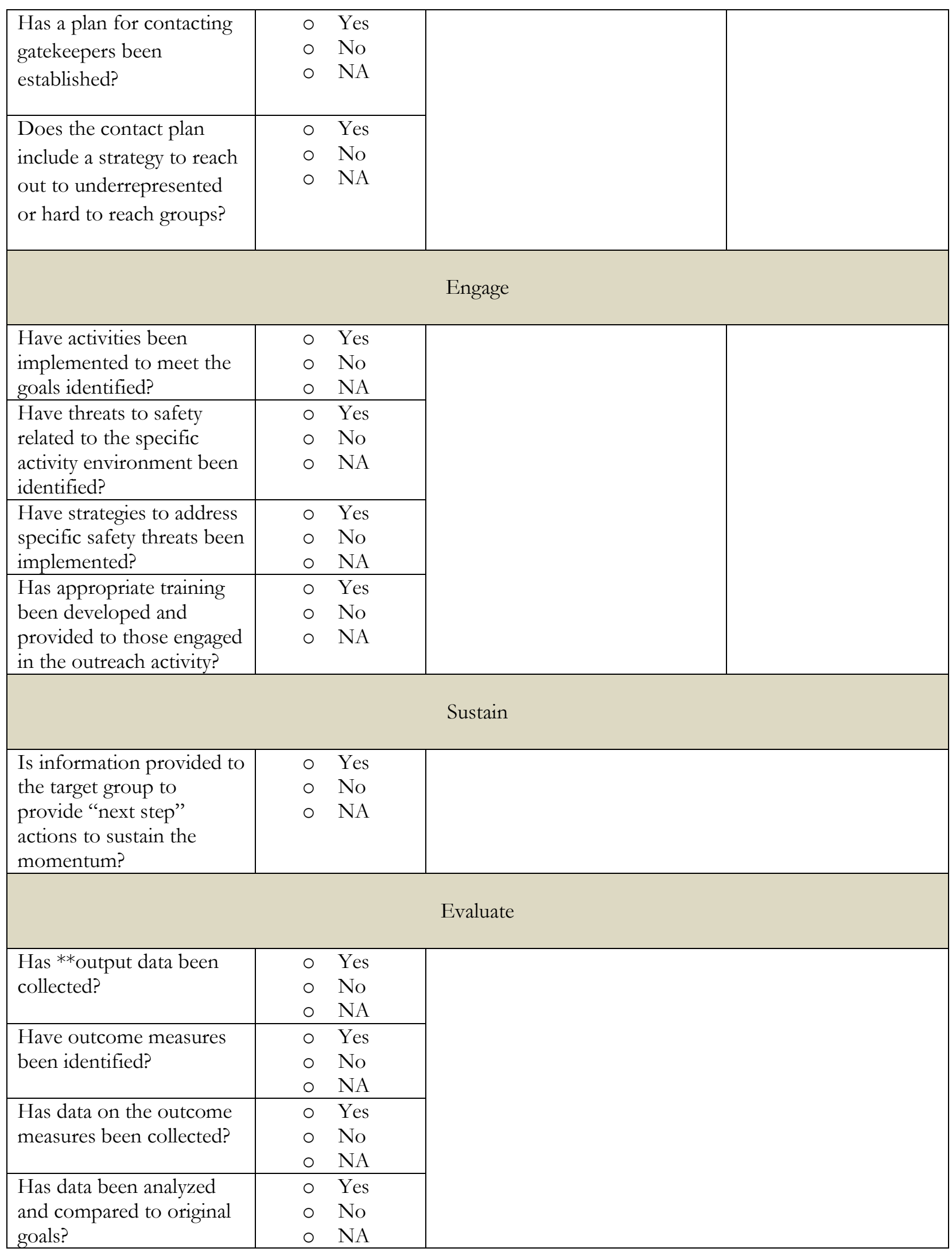




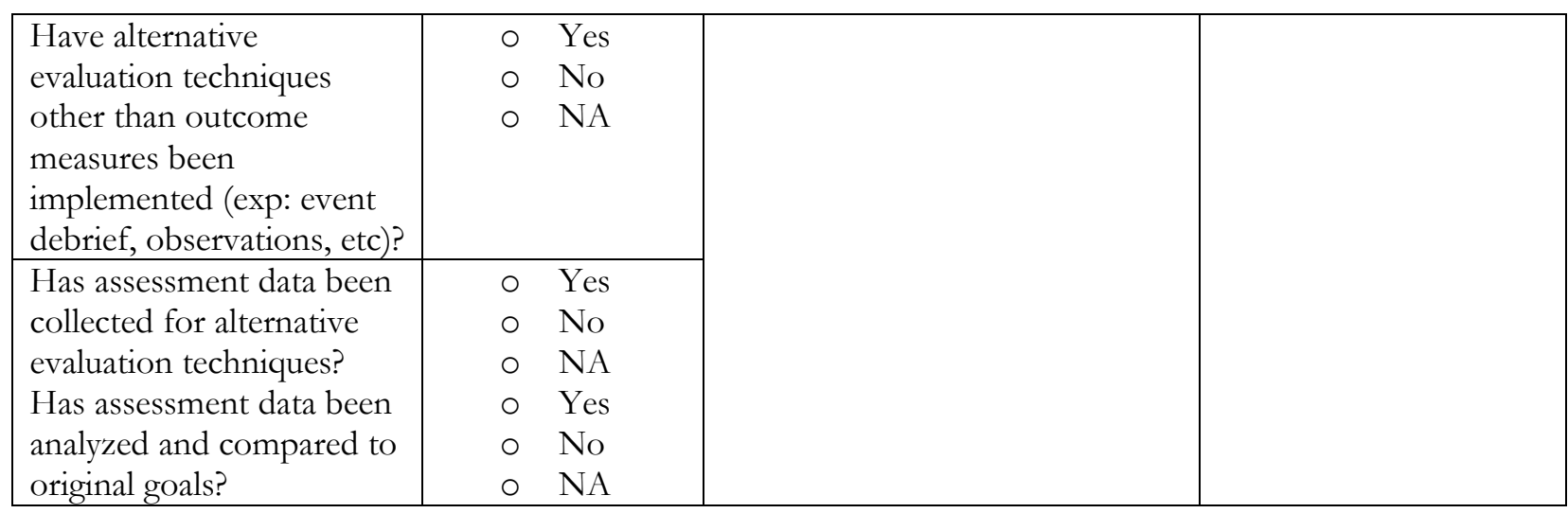

*Gatekeepers are defined as stakeholders who can facilitate or impede outreach (example, school counselors, corporate sponsors)

** Output measures represent what is produced such as the number of participants or outreach events. Outcomes are measures of impact of the outreach such as changes in behavior. Examples of outcome measures may include participants who become pilots, enroll in aviation university programs, become employed in the aviation industry, or change their views about aviation career options. 
Collegiate Aviation Review International, Volume 36, Issue 1 (c) 2018

Special Feature

UAS Pilots Code 

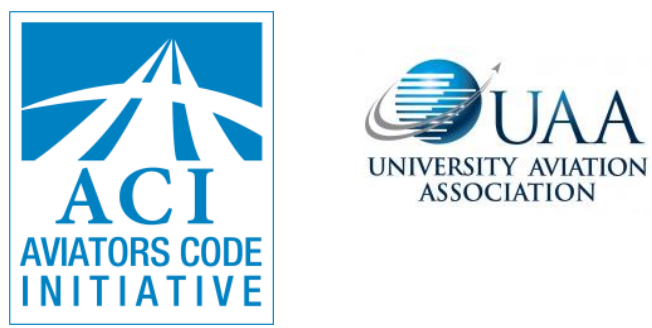

UNIVERSITY AVIATION ASSOCIATION

\section{UAS PILOTs CodE}

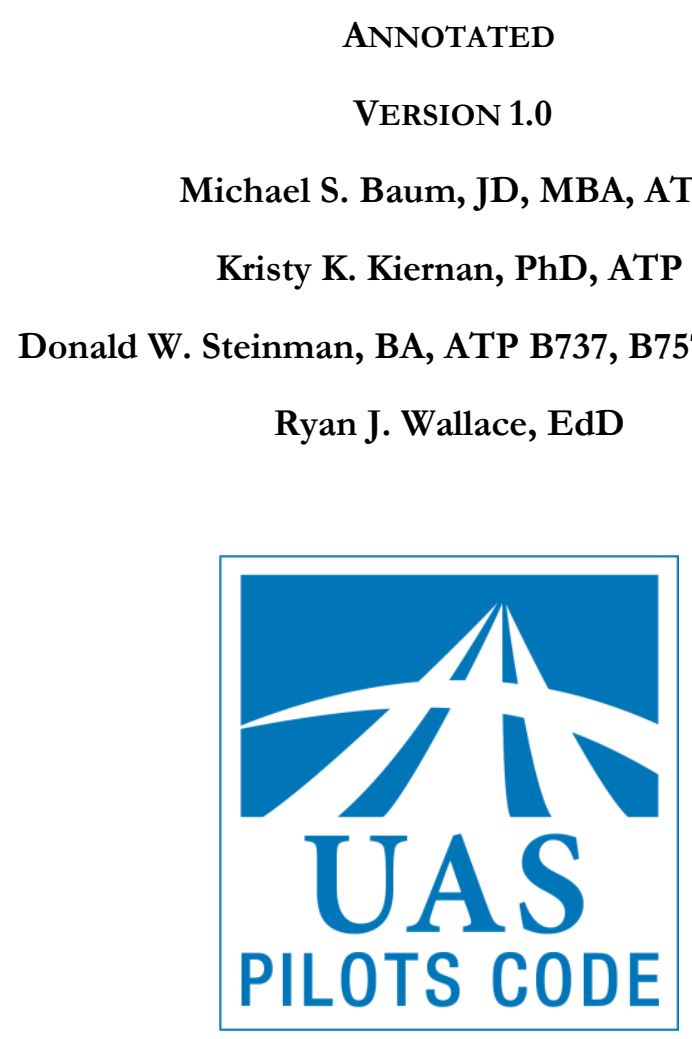

Tools to advance UAS

safety and professionalism 


\section{Revision History}

\begin{tabular}{|c|c|l|}
\hline Revision & Date & \multicolumn{1}{|c|}{ Revision Explanation } \\
\hline 0.3 & -- & Last pre-peer-review working draft \\
\hline 0.4 & $11 / 24 / 17$ & Peer-review prototype \\
\hline $0.5 \mathrm{a}$ & $12 / 23 / 17$ & Peer review draft \\
\hline $0.5 \mathrm{~b}$ & $1 / 5 / 18$ & Peer review draft, updated \\
\hline $0.5 \mathrm{c}$ & $1 / 8 / 18$ & Peer review draft, further updated \\
\hline 1.0 & $1 / 27 / 18$ & First released version \\
\hline
\end{tabular}




\section{UAS Pilot Letter}
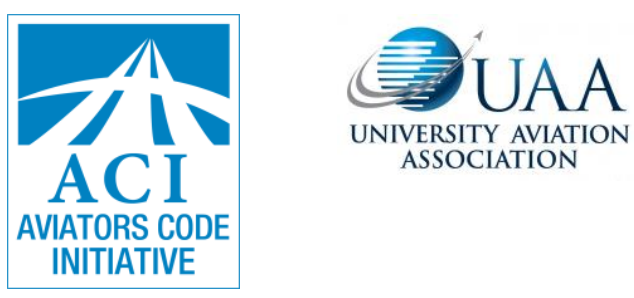

UNIVERSITY AVIATION ASSOCIATION

\section{Permanent Editorial BoARd OF THE Aviators Code INITIATIVE AND THE UNIVERSITY AVIATION ASSOCIATION}

DEAR UAS PILOT:

THIS LETTER INTRODUCES VERSION 1.0 OF THE UAS PILOTS CODE (UASPC). DEVELOPED BY A TEAM OF AVIATION AND UAS PROFESSIONALS, THE UASPC RECOMMENDS OPERATING PRACTICES TO ENHANCE THE QUALITY AND SAFETY OF YOUR OPERATIONS. THE UASPC APPLIES TO A RANGE OF OPERATING ENVIRONMENTS AND EXPERIENCE LEVELS, FROM THE UAS NOVICE TO EXPERIENCED UAS PILOTS.

PILOT CONDUCT AND PROFESSIONALISM AFFECT THE ENTIRE AVIATION COMMUNITY, INCLUDING ITS SAFETY CULTURE. CORRESPONDINGLY, ORGANIZATIONAL SAFETY CULTURE AFFECTS PILOT CONDUCT. A VOLUNTARY, ASPIRATIONAL CODE OF CONDUCT PROMOTES PILOT PROFICIENCY AND OPERATIONAL SAFETY. THE UASPC IS JUST SUCH A TOOL: A SET OF GUIDELINES, AND RECOMMENDED PRACTICES ADAPTABLE TO EACH PILOT AND ORGANIZATIONAL NEED.

THE UASPC REFLECTS YEARS OF SAFETY PRACTICES AND LESSONS LEARNED IN MANNED AND UNMANNED AVIATION THAT ARE APPLICABLE TO UAS OPERATIONS. WE ENCOURAGE YOU TO ADOPT IT, AND TO COMMIT TO THE HIGHEST PRINCIPLES OF AVIATION SAFETY.

THE UASPC WAS DEVELOPED AS A VOLUNTEER EFFORT AND IS PROVIDED AS A FREE PUBLIC SERVICE. THE UASPC AND SUPPORTING MATERIALS CAN BE FOUND ONLINE AT WWW.SECUREAV.COM AND WWW.UAA.AERO. 


\section{UAS Pilots Code -Annotated Version 1.0}

\section{Table of Contents}

REVISION HISTORY 2

UAS PILOT LETTER 3

TABLE OF CONTENTS 4

PREFACE

INTRODUCTION 6

UAS PILOTS CODE 9

I. GeNERAL RESPONSIBILITIES OF UAS PILOTS 9

II. MANNED Aircraft AND PeOple ON THE Surface 14

$\begin{array}{ll}\text { III. TRAINING AND PROFICIENCY } & 16\end{array}$

$\begin{array}{ll}\text { IV. SECURITY AND PRIVACY } & 19\end{array}$

V. ENVIRONMENTAL ISSUES 22

VI. USE OF TECHNOLOGY 24

$\begin{array}{ll}\text { VII. ADVANCEMENT OF UAS AVIATION } & 27\end{array}$

ADDITIONAL RESOURCES 29

$\begin{array}{ll}\text { NOTICE } & 30\end{array}$

EDITS, ERRATA, COMMENTS

ACKNOWLEDGEMENTS 31

$\begin{array}{ll}\text { APPENDICES } & 34\end{array}$

APPENDIX 1 - ABBREVIATIONS

APPENDIX 2 - DEFINITIONS 36

APPENDIX 3 - SELECTED REFERENCES 43

APPENDIX 4 - UASPC CONDENSED VERSION 45

APPENDIX 5 - UASPC ABBREVIATED VERSION 46

$\begin{array}{ll}\text { ENDNOTES } & 47\end{array}$

$\begin{array}{ll}\text { INDEX } & 103\end{array}$ 


\section{UAS Pilots Code -Annotated Version 1.0}

\section{Preface}

[Y]ou don't have to be a manned pilot to understand and embrace a safety culture. We all share the same sky, and we must all consider the impact of what we do on everyone. ${ }^{1}$

Dallas Brooks, Chairman, AUVSI

Director, Raspet Flight Research Lab, MSU 


\section{UAS Pilots Code -Annotated Version 1.0}

\section{Introduction}

The UAS PILOTS CODE ${ }^{2}(U A S P C)^{3}$ offers recommendations to advance flight safety, ${ }^{4}$ ground safety, airmanship, ${ }^{5}$ and professionalism. ${ }^{6}$ It presents a vision of excellence for UAS pilots and operators, and includes general guidance for all types of UAS. The UASPC offers broad guidance-a set of values - to help a pilot interpret and apply standards and regulations, and to confront real world challenges to avoid incidents and accidents. It is designed to help UAS pilots develop standard operating procedures (SOPs), effective risk management, ${ }^{7}$ safety management systems (SMS), and to encourage UAS pilots to consider themselves aviators and participants in the broader aviation community.

The FAA Airman Certification Standards (ACS) establish the pilot certification testing standards. ${ }^{8}$ Regulations and standards 9 alone, however, do not necessarily prepare a pilot to handle every unusual or unanticipated situations, especially those beyond the scope of standard procedures, checklists or operating manuals. The UASPC's principles complement and underscore legal requirements. ${ }^{10}$ Because regulation may lag behind technology developments, the UASPC can be particularly helpful in providing guidance. ${ }^{11}$

The $U A S P C$ is designed to be a living document, intended to be updated periodically to reflect changes in aviation practices and the aviation environment.

This document is applicable to civil unmanned aircraft system (UAS) pilots, ground crew including visual observers, operators, operations managers, safety officers, and other interested or responsible parties. ${ }^{12}$ The UASPC may also serve as a supplemental resource for other UAS operations. ${ }^{13}$

The $U A S P C$ is a model, ${ }^{14}$ not a standard.${ }^{15}$ Users may customize this document to suit their needs including title, ${ }^{16}$ length, organization, and level of technical detail or sophistication. For further help with customization see "Additional Resources." The UASPC is most effective if users commit to the pursuit of professionalism as well as a firm grasp of the fundamentals of UAS flight and flight safety. Three versions of the UASPC are available:

- Annotated Version - this unabridged document includes supplemental materials, extensive supporting endnotes, and drafting considerations,

- Condensed Version - without annotation, intended for pilot implementation (see Appendix 4), and

- Abbreviated Version - containing only the core principles, introducing and promoting the UASPC (see Appendix 5). 


\section{UAS Pilots Code -Annotated Version 1.0}

The UASPC has seven sections, each presenting Principles and Sample Recommended Practices (SRPs). ${ }^{17}$

\section{The Sections:}

I. GENERAL RESPONSIBILITIES OF UAS PILOTS

II. MANNED Aircraft AND PEOPle ON THE SURFACE

III. TRAINING AND PROFICIENCY

IV. SECURITY AND PRIVACY

V. ENVIRONMENTAL ISSUES

VI. USE OF TECHNOLOGY

VII. ADVANCEMENT OF UAS AVIATION

\section{The Principles:}

The Principles are recommended best practices addressing safety, training, risk management, and technology. General and concise, the Principles are designed to provide a foundation for building professionalism and a safety culture.

\section{The Sample Recommended Practices:}

Sample Recommended Practices are suggestions for applying the principles of the UASPC and tailoring them to individuals and organizations. Sample Recommended Practices may be reordered, modified, or eliminated when not applicable, to satisfy the unique capabilities and requirements of each pilot, mission, unmanned aircraft, organization, and flight environment.

\section{The Annotated Version and The Commentary:}

Extensive annotation is presented in this version of the $U A S P C$ to provide support, resources, discussion, and drafting considerations. In addition, commentary is published at www.secureav.com. The commentary provides discussion, interpretive guidance, and suggested ways to adopt the UASPC. The annotated version is intended primarily for flight departments, ${ }^{18}$ managers, UAS businesses, policy administrators, compliance officers, and UAS pilots and operators who wish to explore the UASPC in greater depth. ${ }^{19}$

\section{Definitions:}

Recognizing that the field of unmanned aviation represents a confluence of aviation and consumer technology, terms likely to be more familiar to members of one group than the other are explained in brief parentheses. The annotated version contains extensive definitions of these and other terms.

\section{Benefits of the UASPC:}

The UASPC benefits UAS pilots and the UAS community by:

recommending practices to support safety and professionalism among UAS pilots,

$\square$ encouraging UAS pilots to recognize themselves as aviators and members of the broader aviation community, 


\section{UAS Pilots Code -Annotated Version 1.0}

$\square$ promoting improved training, ${ }^{20}$ airmanship, conduct, personal responsibility, and pilot contributions to the UAS community and society at large,

$\square$ encouraging the development and adoption of ethical practices ${ }^{21}$ and good judgment,

$\square$ advancing self-regulation and responsibility in the UAS community, and

$\square$ supporting improved communications between pilots, regulators, and others in the UAS industry to further enhance safety within the National Airspace System (NAS).

Note: References to civil aviation authorities (CAAs), including the US Federal Aviation

Administration are used as examples. In all jurisdictions, applicable laws and regulations must be followed. 


\title{
UAS Pilots Code
}

\author{
PRINCIPLES AND
}

Sample Recommended Practices

\section{General Responsibilities of UAS Pilots}

UAS pilots should:
a. make safety a top priority, ${ }^{22}$
b. seek excellence in airmanship (knowledge, skill, ability, and attitude that promote safe and efficient operations), ${ }^{23}$
c. adopt sound principles of aeronautical decision-making (ADM) $)^{24}$ (the process used by pilots to consistently determine the best course of action in response to the circumstances), and develop and exercise good judgment, ${ }^{25}$
d. use sound principles of risk management, ${ }^{26}$
e. maintain situational awareness (the accurate perception and understanding of your operation and environment), ${ }^{27}$ and adhere to prudent operating practices, ${ }^{28}$
f. aspire to professionalism, ${ }^{29}$
g. act with responsibility, integrity, ${ }^{30}$ and courtesy, and
h. adhere to applicable laws, regulations, and industry guidance. ${ }^{31}$

Explanation: These General Responsibilities serve as a preamble to the UASPC's other principles.

\section{Sample Recommended Practices:}

a. make safety a top priority

Recognize, plan for and accept the costs of implementing effective safety practices.

- Organizations of any size and scope should apply the principles of a safety management system (SMS): understand the risks in your operations, take steps to control them, and monitor operations to assure that these controls are working. 32

Improve safety margins and reduce unnecessary risk by planning and flying conservatively.

$\square$ Recognize that use of a visual observer enhances safety, even when not required. ${ }^{33}$ 


\section{UAS Pilots Code -Annotated Version 1.0}

$\square$ Do not carry hazardous payloads unless authorized. ${ }^{34}$

$\square$ Do not assume that the altitudes prescribed in UAS Facility Maps are necessarily accurate or appropriate for flight. ${ }^{35}$

$\square$ Create an emergency response plan, and implement it in the event of an incident or accident. ${ }^{36}$

b. seek excellence in airmanship

$\square$ Identify and adapt to changing flight conditions based on airmanship, sound principles of UAS safety and risk management. Be prepared to alter your flight plan or discontinue your flight accordingly. ${ }^{37}$

c. adopt sound principles of aeronautical decision-making, and develop and exercise good judgment

$\square$ Ensure UAS flight controllability is not adversely affected by payload weight, placement, and loading. ${ }^{38}$ Follow manufacturer's instructions if provided. In the absence of provided guidance, use conservative loading practices.

Consider conducting a stability and controllability test at the start of each flight. ${ }^{39}$

$\square$ Understand the unique relationship between UAS piloting and aeronautical decision-making, ${ }^{40}$ ethical choices, and flight safety. ${ }^{41}$

$\square$ Recognize the difficulty of visually estimating UAS altitude and distance. ${ }^{42}$

Incorporate Threat and Error Management (TEM - process of detecting and responding to threats and errors $)^{43}$ into your operation to aid in identifying errors and external threats that could compromise safety. ${ }^{44}$

Employ Crew Resource Management (CRM - the effective use of all available resources: buman resources, hardware, and information) techniques to foster effective crew coordination, teamwork, and enhance safety culture. ${ }^{45}$

Consider the effect of weather such as wind, precipitation, and temperature on power, fuel reserves, and performance, and their impact on the safe completion of flight. ${ }^{46}$

$\square$ Refuse to operate a UAS that is unsafe for flight because of mechanical, electrical or control system discrepancies, failure to meet applicable inspection requirements, airworthiness (suitability for safe flight), or any anomaly that adversely affects airworthiness. ${ }^{47}$

$\square$ Discontinue UAS operations in the event of potential conflict with other aircraft, mechanical anomaly, low power or fuel condition, adverse weather, or any other condition that may compromise safety.

\section{d. Use sound principles of risk management}

$\square$ Use risk management tools to identify, evaluate and mitigate the effects of hazards, and do not subject anyone to unnecessary risks. ${ }^{48}$ 


\section{UAS Pilots Code -Annotated Version 1.0}

Keep operations well clear of airports, heliports, and seaplane bases. ${ }^{49}$ Conduct such operations only when safety can be reasonably assured. Where applicable, make notification, and obtain authorization from proper authorities.

- Recognize the restrictions ${ }^{50}$ associated with flying near airports or other aircraft, in controlled airspace, over people, in inclement weather (including reduced visibility environments), and at night. Be aware of the increased risk associated with flying in congested, urban, ${ }^{51}$ or confined areas; near obstacles; over water, ${ }^{52}$ rugged, mountainous, or forested terrain; in high density altitude conditions $;{ }^{53}$ and in other circumstances that may adversely affect safety. ${ }^{54}$

$\square$ Have a ground safety plan for and ready access to appropriate fire suppression and other emergency equipment and the ability to contact emergency services. .55

$\square$ Recognize that aviation or other charts may not accurately reflect all obstructions and hazards that could affect UAS operations. Maintain chart currency. ${ }^{56}$ Supplement aeronautical charts with visual observers, site survey, and other mapping resources. ${ }^{57}$

$\square$ Prevent distractions that could lead to errors and compromise safety by limiting unnecessary tasks or communication during launch, recovery, and other critical phases of flight. ${ }^{58}$

$\square$ Where practicable, enhance visibility through appropriate use of aircraft lighting and bright paint schemes or markings. Ensure aircraft lighting does not impair night vision. ${ }^{59}$

$\square$ See and be seen. Maintain a robust scan and practice techniques for seeing and avoiding other aircraft. ${ }^{60}$ Recognize that manned aircraft pilots are unlikely to anticipate or see your UAS.

$\square$ Fly at an altitude appropriate to the mission. Consider the risks associated with higher altitude flights, such as higher wind speeds, maintaining separation from other aircraft and potential crash impact velocity with respect to people, ${ }^{61}$ structures or property on the surface. Be aware of the risks of flying at low altitudes, such as manned operations, obstructions, turbulence induced by urban structures, and other relevant hazards. ${ }^{62}$

- Make an honest evaluation of your mental and physical fitness a precondition of each flightfor example, by using the I'M SAFE (Illness, Medication, Stress, Alcohol, Fatigue, Emotion) checklist. ${ }^{63}$

$\square$ Recognize that some emergency scenarios should not be practiced in the absence of an experienced UAS pilot or knowledgeable mentor. ${ }^{64}$

\section{e. Maintain situational awareness, and adhere to prudent operating practices}

Improve situational awareness by using sound principles of airmanship, crew resource management, scenario-based training, and risk management.

$\square$ Become familiar with and monitor appropriate aviation frequencies to enhance your awareness of other aircraft in proximity to your UAS operation. ${ }^{65}$ Where authorized, accurately inform other pilots of your position and intentions on appropriate frequencies, and air traffic control of emergencies including loss of separation with other aircraft, or loss of control of your UAS. ${ }^{66}$ 


\section{UAS Pilots Code -Annotated Version 1.0}

For flights to, from, at, or in proximity to airports, ${ }^{67}$ contact the controlling facility, and review applicable Chart Supplements (formerly Airport Facilities/Directory (AF/D) ${ }^{68}$ and other resources to ascertain each airport's environment, operational conditions, surrounding terrain and obstructions.

$\square$ Remain aware of changing or deteriorating weather and other circumstances that may make continued flight unsafe. Be particularly aware of crosswinds, tailwinds, and gusty wind/turbulent conditions when landing, departing, or hovering. In such cases, make an informed risk management decision whether to continue the flight.

$\square$ Avoid the flow of all manned aircraft traffic unless directed otherwise by air traffic control (ATC). For off-airport flights, include review of relevant maps, and local knowledge.

$\square$ Plan for the possibility that curious onlookers may approach your UAS operation creating a potential distraction or hazard.

- Check relevant Notices to Airmen (NOTAMs) ${ }^{69}$ including Temporary Flight Restrictions (TFRs) ${ }^{70}$ prior to commencing flight operations, and update as practicable during extended or multi-flight operations. When appropriate, file and update NOTAMs regarding your flight. ${ }^{71}$

$\square$ Complete a comprehensive preflight inspection prior to commencing flight operations ${ }^{72}$ to determine that the UAS is airworthy.

$\square$ Ensure that your aircraft's firmware (software that controls essential system functions) and other software is up to date. ${ }^{73}$ Recognize that various systems may require update, including aircraft, ground station, control application or display tablet and power supply. Be sure you understand the impact of any firmware/software updates. ${ }^{74}$

$\square$ As part of preflight planning, identify options for emergency landing locations. ${ }^{75}$

$\square$ Develop, use, periodically review, and refine checklists ${ }^{76}$ and personal minimums (an operational envelope within which the pilot is adequately trained and competent) for all phases of flight. Review these materials regularly with an experienced UAS pilot or knowledgeable mentor.

$\square$ Before takeoff, understand your mission plan. ${ }^{77}$ The mission plan should include consideration of the objectives, pilot capabilities, UAS platform, operations area, environmental conditions, and other external factors affecting flight safety.

$\square$ Maintain an altitude and configuration that will permit an emergency landing without undue hazard to people or property.

\section{f. aspire to professionalism}

$\square$ As part of preflight planning, identify locations where either manned or unmanned aircraft may be encountered and develop contingencies for avoidance. UAS pilots may encounter VFR aircraft at lower than normal altitudes during periods of reduced visibility or limited ceiling height.

$\square$ Be aware of personal susceptibility to, and seek to avoid or manage distraction, fatigue, and stress. 


\section{UAS Pilots Code -Annotated Version 1.0}

$\square$ Be aware of your personal susceptibility to attitudes that adversely influence good aeronautical decision-making.

Develop conservative personal operating limitations ${ }^{78}$ reflecting experience, and proficiency, especially in challenging conditions. 


\section{UAS Pilots Code-Annotated Version 1.0}

g. act with responsibility, integrity, and courtesy

A Approach UAS operations with seriousness, commitment, and diligence, recognizing that your actions may jeopardize the lives, well-being, and property of people in manned aircraft and on the surface. ${ }^{79}$

\section{h. adhere to applicable laws, regulations, and industry guidance}

Understand and comply with the privileges and limitations of your certificates, authorizations, and waivers. ${ }^{80}$

Adhere to rules and operating practices of your airport or operating location, ${ }^{81}$ employer, flight school, or flight center, and recommendations from recognized UAS organizations.

$\square$ Maintain awareness of local laws, regulations, or ordinances that may affect UAS operations. ${ }^{82}$

- As soon as practicable but no later than 10 days after an occurrence, report UAS accidents to the FAA; 83 immediately report accidents that meet NTSB thresholds to the NTSB, and report near mid air collisions to the FAA's Near Mid Air Collision System (NMACS), ${ }^{84}$ and/or safety incidents via the Aviation Safety Reporting System (ASRS). ${ }^{85}$

$\square$ Comply with manufacturer's operating manuals and instructions, especially with regard to performance, limitations, and abnormal/emergency conditions.

- Understand the requirements and benefits of complying with manufacturer's recommended inspections and maintenance guidance, and in the absence thereof, consider developing a scheduled maintenance plan that achieves the longest and safest service life of the UAS. ${ }^{86}$

- Complete post-flight procedures such as ATC flight completion notification, cancellation of flight plan, post-flight inspections, and discrepancy reporting. ${ }^{87}$ Keep a log of UAS maintenance and operational status and ensure that appropriate measures are taken to correct system deficiencies. ${ }^{8} 8$

$\square$ Identify safety and compliance issues, and communicate them appropriately. ${ }^{89}$

$\square$ Confirm availability of all required or recommended ground support equipment before initiating flight operations. ${ }^{90}$

$\square$ Learn and remain familiar with lost control link, ${ }^{91}$ stabilization, and other automation failure procedures..$^{92}$ Follow manufacturer's or builder's instructions if provided.

Use caution when charging, transporting, discharging, storing, disposing or otherwise handling batteries to minimize risk to persons or property. ${ }^{93}$ 


\section{UAS Pilots Code -Annotated Version 1.0}

\section{Manned Aircraft and People on the Surface}

UAS pilots should:

a. manage and avoid unnecessary risk to manned aircraft, and to people and property on the surface, ${ }^{94}$ and

b. avoid operations that may alarm or disturb people on the surface ${ }^{95}$ or in manned aircraft.

Explanation: UAS pilots must avoid harming persons or property. Civil aviation authorities accommodate flight operations with the expectation that UAS pilots exercise due care and adequately mitigate risks to others and their property.

\section{Sample Recommended Practices:}

a. Manage and avoid unnecessary risk to manned aircraft, and to people and property on the surface

Recognize that responsible planning precedes every UAS mission.

Give right-of-way to all manned aircraft. ${ }^{96}$

口 Do not operate over people without authorization, proper training and equipment. ${ }^{97}$ Consider using a covered area or safety line to segregate flight operations from nonparticipants and minimize risk to people. ${ }^{98}$

$\square$ To the extent practicable, use aircraft and payloads composed of frangible or energyabsorbing materials, propeller guards, and other available mechanisms ${ }^{99}$ to mitigate risk of injury to persons. ${ }^{100}$

$\square$ Monitor people within the proximity of your intended operations closely. Keep them informed and clear of potential UAS hazards including propellers, rotors, and hazardous materials.

$\square$ UAS pilots and crew members should consider the use of protective, highly-visible clothing (such as safety vests and other markers), helmets, and eye protection. ${ }^{101}$ Use high visibility area markers such as traffic cones to denote takeoff and landing areas to protect everyone.

$\square$ Maintain adequate insurance coverage for all UAS operations. Understand and comply with all policy terms and limitations. ${ }^{102}$

B Brief all participants on the planned UAS operation to mitigate the potential for injury.

- Instruct non-crewmembers to avoid touching or obstructing equipment and payload.

$\square$ Develop and maintain an operations manual ${ }^{103}$ to help identify and describe the system and operations characteristics, including specifications of the aircraft, responsibilities of the crew, scope of operational decision-making authority, pre- and post-flight checklists, and processes that promote risk management.

$\square$ Collision avoidance may require UAS pilots to perform an aggressive maneuver. During such maneuvers be aware of the increased risk of impact with aircraft and people or structures on the surface.

- Consider the use of visual observers to aid the UAS pilot in maintaining situational awareness as well as identifying both airborne and ground hazards. 


\section{UAS Pilots Code -Annotated Version 1.0}

b. avoid operations that may alarm or disturb people on the surface or in manned aircraft

$\square$ Ensure adequate separation from people, other aircraft, and unauthorized airspace. ${ }^{104}$

- Avoid manned aircraft traffic patterns unless authorized and operationally required.

- Act professionally towards all people affected by your UAS operations.

- Tactfully disclose risks to all affected parties and address their concerns regarding flight operations, and seek to accommodate their needs.

$\square$ Take responsibility for any harm you may cause to people, property, or wildlife. ${ }^{105}$ 


\section{UAS Pilots Code -Annotated Version 1.0}

\section{Training and Proficiency}

UAS pilots should:

a. participate in regular training to maintain and improve proficiency ${ }^{106}$ beyond minimum requirements, 107

b. pursue a rigorous, lifelong course of aviation study,

c. remain vigilant and avoid complacency,

d. train to recognize and effectively respond to emergencies, and

e. maintain an accurate $\log$ to document your experience and improve future aeronautical decision-making and risk management.

Explanation: Training and proficiency underlie aviation safety. Regular training is a primary component of proficiency and should include both air and ground training. Training and proficiency each contribute significantly to flight safety and neither can substitute for the other.

\section{Sample Recommended Practices:}

\section{a. participate in regular training to maintain and improve proficiency beyond minimum requirements}

Develop and follow a training regimen that incorporates the assessment of your progress. Obtain guidance and seek feedback from an experienced UAS pilot or mentor.

- Obtain equipment and operational training before commencing flight operations.

- Learn appropriate use of the UAS manufacturer's manual ${ }^{108}$ or instructions to conduct flight planning, properly secure payloads, ${ }^{109}$ determine aircraft limitations, performance, and power or fuel requirements, assess weight and balance, and safely undertake flight operations.

- Recognize applicable safety or informational placards placed on the UAS platform, components, attachments, related devices, or manuals. Understand and comply with all placard instructions, limitations, or information. Ensure placards are visible and properly affixed. ${ }^{110}$

- Become familiar with orientation or aircraft status lighting and their related meaning to enhance situational awareness. ${ }^{111}$

Learn and adhere to airspace classes, requirements, and restrictions. ${ }^{112}$

$\square$ Integrate manual flight, autonomous flight, ${ }^{113}$ and scenario-based training (real-world situations that meet flight training objectives in an operational environment) in the training regime.

Incorporate simulation into your training program, ${ }^{114}$ with an emphasis on abnormal/emergency conditions, including loss-of-control 115 and traffic conflicts.

$\square$ Learn how your automated systems work and understand their limitations.

$\square$ Learn and practice obstacle and wire avoidance techniques. ${ }^{116}$

- Complete training appropriate to specialized operations or unique mission requirements. ${ }^{117}$

- Develop a systematic approach to obtaining timely and reliable weather information ${ }^{118}$ and evaluating flight conditions. 


\section{UAS Pilots Code -Annotated Version 1.0}

$\square$ Learn and remain familiar with aviation regulations and associated guidance material. Understand their intent and implications.

- Train for flight over challenging environments such as water, remote areas, desert, or mountainous terrain, woodlands, urban areas, and understand that such environments may compromise or degrade the performance or functionality of some UAS. ${ }^{119}$

$\square$ Learn how to determine and adhere to airworthiness requirements for each UAS you fly, and confirm its airworthiness before each flight by conducting a thorough preflight inspection. ${ }^{120}$

$\square$ Develop a practical understanding of the mechanics, systems, and unique risks of each UAS you fly.

$\square$ Conduct a periodic review of recent accidents, incidents, and unsafe conditions focusing on probable causes. ${ }^{121}$

\ Periodically demonstrate mastery of applicable Airman Certification Standards (ACS); ${ }^{122}$ study and train to exceed ACS requirements.

- Select an appropriate training area, taking into consideration property ownership, airspace, local restrictions, and potential safety and privacy issues. ${ }^{123}$

Fly often enough to maintain proficiency consistent with your certificates and authorizations.

$\square$ Use flight simulators and other training devices that appropriately reflect your system's automation. ${ }^{124}$

b. pursue a rigorous, lifelong course of aviation study

Invite and accept constructive criticism ${ }^{125}$ from your fellow aviators and provide the same when asked.

口 Attend aviation training programs, ${ }^{126}$ FAA Pilot Proficiency Program ("WINGS”) safety seminars, and complete online FAAST courses and training materials. ${ }^{127}$

$\square$ Participate in organizations that can improve your UAS platform knowledge and flight skills regarding their capabilities, limitations, and safe operation. ${ }^{128}$

- Achieve and maintain proficiency in the operation of UAS systems, manual flight controls and automation.

C Commit to and maintain an ongoing course of training in both flight skills and aeronautical knowledge.

$\square$ Register at www.faasafety.gov to receive announcements of safety meetings and literature, and to review appropriate safety courses.

$\square$ Stay current with relevant aviation publications. ${ }^{129}$

c. remain vigilant and avoid complacency

$\square$ Obtain adequate training before flying an unfamiliar UAS, or operating unfamiliar UAS automation or systems, even if you have flown a similar make or model in the past. ${ }^{130}$

$\square$ Ensure before each flight that your safety, failsafe, and other settings are configured appropriately.

- UAS pilots who are not certificated to fly manned aircraft may benefit from introductory ground and flight training in manned flight. Such training will help the UAS pilot better 


\section{UAS Pilots Code -Annotated Version 1.0}

understand the unique challenges of operating manned aircraft, including detecting and avoiding UAS operations. ${ }^{131}$

$\square$ Manned aircraft pilots who intend to fly UAS should obtain additional training to address the unique challenges of conducting UAS operations. Such training may cover command and control (C2) systems, ${ }^{132}$ including telemetry, data management, failure modes, autonomous operations, ${ }^{133}$ and aerodynamics. ${ }^{134}$

$\square$ Recognize the vulnerability of UAS to wind, turbulence, and other weather conditions, and how these effects may vary in fixed-wing, multirotor, and hybrid unmanned aircraft.

\section{d. train to recognize and effectively respond to emergencies}

$\square$ Practice emergency procedures regularly. Recognize that improper responses to simulated emergencies can lead to actual emergencies. ${ }^{135}$

Understand your authority and responsibilities as a UAS pilot including recognizing an emergency when it occurs, and communicating that knowledge to crew, bystanders or external authorities as appropriate.

$\square$ Understand and train to use appropriate procedures in the event of system malfunctions or failures such as electrical, rotor, propulsion, or loss of control link. ${ }^{136}$

e. maintain an accurate log to document your experience and improve future aeronautical decision-making and risk management

$\square$ Debrief each flight. Review your objectives, identify mistakes and any unnecessary risks to enhance safety and improve your performance on future flights. Maintain a log to track errors and lessons learned during each flight. 


\section{UAS Pilots Code -Annotated Version 1.0}

\section{Security and Privacy}

\section{UAS pilots should:}

a. take measures to maintain the security of persons and property affected by UAS activities,

b. remain vigilant and immediately report suspicious, reckless, or illegal UAS activities, ${ }^{137}$

c. become familiar with current security and privacy rules and best practices, ${ }^{138}$

d. avoid controlled and special activity/special use airspace ${ }^{139}$ except when approved or necessary in an emergency, and

e. recognize and respect the public's reasonable expectation of privacy.

Explanation: Security pertains to measures taken to protect people, property, and information from criminal or terrorist acts. It also includes measures taken by UAS pilots to avoid inadvertently becoming a real or perceived security threat. In addition, UAS operations present a new and unique potential to compromise privacy. This section addresses the UAS pilot's essential role in promoting national security, preventing criminal acts, and respecting privacy rights. ${ }^{140}$

\section{Sample Recommended Practices:}

\section{a. take measures to maintain the security of persons and property affected by $U A S$ activities}

$\square$ Secure your UAS if it will be unattended. ${ }^{141}$

$\square$ Determine the ownership of property on which you desire to launch or recover, and seek prior permission where required. ${ }^{42}$

$\square$ Do not deactivate or degrade geo-fencing or other security features on your equipment unless they present a flight hazard or impede authorized operations. ${ }^{143}$

$\square$ To the extent practicable, seek to avoid even the appearance of a security threat. ${ }^{144}$ UAS operations may be perceived as a threat by property owners, security, military, or law enforcement personnel, and may put the UAS at risk of being disabled, damaged, destroyed, or confiscated in response to a perceived threat. ${ }^{145}$ If your UAS operation may have been perceived as a threat, move away, change the flight path, or consider landing the UAS and explaining your intentions.

\section{b. remain vigilant and immediately report suspicious, reckless, or illegal UAS activities}

- Become familiar with the means to report and deter suspicious activities, such as a call to law enforcement and follow-up to the FAA Hotline https://hotline.faa.gov/.

\section{c. become familiar with current security and privacy rules and best practices}

Comply with applicable UAS registration requirements, including the proper display of registration number. ${ }^{146}$ 


\section{UAS Pilots Code -Annotated Version 1.0}

$\square$ Comply with applicable requirements for electronic identification, tracking, and authorization. ${ }^{147}$

$\square$ Comply with all rules relating to UAS payload or cargo, such as the carriage of hazardous materials, weapons, ammunition, or other contraband. ${ }^{148}$

$\square$ Consider use of systems that improve data security (including encrypted command and control systems, and relevant security standards ${ }^{149}$ ), and provide at least the level of security required to satisfy information security requirements. ${ }^{150}$

$\square$ Complete any required or recommended security training applicable to your flight operations. ${ }^{151}$

d. avoid controlled and special activity/special use airspace except when approved or necessary in an emergency

D During preflight preparation, check airspace and location restrictions applicable to your operation, including NOTAMs ${ }^{152}$ and temporary flight restrictions (TFRs). ${ }^{153}$

$\square$ Avoid TFRs, public safety/emergency operations or other areas of intensive manned aircraft operations, and events that may attract other aircraft or crowds. ${ }^{154}$

- Avoid UAS operations near prisons, power plants, military bases, and other critical infrastructure. ${ }^{155}$ Notify such entities prior to operating nearby.

- Be cognizant of operations that may be subject to privacy, trespass, ${ }^{156}$ nuisance, ${ }^{157}$ intrusion upon seclusion, ${ }^{158}$ or other considerations. ${ }^{159}$

$\square$ Query applicable charts, available/approved applications, Flight Service (air traffic facilities that provide preflight briefings, flight plan processing, and inflight advisories), ${ }^{160}$ or ATC to avoid operating in special activity/special use airspace ${ }^{161}$ or other areas not authorized for UAS flight. ${ }^{162}$

$\square$ Comply with airspace restrictions and authorized operational limitations approved for your flight and UAS platform. ${ }^{163}$

e. recognize and respect the public's reasonable expectation of privacy

$\square$ Understand and respect the public's reasonable expectation of privacy rights of others by conducting your UAS operations with prudence and restraint. ${ }^{164}$

$\square$ Seek to avoid even the appearance of impropriety regarding potential violations of privacy with your operations. ${ }^{165}$

$\square$ Limit data capture to mission-related objectives. ${ }^{166}$

- Retain personal data only when legally and purposefully collected, and only for the duration necessary. ${ }^{167}$

$\square$ Avoid the collection of personal data ${ }^{168}$ without the subject's consent. Delete such data immediately upon discovery, and maintain a de-identified log of the deletion.

Implement a written privacy policy that is appropriate and responsive to your UAS operations. ${ }^{169}$

$\square$ Recognize that limited societal experience may cause some people to consider unmanned aircraft harassing, invasive, or threatening. Respond with courtesy and professionalism. 


\section{UAS Pilots Code -Annotated Version 1.0}

\section{Environmental Issues}

\section{UAS pilots should:}

a. recognize and seek to mitigate the environmental impact of UAS operations, ${ }^{170}$

b. minimize the discharge of fuel, oil, and other chemicals into the environment during refueling, preflight preparations, servicing, and flight operations,

c. recognize that some UAS components, including batteries, other fuels, and lubricants, may be hazardous and require special handling procedures,

d. respect and protect environmentally sensitive areas, ${ }^{171}$ and

e. avoid flight over noise-sensitive areas, and comply with applicable noiseabatement procedures.

Explanation: Environmental issues can cause harm, hamper operations, and increase regulatory burdens. Mitigating the environmental impact of UAS operations will improve public health and society's perceptions of the industry. ${ }^{172}$ Through the thoughtful exercise of responsible practices, most environmental issues are manageable. ${ }^{173}$

\section{Sample Recommended Practices:}

a. recognize and seek to mitigate the environmental impact of UAS operations

- Learn and adopt environmentally responsible methods for all aspects of UAS care.

$\square$ Adopt organizational policies for managing environmental issues.

$\square$ Complete a post-flight assessment to ensure that the UAS operations did not cause environmental harm. If the UAS operation causes damage to property or the environment, restore it to its previous condition.

Patronize service providers that adhere to environmentally friendly practices.

b. minimize the discharge of fuel, oil, and other chemicals into the environment during refueling, preflight preparations, servicing, and flight operations; and c. recognize that some UAS components, including batteries, other fuels, and lubricants, may be bazardous and require special handling procedures

- Adopt environmentally sound and legally compliant procedures for battery or fuel transportation, storage, fueling ${ }^{174}$ sampling, defueling, disposing of batteries ${ }^{175}$ or fuel samples, and remediating fuel spills.

\section{d. respect and protect environmentally sensitive areas}

$\square$ Consider the potential impact of UAS on animal life, and comply with recommended practices when flying near wilderness, wildlife, marine sanctuaries, ${ }^{176}$ and other environmentally sensitive areas. Recognize that UAS may attract, frighten, or injure birds and other animals. Remember that UAS may be mistaken as predators by nesting birds and other wildlife, causing harmful stress or abandonment of nests and habitat. ${ }^{177}$

\section{e. avoid flight over noise-sensitive areas, and comply with applicable noise-abatement procedures}

If practicable, avoid residential and other noise-sensitive areas. 


\section{UAS Pilots Code -Annotated Version 1.0}

$\square$ Be aware of the noise signature of your aircraft, take steps to limit ambient UAS noise, and consider system modifications that do so. ${ }^{178}$

$* *$ 


\section{UAS Pilots Code -Annotated Version 1.0}

\section{Use of 'Technology}

\section{UAS pilots should:}

a. become familiar with UAS equipment and related technologies, ${ }^{179}$

b. make effective use of technology by integrating technical guidance and solutions into your standard operating procedures,

c. practice effective system monitoring and ensure you are prepared to revert to manual operations if available,

d. Identify failure modes, and where practicable, test and deploy fault-tolerant or redundant ${ }^{180}$ equipment, and

e. use, and understand the limitations of, position-indicating technologies including detect-and-avoid (DAA), if available and authorized. ${ }^{181}$

Explanation: Innovative, compact, and inexpensive aviation technologies offer expanded capabilities and enhanced safety. This section encourages the use and promotion of such safety- and capability-enhancing technologies.

\section{Sample Recommended Practices:}

a. become familiar with appropriate UAS and other technologies

When practicable, invest in new technologies that enhance your proficiency, knowledge, situational awareness, and advance flight safety.

Recognize that new technologies will increasingly provide enhanced safety capabilities, including, e.g., detect-and-avoid, ${ }^{182}$ obstacle avoidance, graceful degradation, ${ }^{183}$ and advanced UAS traffic management (UTM) capabilities ${ }^{184}$ supporting beyond visual line of sight (BVLOS) operations. ${ }^{185}$

$\square$ Do not engage in UAS operations unless the instruments and equipment needed for the type of flight operation, including controls, transmitters, and sensors, are installed and in an operable condition. ${ }^{186}$

- Recognize conditions that may induce control signal attenuation, interference, or disruption. ${ }^{187}$ Electromagnetic fields near power lines, transmission towers, or other transmitting devices may disrupt control signals. ${ }^{188}$ Determine the potential impact and develop contingency plans if the UAS encounters signal interference. ${ }^{189}$

$\square$ Recognize many UAS contain magnetic sensors critical for navigation. Consider conditions that may induce magnetic interference, ${ }^{190}$

$\square$ Understand how to interpret and respond to weather radar imagery and other advanced weather tools, and become apprised of new weather products that may inform and enhance flight planning and safety. ${ }^{191}$

Understand the currency of weather information sources, and obtain weather updates as appropriate.

Consider the use of flight data monitoring, tracking, and flight recording to improve training, flight operations, post-flight review or debrief, and post-crash/injury investigation. 


\section{UAS Pilots Code-Annotated Version 1.0}

Use web-based flight planning, compliance, ${ }^{192}$ and management tools to enhance safety, situational awareness, and efficiency. ${ }^{193}$

Understand and comply with any licensing requirements for use of certain radio frequency bands. ${ }^{194}$

b. make effective use of technology by integrating technical guidance and solutions in your standard operating procedures

Understand the accuracy limitations of the aircraft's altimetric equipment. ${ }^{195}$

$\square$ Understand the accuracy limitations of your GPS and other navigation systems, learn to identify degradation or failures, and how to apply effective recovery procedures. ${ }^{196}$

- Familiarize yourself with your UAS's entire feature set, and configure all systems to ensure safe operations. ${ }^{197}$ Do not assume that factory default settings are necessarily safe or adequate. Modify factory default settings as needed.

Understand the capabilities, limitations, and proper operation of safety devices (such as prop guards and parachutes). ${ }^{198}$

c. practice effective system monitoring and ensure you are prepared to revert to manual operations if available

$\square$ Learn and understand manual and automated features, limitations, and proper use of UAS control system technologies.

$\square$ Properly manage autoflight systems. Understand that programming avionics during flight operations may cause distractions and that distractions may lead to errors, particularly during critical phases of flight. ${ }^{199}$

- Recognize that increasingly complex UAS may be subject to unpredictable anomalies. ${ }^{200}$

- Maintain basic flying and navigating skills to enhance safety in the event of in-flight emergencies or abnormal conditions.

d. Identify failure modes, and where practicable, test and deploy fault-tolerant or redundant equipment

$\square$ Test third-party applications and devices before mission critical operations.

- Consider keeping backup devices ${ }^{201}$ accessible including extra batteries ${ }^{202}$ or power supplies.

- Learn to identify and correct system degradation or failures. Incorporate risk management practices into the decision process to continue, modify, or cancel a flight under degraded system conditions.

$\square$ Report inoperative GPS and other navigation signals and areas of poor radio/signal coverage to the appropriate authority. ${ }^{203}$

e. use, and understand the limitations of, position-indicating technologies including detect-and-avoid (DAA), if available and authorized

$\square$ Understand the limitations for the use of (DAA) detect-and-avoid technologies, and comply with DAA alerts, cautions, and warnings. ${ }^{204}$ 


\section{UAS Pilots Code -Annotated Version 1.0}

\section{ADVANCEMENT OF UAS AVIATION}

\section{UAS pilots should:}

a. advance and promote aviation safety as well as adherence to the UASPC,

b. collaborate with or assist organizations that advance UAS aviation and contribute to society at large; encourage other UAS pilots to do so as well,

c. demonstrate appreciation for aviation professionals and service providers,

d. advance an aviation culture that values openness, humility, positive attitudes, and the pursuit of personal improvement,

e. promote ethical behavior within the UAS community, 205 and

f. mentor new and future UAS pilots.

Explanation: Vigilance and responsive action are essential to ensure aviation vitality and to enhance the aviation community.

Sample Recommended Practices:

a. advance and promote aviation safety as well as adherence to the UASPC

- Strive to adopt the UASPC. ${ }^{206}$

$\square$ Be aware of the impact of your UAS on manned aviation. As a UAS pilot, be a respectful207 user of the National Airspace System, recognizing that adherence to regulations, best practices, and safe operational procedures protects all users of shared airspace.

b. collaborate with or assist organizations that advance UAS aviation, contribute to society at large, and encourage other UAS pilots to do so as well

$\square$ Advocate and promote the development of unmanned aviation.

- Consider participating in local government efforts that advance flight safety and advocate appropriate enforcement of UAS regulation. ${ }^{208}$

- Participate in local aviation and recognized UAS associations ${ }^{209}$ to learn and contribute to the knowledge base on the safe operation of UAS.

Participate in the review of UAS Facility Maps to ensure they reflect safe altitude separation between UAS and manned aircraft, or other safety hazards. ${ }^{210}$

- Consider making charitable use of your expertise and resources such as participating in community events, humanitarian initiatives, or donating flight time to search and rescue organizations and environmental programs.

$\square$ Participate in FAA Safety Team meetings and events. Learn from and interact with other aviation professionals. ${ }^{211}$

c. demonstrate appreciation for aviation professionals and service providers

$\square$ Express appreciation to air traffic controllers, airport staff, and service personnel for their valuable assistance. 


\section{UAS Pilots Code -Annotated Version 1.0}

d. advance an aviation culture that values openness, bumility, positive attitudes, and the pursuit of personal improvement

Consider your responsibility to promote safe and appropriate behavior to other pilots and aviation professionals.

- Recognize that your actions can reflect upon the entire UAS community.

$\square$ Serve as an aviation ambassador to the public by providing accurate information, refuting misinformation concerning UAS activities, and encouraging prospective UAS pilots.

e. promote ethical behavior within the UAS community

- Adhere to the highest ethical principles in all aviation dealings, including business practices. ${ }^{212}$

$\square$ Seek to resolve disputes quickly and informally.

$\square$ Advance the promotion of data privacy. ${ }^{213}$

f. mentor new and future UAS pilots

- Strive to engender professionalism, to serve as a role model and convey best practices to new and future UAS pilots. ${ }^{214}$ 


\section{UAS Pilots Code -Annotated Version 1.0}

\section{Additional Resources}

- Annotated commentary, source materials, implementation examples, and supplemental aids for the Codes of Conduct are available at secureav.com, and Notes for Implementers at secureav.com/Notes-for-Implementers.pdf.

- The Aviation Maintenance TeChnicians, Aviators, Flight Instructors, Glider Aviators, Helicopter Pilots, Light Sport Aviators, Seaplane Pilots, Student Pilots, UnManNed Aircraft Systems MOdel CODES of CONDUCT, and SAFETy Guidance for Manned Aircraft Pilots Operating in the Presence of Drones are available at secureav.com.

$\square$ Further information about UAS is available at:

FAA

AEA

AMA

AOPA

ASTM Int'1

AUVSI

CANSO

CTA

EAA

EASA

EUROCAE

Flight Service

ICAO

ISO

JARUS

NBAA

RTCA

SAE Int'1

UVS Int'1 $\underline{\text { www.faa.gov/uas }}$

www.aea.net

www.modelaircraft.org

www.aopa.org $/ 215$

www.astm.org 216

www.auvsi.org

www.canso.org

www.cta.tech

www.eaa.org

$\underline{\text { www.easa.europa.eu }}{ }^{217}$

www.eurocae.net $^{218}$

1-800-WX-BRIEF

www.icao.int ${ }^{219}$

www.iso.org 220

http://jarus-rpas.org/publicati>ons

www.nbaa.org

www.rtca.org

http://www.sae.org/

https://rps-info.com 


\section{UAS Pilots Code -Annotated Version 1.0}

\section{Notice}

The UASPC is available at secureav.com and UAA.aero. UAS Pilots CODE (C) Aviators Code Initiative (ACI) and University Aviation Association (UAA). All Rights Reserved. Terms of Use are available at secureav.com/terms.pdf.

The UASPC is a joint initiative between the Aviators Code Initiative and the University Aviation Association.

The UASPC does not purport to address every possible safety concern. It is the responsibility of the user of the UASPC to establish appropriate safety and health practices and determine the applicability of regulatory limitations prior to use. It is not intended to provide legal advice and must not be relied upon as such.

\section{Edits, Errata, Comments}

Please send your suggestions, edits, errata, questions and comments to: PEB@secureav.com. 


\section{UAS Pilots Code-Annotated Version 1.0 \\ Acknowledgments}

The UASPC Drafting Team:

Michael S. Baum, JD, MBA, ATP

Kristy K. Kiernan, PhD, ATP

Donald W. Steinman, BA, ATP B737, B757/767, A320

Ryan J. Wallace, EdD

The Aviators Code Initiative Permanent Editorial Board:

Don Arendt, PhD, CFI, ATP

Michael S. Baum, JD, MBA, ATP

Ric Peri

Michael Radomsky, CFII

Bill Rhodes, $\mathrm{PhD}$

Stan Rose

Rusty Sachs, JD, DhE, MCFI

Don Steinman, ATP, CFII

Various subject matter experts have provided input for the UASPC. We gratefully acknowledge their editorial assistance. Not all reviewers concur with all positions taken. The list does not include those reviewers who requested anonymity.

\section{The Reviewers:}

Rex Alexander, Head of Aviation Infrastructure, Uber Technologies, Inc.

Tim Bean, CEO, Fortum Technologies

Fred Borda, Co-founder, COO, Aerial Innovation, LLC

Amanda Brandt, Assistant Professor and Chief UAS Pilot, University of North Dakota

John Bridewell, EdD, Professor of Aviation, Univ. of North Dakota

Amanda Briggs, Flight Instructor, Inst. of Aviation, Parkland College

Tim Bruner, UAS Researcher, Kansas State Polytechnic

Scott S. Burgess, PhD, CFI/IP, RPC, Associate Professor, ERAU-Worldwide

Kendell Clutts, Flight Validation Lead, GoPro Inc.

Linda Connell, Dir., Aviation Safety Reporting System, NASA

Chris Covell, Flight Operations Manager, GoPro Inc.

Michael L. Dworkin, Esq., Avialex 


\section{UAS Pilots Code -Annotated Version 1.0}

Paul Duty, CFI, CFII, MEI, AGI, Aviation Instr., Aviation Marketing Specialist, Gleim

Patrick Egan, Managing Partner, sUAS News

Tom Farrier, Clancy Int'l, CTR, Prin. Safety Analyst, FAA Emerg. Tech. Team (AJV-115)

Nicholas T. Flom, Exec. Dir., Northern Plains Unmanned Aircraft Systems Test Site

Michael Gadd (FRAeS), Policy Lead, UAS, Civil Aviation Authority (UK)

John T. Van Geffen, Esq., Avialex

David Graves, Founder and CEO, SkyVector

Rich Hansen, President, Academy of Model Aeronautics

Brad Hayden, President \& CEO, Robotic Skies

Becky L. Hooey, PhD, Human Systems Integration Div., NASA Ames Research Center

David Ison, PhD, Editor-in-Chief, IJAAA; Asst. Prof. of Aeronautics, ERAU; Pres., UAA

Kenneth Kelly, FAA, Airworthiness FPM/POC sUAS Ed. Outreach, SPPO, AFS-920

Parimal Kopardekar ("PK”), Sr. Tech. Air Transport, Auton. Expert, Co-EIC, JAO, NASA

Christopher T. Kucera, Director, Air Operations, Analytical Graphics, Inc.

Tracy Lamb, VP, Reg. \& Safety Affairs-Chief Pilot, AUVSI

Leonard Ligon, Corp. Lead; Global UTM, WhiteFox Defense Group

John Marselus, DDiv, Director of Aviation, San Diego Christian College

Douglas M. Marshall, Esq., Principal, TrueNorth Consult. LLC; Adj. Prof., De Paul C.o.L.

Frank Matus, Dir., Strategy \& Business Development, Thales

Nick Mayhew, Senior Program Manager, L3 Link Training \& Simulation

Mary Mikolajewski, Manager, Technical Committee Operations, ASTM Int'l

Brandon Montellato, University Relations Manager, DJI

David Morss, ATP, Test Pilot, Reno Air Races Pilot

Jorge B. Moya, ASRS, NASA Ames; Booz Allen Hamilton, Inc.

R. Lance Nuckolls, FAA, Aviation Safety Inspector

Frank Paskiewicz, VP - Production and Airworthiness, Padina Group, Inc.

Kuldeep S. Rawat, PhD, Dep't Chair, Dir. of Aviation, Elizabeth City State University.

Timothy Reuter, Civil Drones Project Head, World Econ. Forum

John Robbins, PhD, Assistant Professor, ERAU

Fred Roggero, President and CEO, Resilient Solutions, Ltd.

Wes Ryan, Mgr., Advanced Technology Branch, FAA

Confesor Santiago, III, Aerospace Engineer, Ames Research Center 


\section{UAS Pilots Code -Annotated Version 1.0}

Karl Schweikert, Esq., AV8 Law Group

Jackie Spanitz, General Manager, Aviation Supplies \& Academics (ASA Inc.)

Tyler Spence, PhD, Assistant Professor, Dep't Avi. \& Tech., San Jose State University

Werner von Stein, Founder, SF Drone School

Walter Stockwell, Director of Technical Standards, DJI

Scott Strimple, Chief Flight Instructor, Drone Flight School

Joseph J. Vacek, JD, Assistant Professor of Aviation. University of North Dakota

John Scull Walker, Senior Partner, Padina Group; Chair, ISO TC 20/SC 16

Reiner von Weber, Founder, SF Drone School; STEAM Capt., X Class Drone Racing L

Gretchen West, Sr. Advr., Hogan Lovells US LLP; Co-Exec. Dir., Comm. Drone Alliance

Ted Wierzbanowski, Immediate Past Chair, ASTM Int'l, Committee F38

Michael Wiggins, EdD, MBA, Professor and Depart. Chair, Aeronautical Science, ERAU

Heidi Williams, Dir., Air Traffic Services \& Infrastructure, NBAA

Randy Willis, Manager, FAA ATO, Emerging Technologies Team

Harrison Wolf, Project Lead, World Economic Forum

Gilead Wurman, PhD, CFI, Senior Seismologist and UAS Program Mgr., ENGEO 


\title{
UAS Pilots Code -Annotated Version 1.0
}

\section{Appendices}

\author{
Appendix 1 - Abbreviations
}

AC

ACI

ACS

$\mathrm{AD}$

ADS-B

AIM

AFSS

AGL

API

ATC

ATO

AUVSI

BVLOS

CAA

C2

C.F.R.

CRM

DAA

DHS

EASA

FAA

FAAST

FCC

Fed. Reg.

Final Rule

FSIMS

FTC

GPS

HEMS

ICAO

IFR

IoT

JARUS

JARUS-SORA

LAANC

NAS

NEPA
Advisory Circular

Aviators Code Initiative

Airman Certification Standards

Airworthiness Directive

Automatic Dependent Surveillance-Broadcast

Aeronautical Information Manual

Automated Flight Service Station

Above Ground Level

Application Interface

Air Traffic Control

Air Traffic Organization

The Association for Unmanned Vehicle Systems International

Beyond Visual Line of Sight

Civil Aviation Authority

Command and Control

US Code of Federal Regulations

Crew Resource Management

Detect-and-Avoid

US Department of Homeland Security

European Aviation Safety Agency

Federal Aviation Administration

FAA Safety Team

Federal Communications Commission

US Federal Register

14 C.F.R. Part 107, Small Unmanned Aircraft Systems

FAA Flight Standards Information System

Federal Trade Commission

Global Positioning System

Helicopter Emergency Medical Services (HEMS) Tool

International Civil Aviation Organization

Instrument Flight Rules

Internet of Things

Joint Authority for Rulemaking on Unmanned Systems

JARUS Specific Operations Risk Assessment (Annex 1 - Glossary)

Low Altitude Authorization and Notification Capability

National Airspace System

National Environmental Policy Act 


\section{UAS Pilots Code -Annotated Version 1.0}

NGO

NOTAM

NTIA

Part 107

PEB

PKI

RP

RPA

RPIC

RPAS

RPS

SAA

SB

sm

SMS

SOP

SRM

SRP

SUA

sUAS

TFR

UA

UAS

UASPC

UAT

UAV

UTM

VFR

VLOS

VMC

WAAS

WX
Non-Governmental Organization

Notice to Airmen

National Telecommunications and Information Administration

14 C.F.R. Part 107

Permanent Editorial Board, Aviators Code Initiative

Public Key Infrastructure

Remote Pilot

Remotely Piloted Aircraft

Remote Pilot In Command

Remotely Piloted Aircraft System

Remote Pilot Station

Special Activity Airspace

Service Bulletin

Statute Mile

Safety Management System

Standard Operating Procedure

Safety Risk Management

Sample Recommended Practice

Special Use Airspace

Small UAS

Temporary Flight Restriction

Unmanned Aircraft

Unmanned Aircraft System

UAS Pilots Code

Universal Access Transceiver

Unmanned Aerial Vehicle

UAS Traffic Management

Visual Flight Rules

Visual Line of Sight

Visual Meteorological Conditions

Wide Area Augmentation System

Weather 


\title{
UAS Pilots Code -Annotated Version 1.0
}

\author{
Appendix 2 - Definitions221
}

accident-An unplanned event or series of events that result in death, injury, or damage to, or loss of, equipment or property. 222

aeronautical decision-making (ADM) — A systematic approach to the mental process used by aircraft pilots to consistently determine the best course of action in response to a given set of circumstances. $^{223}$ Effective ADM skills incorporate systematic approaches to risk assessment and risk mitigation. ${ }^{224}$

aircraft - A device that is used or intended to be used for flight in the air. ${ }^{225}$ airplane-An engine-driven fixed-wing aircraft heavier than air, that is supported in flight by the dynamic reaction of the air against its wings. 226

airport-An area of land or water that is used or intended to be used for the landing and takeoff of aircraft, and includes its buildings and facilities, if any.227

airport environment-The area or airspace on or proximate to an airport, generally defined as: a) Class A, B, C, D, or E controlled airspaces which touch the surface with an airport and/or controlled airspaces which do not touch the surface, but in connection to an airport (normally depicted on aeronautical charts and sectionals); or b) Any Mode C Veil (US) or TMZ (Europe) in Class A, B, C, $\mathrm{D}$, or E, controlled airspace; or c) 5 nautical miles from an airport having an operational control tower; or d) 3 nautical miles from an airport with a published instrument flight procedure, but not an operational tower; or e) 2 nautical miles from an airport without a published instrument flight procedure or an operational tower; or f) 2 nautical miles from a heliport with a published instrument flight procedure. ${ }^{228}$

airworthiness-See "airworthy". airworthy_A UAS conforming to its type design (TD), if certificated, or in lieu of a certificated design, the manufacturer's design, and determined to be in a condition for safe operation. ${ }^{229}$ autonomous aircraft-An unmanned aircraft that does not allow [or is capable of operating without] pilot intervention in the management of the flight. ${ }^{230}$

autonomous operation-An operation during which a remotely-piloted aircraft is operating without pilot intervention in the management of the flight. ${ }^{231}$

best practice - a procedure that has been shown by research and experience to produce optimal results and that is established or proposed as suitable for widespread adoption.

beyond visual line of sight (BVLOS) — A means of flying the UAS without the direct, unaided visual supervision of the aircraft [by the crewmembers]. ${ }^{232}$

C2 link - The data link used for the purpose of UAS command and control (C2).233

C2 link loss-Any situation in which the unmanned aircraft can no longer be controlled by the remote pilot due to the degradation or failure of the communication channel between the RP and UAS. ${ }^{234}$

civil aircraft-Aircraft other than public (or state) aircraft. ${ }^{235}$

command and control link-See "C2 link". ${ }^{236}$ 


\section{UAS Pilots Code -Annotated Version 1.0}

concept of operations (CONOPS) - A user-oriented document that describes systems characteristics and limitations for a proposed system and its operation from a user's perspective. A CONOPS also describes the user organization, mission, and objectives from an integrated systems point of view and is used to communicate overall quantitative and qualitative system characteristics and operational procedures to stakeholders.

condition for safe operation-See "airworthy".

configuration - The requirements, design and implementation that define a particular version of a system or system component. ${ }^{237}$

control station (CS) - The equipment used to maintain control of, communicate with, guide, or otherwise pilot an unmanned aircraft. 238

controlled airspace-An airspace of defined dimensions within which air traffic control service is provided to IFR flights and to VFR flights in accordance with the airspace classification. In the US, controlled airspace is a generic term that covers Class A, Class B, Class C, Class D, and Class E airspace. 239

covered data-Information collected by a UAS that identifies a particular person. If data collected by UAS likely will not be linked to an individual's name or other personally identifiable information, or if the data is altered so that a specific person is not recognizable, it is not covered data. ${ }^{240}$

crewmember-Remote pilot in command (RPIC), other person manipulating the controls, a visual observer, or crewmembers necessary for the safety of the UAS operation. ${ }^{241}$

critical infrastructure - Systems and assets, whether physical or virtual, so vital to a sovereign state that the incapacity or destruction of such systems and assets would have a debilitating impact on security, national economic security, national public health or safety, or any combination of those matters. $^{242}$

critical system-Systems needed to perform one or more safety functions, in which failure would cause a significant increase in the safety risk for the third parties and/or environment involved.

data link-Interconnections to, from and within the remotely piloted aircraft system, includes control, flight status, communication, and payload links.

detect and avoid (DAA) - The capability to see, sense or detect conflicting traffic or other hazards and take the appropriate action to comply with the acceptable rules of flight. ${ }^{243}$

failure mode-A loss of function or a malfunction of a system or a part thereof.

flight manual - A manual, [where applicable, associated with the certificate of airworthiness,] containing limitations within which the aircraft is to be considered airworthy, and instructions and information necessary to the flight crew members for the safe operation of the aircraft.

flight safety-See "safety".

flight termination-Flight termination is a system, procedure or function which aims to [immediately] end the flight. It can be initiated by pilot or autonomously. Flight termination is not a return-home function. 


\section{UAS Pilots Code -Annotated Version 1.0}

fly-away_Unintended flight outside of operational boundaries (altitude/airspeed/lateral) as the result of a failure of the control station or onboard systems or both. Fly-away is a loss of trajectory control. geo-fencing-A system that would prevent UAS flight in specifically designated areas or constrain the flight to within specifically designated areas.

ground control station-See "control station (CS)".

guidelines-Recommended practices for promoting safety, proficiency and, as applicable, compliance with regulations.

hazard-A potentially unsafe condition resulting from failures, malfunctions, external events, errors, or a combination thereof. ${ }^{244}$

human factors - how people respond to and interact with machines, with procedures and with the environment [including other people] about them. ${ }^{245}$

incident-An occurrence other than an accident that affects or could affect the safety of operations. IFR conditions-Weather conditions below the minimum for flight under visual flight rules. ${ }^{246}$ likelihood-Estimated probability or frequency, in quantitative and qualitative terms, of a hazard's effect or outcome.

lost link-The loss of command and control link contact with the UAS such that the remote pilot can no longer manage the aircraft's flight. Lost link is not inherently a fly-away.

maintenance-Inspection, overhaul, repair, preservation, and the replacement of parts. ${ }^{247}$ malfunction-Failure of a system or component to operate as specified or designed.

model aircraft - An unmanned aircraft that is: (1) capable of sustained flight in the atmosphere; (2) flown within visual line of sight of the person operating the aircraft; and (3) flown for hobby or recreational purposes. ${ }^{248}$

navigable airspace-Airspace at and above the prescribed minimum flight altitudes, including airspace needed for safe takeoff and landing. ${ }^{249}$

near mid air collision (NMAC) - An incident associated with the operation of an aircraft in which a possibility of a collision occurs as a result of proximity of less than 500 feet to another aircraft, or a report is received from a pilot or flight crew member stating that a collision hazard existed between two or more aircraft. A report does not necessarily involve the violation of regulations or error by the air traffic control system, nor does it necessarily represent an unsafe condition. ${ }^{250}$ night-The time between the end of evening civil twilight and the beginning of morning civil twilight, as published in the Air Almanac, converted to local time. ${ }^{251}$ non-participant-Any individual in the vicinity of a UAS operation who is not participating in the operation of the UAS.

operational risk assessment (ORA) — Evaluation of the proposed design and operation of the UAS, its intended mission, and proposed area of operation to determine potential risk to persons and property. 


\section{UAS Pilots Code -Annotated Version 1.0}

operational risk management (ORM) - A systematic, cyclical process of identifying hazards, assessing the associated risks, and facilitating informed and effective risk management decisions by individuals and organizations. ${ }^{252}$

operations manual-A manual containing procedures, instructions and guidance for use by operational personnel in the execution of their duties.

operator-A person, organization or enterprise engaged in or offering to engage in an aircraft operation. ${ }^{253}$

participant-Those persons directly involved with the operation of the UAS or fully aware that the UAS operation is being conducted near them. Active participants should be fully aware of the risks involved with the UAS operation and have accepted these risks. Active participants are informed on and able to follow relevant effective emergency procedures and/or contingency plans.

payload-A system, an object or collection of objects onboard or otherwise connected to the UAS that performs, or is related to, a mission function but is not required for flight. ${ }^{254}$

personal data-See "covered data". 255

pilot-Remote pilot-in-command (RPIC) or other pilot who is controlling the flight of a UAS under the supervision of the RPIC.

practice-Recommended methods, rules, and designs for voluntary compliance.

public aircraft - An aircraft owned, operated, or under contract to any federal, state, local or tribal government entity, and performing a government function. ${ }^{256}$

radio line of sight (RLOS) - Operational state in which radio communications are over distances where the path between the transmitter and receiver is not obstructed by the curvature of the earth or other obstructions such as terrain or structures.

rating-A statement that, as a part of a certificate, sets forth special conditions, privileges, or limitations. ${ }^{257}$

reliability - The probability that an item will perform a required function under specified conditions, without failure, for a specified period of time.

remote pilot station (RPS)-See "control station (CS)".

remote pilot-in-command (RPIC) - Person who is directly responsible for and is the final authority as to the operation of the UAS, has been designated as remote pilot in command before or during the flight of a UAS, and holds the appropriate certificate(s) for the conduct of the flight. remotely piloted aircraft system (RPAS) - A remotely piloted aircraft, its associated remote pilot station(s), the required command and control links and any other components [as specified in the type design]..$^{258}$

required link performance (RLP)—Generic term for required end to end C2 link performance. ${ }^{259}$ residual risk-Any risk that remains after mitigation or other control actions.

risk-Composite of predicted severity and likelihood of the potential effect of hazards. 


\section{UAS Pilots Code -Annotated Version 1.0}

risk analysis-Analyses used to determine or estimate the likelihood of an event (usually described as an accident, fatal accident, etc.) and the potential severity of the event if it occurs. These analyses could be either quantitative or qualitative.

risk management - A formalized method of dealing with hazards through the logical process of weighing the potential costs of risks against the possible benefits of allowing those risks to stand uncontrolled. 260

risk mitigations - The process of incorporating defenses or preventive controls to lower the severity and/or likelihood of a hazard's projected consequence.

safety - The state in which the possibility of harm to persons or of property damage is reduced to, and maintained at or below an acceptable level through a continuing process of hazard identification and safety risk management. ${ }^{261}$

safety management system (SMS) — The formal, top-down, organization-wide approach to managing safety risk and assuring the effectiveness of safety risk controls. ${ }^{262}$ SMS is comprised of four functional components, including an intangible, but always critical, aspect called safety culture: (1) safety policy, (2) safety risk management, (3) safety assurance, and (4) safety promotion, including promotion of a safety culture within all levels of a workforce. ${ }^{263}$

see and avoid-The requirement for the pilot of an aircraft to "see" and to remain well clear of other aircraft, and "avoid" a collision. ${ }^{264}$

situational awareness - The accurate perception and understanding of all the factors and conditions within the five fundamental risk elements (flight, pilot, aircraft, environment, and type of operation that comprise any given aviation situation) that affect safety before, during, and after the flight. Thus, loss of situational awareness results in a pilot not knowing where he or she is, an inability to recognize deteriorating circumstances, and the misjudgment of the rate of deterioration. ${ }^{265}$ small unmanned aircraft (sUA) - An unmanned aircraft weighing less than 55 pounds on takeoff, including everything that is on board or otherwise attached to the aircraft. ${ }^{266}$

small unmanned aircraft system (sUAS) - A small unmanned aircraft and its associated elements (including communication links and the components that control the small unmanned aircraft) that are required for the safe and efficient operation of the small unmanned aircraft in the national airspace system. ${ }^{267}$

special activity airspace (SAA) - Airspace with defined dimensions within the National Airspace System wherein limitations may be imposed upon aircraft operations. ${ }^{268}$

special use airspace (SUA) - Airspace of defined dimensions identified by an area on the surface of the earth wherein activities must be confined because of their nature and/or wherein limitations may be imposed upon aircraft operations that are not a part of those activities. ${ }^{269}$

standard operating procedure-A set of instructions covering those features of operations which lend themselves to a definite or standardized procedure without loss of effectiveness.

threat-Events or errors that occur beyond the influence of an operational person, increase operational complexity and must be managed to maintain the margin of safety. ${ }^{270}$ 


\section{UAS Pilots Code -Annotated Version 1.0}

threat and error management (TEM) - The process of detecting and responding to threats and errors to ensure that the ensuing outcome is inconsequential, i.e. the outcome is not an error, further error or undesired state. ${ }^{271}$

uncontrolled airspace-Airspace excluding Class A, Class B, Class C, Class D, and Class E airspace. ${ }^{272}$

unmanned aircraft - An aircraft operated without the possibility of direct human intervention from within or on the aircraft. ${ }^{273}$

unmanned aircraft system (UAS) — Unmanned aircraft and associated elements (including communication links and the components that control the unmanned aircraft) that are required for safe and efficient operation in a national airspace system.

visual flight rules (VFR) - Flight rules adopted by a CAA governing aircraft flight using visual references. VFR operations specify the amount of ceiling and the visibility the pilot must have in order to operate according to these rules. When the weather conditions are such that the pilot cannot operate according to VFR, he or she must use instrument flight rules (IFR). ${ }^{274}$

visual line of sight (VLOS) - An operation in which the RPIC and the person manipulating the controls (and visual observer, if used) is capable of seeing the unmanned aircraft with vision unaided by any device other than corrective lenses. ${ }^{275}$

visual observer (VO) - Person who is designated by the RPIC to assist the RPIC and the person manipulating the flight controls of the UAS to see and avoid other air traffic or objects aloft or on the ground.

\section{Appendix 3 -}

\section{Selected References}

ASSURE, http://www.assureuas.org/index.php

Aviators Code Initiative, www.secureav.com

FAA, Advisory Circular, AC 107-2, Subj. Small Unmanned Aircraft Systems (June 21, 2016), https://www.faa.gov/uas/media/AC 107-2 AFS-1 Signed.pdf

FAA, Integration of Civil Unmanned Aircraft Systems (UAS) in the National Airspace System (NAS) Roadmap (1st ed. 2013), http://www.faa.gov/uas/media/uas roadmap 2013.pdf FAA, Modernization and Reform Act of 2012, 49 USC \40101, Pub. L. 112-95, 126 Stat 11 (Feb. 14, 2012), https://www.gpo.gov/fdsys/pkg/PLAW-112publ95/pdf/PLAW-112publ95.pdf

FAA, Pilot's Handbook of Aeronautical Knowledge, FAA-H-8030-25B (2016), https://www.faa.gov/regulations policies/handbooks manuals/aviation/phak/

FAA, Risk Management Handbook, FAA-H-8083-2 (2016), https://www.faa.gov/regulations policies/handbooks manuals/aviation/media/risk management hb change 1.pd

FAA, Small Unmanned Aircraft System Study Guide, FAA-G-8082-22 (Aug. 2016), https://www.faa.gov/regulations policies/handbooks manuals/aviation/media/remote pilot study guide.pdf

FAA, Small Unmanned Aircraft Systems, 14 C.F.R. Part 107, https://www.eC.F.R..gov/cgi$\underline{\mathrm{bin} / \text { text-idx?SID }=5 \mathrm{a} 94599 \mathrm{c} 486631 \mathrm{fe} 22 \mathrm{f} 2127461 \mathrm{f38a} 26 \& \mathrm{mc}=\text { true } \& \text { node }=\mathrm{pt} 14.2 .107 \& \mathrm{agn}=\operatorname{div} 5}$ 


\section{UAS Pilots Code -Annotated Version 1.0}

ICAO, Annex 1 to the Convention on Int'l Civil Aviation, Personnel Licensing, 11th Ed., AN 1 (July 2011), available (fee) at www.icao.int, and (free) at https://www.universiteitleiden.nl/binaries/content/assets/rechtsgeleerdheid/instituut-voorpubliekrecht/lucht--en-ruimterecht/international-air-law-moot-court/annex-1.pdf ICAO, Manual on Remotely Piloted Aircraft Systems (RPAS), Doc. 10019, Ch. 1, \$ 10.1.5 (2015), available (fee) at https://store.icao.int/manual-on-remotely-piloted-aircraft-systems-rpas-doc10019-english-printed-12792.html, and (free) at http://servicos.decea.gov.br/arquivos/drone/Doc 10019 Manual on RPAS English.pdf ICAO, Safety Management Manual, Doc. 9859 AN/474 (3d. ed. 2013), https://www.icao.int/safety/SafetyManagement/Documents/Doc.9859.3rd\%20Edition.alltext.en.pd $\underline{f}$

JARUS, JARUS guidelines on Specific Operations Risk Assessment (SORA), Doc. JAR-DELWG6-D.04 (June 26, 2017), available at http://rpas-regulations.com/wpcontent/uploads/2017/07/170626 JARUS Specific-Operations-Risk-Assessment SORA v1.0.pdf Marshall, D.M., Barnhard, K.R., Shappee, E., \& Most, M., Introduction to Unmanned Aircraft Systems, 2nd Ed., CRC Press (2016), available at http://tinyurl.com/y7h86spc NIST, Cybersecurity Framework, https://www.nist.gov/cyberframework NTIA, Voluntary Best Practices for UAS Privacy, Transparency, and Accountability (May 18, 2016), https://www.ntia.doc.gov/files/ntia/publications/uas privacy best practices 6-21-16.pdf Terwilliger, B., Ison, D., Robbins, J., \& Vincenzi, D., Small Unmanned Aircraft Systems Guide: Exploring Designs, Operations, Regulations, and Economics, ASA (2017) Unmanned Systems Canada, Small RPAS Best Practices for BVLOS, v1.1 (Feb. 16, 2017), https://www.unmannedsystems.ca/download/usc-small-rpas-bvlos-best-practices/ 


\section{UAS Pilots Code -Annotated Version 1.0}

\section{Appendix 4 - UASPC Condensed Version}

The UASPC Condensed Version is intended for pilot implementation. Its content includes the introduction, provisions, and the sample recommended practices contained in the UASPC Annotated Version. It is available at secureav.com/UAS.

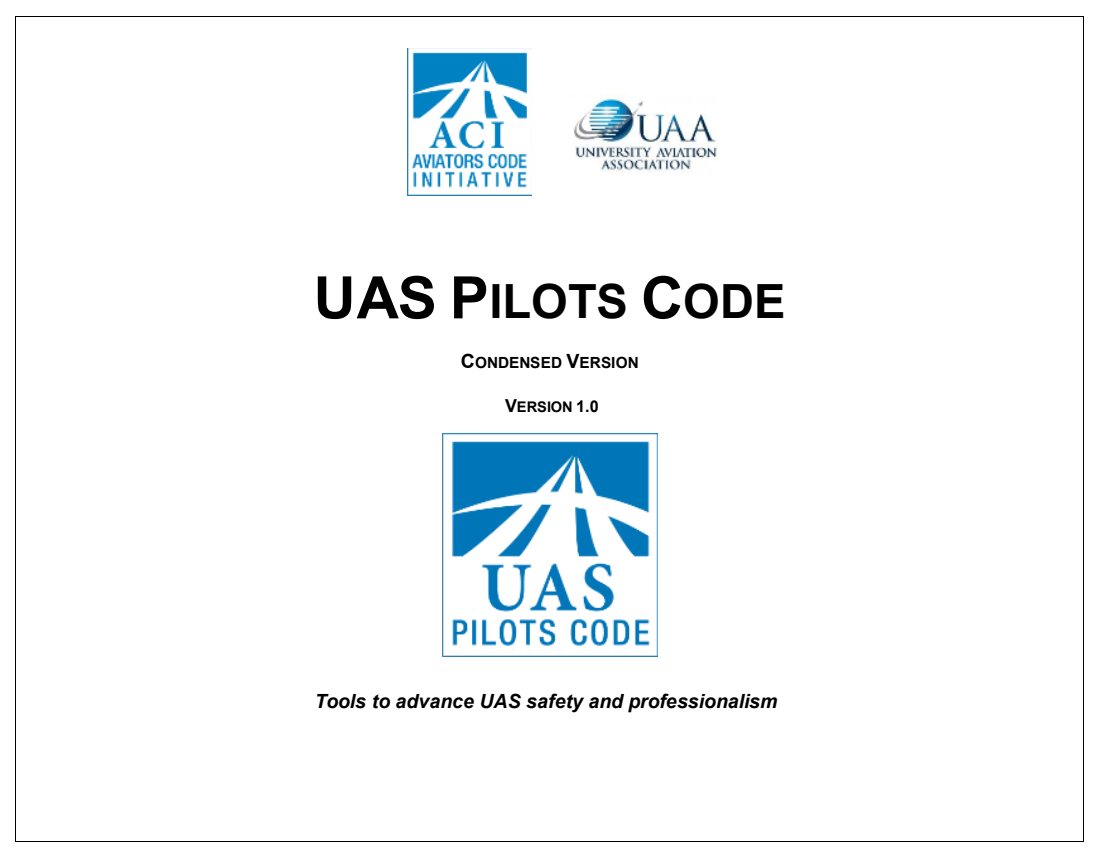

The UASPC Condensed Version cover page. 


\section{UAS Pilots Code -Annotated Version 1.0}

\section{Appendix 5 - UASPC Abbreviated Version}

The UASPC Abbreviated Version includes a brief introduction, the provisions (without sample recommended practices), and links to all $U A S P C$ versions and resources. It provides an introduction to, and promotion of the UASPC. It is available at secureav.com/UAS.

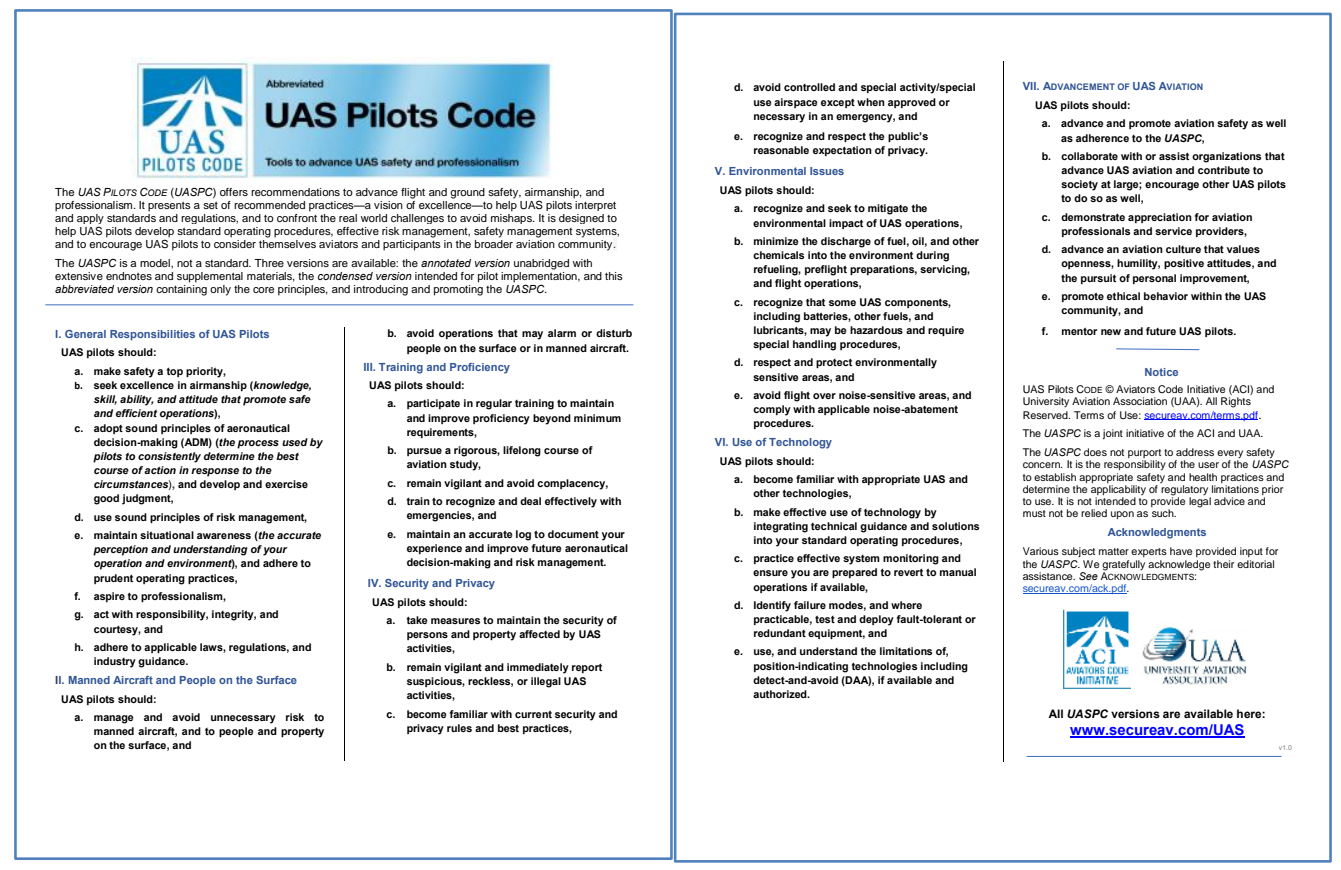


14 C.F.R. Part 107, 71, 72 , 80, 9
Abbreviated Version, 40
abnormal conditions, 61
ACI, 67, 71, 9

Acknowledgments, 68

Additional Resources, 66

ADVANCEMENT OF UAS

Aviation, 41, 63

Advisory Circular, AC 107-2,

80

aeronautical decision-

making, 43, 44, 47, 51, 53,

73

$\mathrm{AF} / \mathrm{D}, 46$

air traffic controllers, 64

airmanship, 40, 42, 43, 44,

46

Airport Facilities/Directory, 46

airspace, 45, 50, 51, 52, 55, $56,63,73,74,75,78,9$ airworthiness, 45, 52, 73, 75 airworthy, 46, 73, 74, 75

altimetric equipment, 61
AMA, 66

Annotated Version, 40

anomalies, 61

Appendix 1 - Abbreviations, 71

Appendix 2 - Definitions, 73

Appendix 3 - Selected

References, 80

Appendix 4 - UASPC

Condensed Version, 82

Appendix 5 - UASPC

Abbreviated Version, 83

applications, 56, 62

ASRS, 48, 69

ASTM, 66, 69, 70

ATC, 46, 48, 56, 71

attitudes, 47, 63, 65

Audience, 9

authorization, 45, 49, 56

autonomous, 51, 53, 73, 9

aviation ambassador, 65

aviation safety, $37,51,63$

Aviation Safety Reporting

System, 48, 69 


\section{UAS Pilots Code -Annotated Version 1.0}

Aviators Code Initiative, 37, $67,68,71,72,80,9$

batteries, 48, 58, 62

behavior, 63, 65

best practices, 41, 55, 56, 63, 65

beyond visual line of sight, 60 , 73

birds, 58

BVLOS, 60, 71, 73, 81

C2 link, 73, 74, 77

CAA, 71, 78

Canada, 81

cautions, 62

Chart Supplements, 46

checklists, 40, 47, 49

complacency, 51, 53

concept of operations, 74

Condensed Version, 40

CONOPS, 74

control signals, 60

control station, 74, 75, 76

control system, 45, 61, 76

courtesy, 43, 48, 57
Crew Resource Management, 44, 71

critical infrastructure, 56, 74

culture, 37, 39, 41, 44, 63, 65, 77

DAA, 60, 62, 71, 74

data, 53, 56, 57, 61, 65, 73, 74,76

Debrief, 53

degradation, 60, 61, 62, 74

detect-and-avoid, 60, 62

EASA, 66, 71

Electromagnetic, 60

emergencies, 46, 51, 53, 61

enforcement, 63

environment, 40, 41, 43, 46, $51,58,73,74,75,77$

Environmental Issues, 41, 58

environmentally sensitive, 58

Errata, 67

ethical, 42, 44, 63, 65

EUROCAE, 66 
FAA, 40, 48, 52, 55, 64, 66, $69,70,71,80,9$

FAA, Modernization and

Reform Act of 2012, 80

Facility Maps, 44, 63

failure modes, 53, 60, 62

fault-tolerant, 60,62

flight operations, 46, 48, 49,

$50,51,56,58,61$

flight planning, 51, 61

flight safety, 40, 44, 47, 51, $60,63,75$

fly-away, 75

fuel, 44, 45, 51, 58

fuel spills, 58

geo-fencing, 55, 75

GPS, 61, 62, 71

hazardous materials, 49, 56

hazards, 45, 49, 50, 63, 74, 76,77

humility, 63, 65

I'M SAFE, 46

ICAO, 66, 71, 80, 9
ICAO, Manual on Remotely

Piloted Aircraft Systems

(RPAS, 80, 9

identification, 56, 77

incident, 44, 75

industry guidance, 43,48

information security, 56

integrity, 43, 48

interference, 60

Introduction, 40

ISO, 66, 70

JARUS, 66, 71, 80

JARUS guidelines on

Specific Operations Risk

Assessment, 80

judgment, 42, 43, 44

Kopardekar, 69

law enforcement, 55

laws, 42, 43, 48

licensing, 61

lighting, 45, 51

local government, 63

$\log , 48,51,53,57$

malfunctions, 53, 75 
manned aircraft, 45, 46, 48, $49,50,53,56,63,9$

Manned Aircraft and People on the Surface, 41, 49

manual, 49, 51, 52, 60, 61, $75,76,80,9$

Manual on RPAS, 9

mentor, 46, 47, 51, 63, 65

military bases, 56

minimum requirements, 51

NAS, 42, 72, 80

National Airspace System, 42,

$63,72,78,80$

national security, 55

navigation, $60,61,62$

NIST, 80

NMAC, 75

noise, 58, 59

noise-abatement, 58, 59

NOTAM, 72

NOTAMs, 46, 56

Notes for Implementers, 66

Notice, 67, 72

Notices to Airmen, 46
NTIA, 72, 81

NTSB, 48

obstacle avoidance, 60

operator, 76

payloads, 44, 49, 51

perceived threat, 55

performance, $44,48,51,52$, 53, 77

Permanent Editorial Board, $37,68,72$

personal improvement, 63,

65

PKI, 72

post-flight, 48, 49, 58, 61

Preface, 39

Principles, 41

prisons, 56

privacy, 52, 55, 56, 57, 65,

81

professionalism, 35, 37, 40, $41,43,47,57,65$

professionals, 37, 63, 64, 65

proficiency, 37, 47, 51, 52,

60, 75 
property, 45, 47, 48, 49, 50,

$52,55,58,73,76,77$

public aircraft, 76, 9

radar, 61

radio, $61,62,76$

radio frequency, 61

registration, 56

regulations, 40, 42, 43, 48,

$52,63,75,76,80$

report, 48, 55, 75

Reviewers, 68

Revision History, 36

risk analysis, 77

risk management, 40,41 , $43,44,45,46,49,51,53$, $62,76,77$

RPAS, 72, 77, 80, 81, 9

safe operation, $52,63,73$, 74,75

safety, 35, 37, 39, 40, 41, $42,43,44,45,48,49,51$, $52,53,56,60,61,63,67$, $74,75,77,78,80,9$

security, 55, 56, 74

Security and Privacy, 55 see and avoid, 77, 78

sensors, 60

service providers, $58,63,64$

settings, 53, 61

simulators, 52

situational awareness, 43, 46, $50,51,60,61,77$

SORA, 71, 80

study, 51, 52, 80

SUA, 72, 78

suspicious, 55

Table of Contents, 38

technologies, 60, 61, 62

temporary flight restrictions,

56

TFR, 72

Threat and Error Management, 44

tracking, 56, 61

training, 41, 42, 46, 49, 51,

$52,53,56,61$

Training, 41, 51, 69

Training and Proficiency, 41,51 


\section{UAS Pilots Code -Annotated Version 1.0}

training regime, 51

transmitting, 60

UAS pilot, 46, 47, 50, 51, 53, 55, 63

UAS Pilot Letter, 37

UASPC Abbreviated Version, 83

UASPC Drafting Team, 68 $\mathrm{UK}, 69$

Use of Technology, 41, 60
UTM, 60, 69, 72

values, $40,63,65$

visual observer, 44, 74, 78

VLOS, 72, 78

waivers, 48

warnings, 62

weather, 44, 45, 46, 52, 53, 61,78

weight and balance, 51

wildlife, 50, 58 


\section{UAS Pilots Code-Annotated Version 1.0}

\section{Endnotes}

${ }^{1}$ Five Questions for Dallas Brooks, AOPA (June 12, 2017), https://www.aopa.org/news-and-media/allnews//2017/June/12/Five-questions-for-DallasBrooks?utm source=drone\&utm medium=email\&utm campaign=170613drone.

${ }^{2}$ A family of aviation codes of conduct was developed by the Aviators Code Initiative (ACl), formerly known as the Aviators Model Code of Conduct (AMCC) Initiative, www.secureav.com. See ACl, Introduction to the Aviators Model Code of Conduct, http://www.secureav.com/Comment-AMCC-Introduction.pdf.

${ }^{3}$ Title - Resolving a title for the UASPC was challenging because relevant taxonomy in both industry and government is still evolving. The title, UAS Pilots Code, reflects the following considerations:

Audience -

The primary audience includes civil, commercial unmanned aircraft system (UAS) pilots, operators, visual observers, operations managers, safety officers, and other interested or responsible parties. The UASPC also serves as a supplemental resource for diverse UAS operations, and may be useful for some public aircraft operations.

"UAS" -

A. UAS Vs. RPAS: The term "UAS" enjoys widespread usage in the US and other jurisdictions, and regulatory adoption in the FAA's Small Unmanned Aircraft Systems rule, 14 C.F.R. Part 107, available at https://www.eC.F.R..gov/cgi-bin/textidx?SID=5a94599c486631fe22f2127461f38a26\&mc=true\&node=pt14.2.107\& rgn=div5. The term "RPAS" is largely unfamiliar outside of military aviation in the US. In contrast, while focused on civil UAS, the UASPC applies broadly to any type of non-military unmanned aircraft operation. Thus, "UAS" most accurately characterizes the UASPC's scope and content.

The ICAO, Manual on Remotely Piloted Aircraft Systems (RPAS), Doc. 10019, Fig. 1-2 \& $\S$ 1.5.1 (2015) ("Manual on RPAS"), available (fee) at https://store.icao.int/manual-onremotely-piloted-aircraft-systems-rpas-doc-10019-english-printed-12792.html graphically presented remotely piloted aircraft, model aircraft, and autonomous aircraft each "as one subset of UAS." ICAO's UAS Study Group (UASSG) "first considered introducing the term 'remotely piloted' [in] 2009, after reaching the conclusion that only unmanned aircraft that are remotely piloted could be integrated alongside manned aircraft in nonsegregated airspace and at aerodromes [and] therefore narrow[ed] its focus from all UAS to those that are remotely piloted." ICAO, § 1.2.14. Cf., it has been recognized that "Art. 8 of the 'Chicago Convention' means there must [be] a person accountable for the operation of the aircraft, hence under the ICAO framework there is a need to refer to RPAS (rather than the more generic UAS) to reflect the pilot aspect." Michael Gadd (FRAeS), Policy Lead, UAS, Civil Aviation Authority (UK) (Jan. 21, 2018).

Drafting Considerations: The term "UAS" is used to make the UASPC more accessible and relevant to the broadest possible audience.

B. UAS vs. Drone: The term "drone" has historically applied to airborne military practice targets, and more recently to model or hobbyist aircraft. In contrast, the term "UAS" is widely recognized as applying to civil, scientific or professional operations, among others. 


\section{UAS Pilots Code -Annotated Version 1.0}

C. UAS vs. sUAS: We use the blanket "UAS" when we mean all, and "sUAS" (small UAS) only when we mean that specific subset of UAS.

\section{"Pilots" -}

A. Pilots vs. Operators: The term "pilots" was adopted rather than "operators" reflecting (1) broad industry and government consensus that licensed UAS aviators should be considered pilots, (2) the FAA's and other civil aviation authorities (CAAs) issuance of UAS "pilot" certificates, and (3) the specific meaning of the word "pilot" as someone who operates the controls of an aircraft. See FAA, Becoming a Pilot, www.faa.gov/uas/getting started/fly for work business/becoming a pilot. As UAS platforms become increasingly automated, the transfer of direct control shifts from the human operator or "pilot" to automated systems. The term "pilot" underscores that automation should be subordinate to the responsibility and authority of the human component. Notwithstanding, the UASPC addresses and seeks to include "operators" extensively. See UASPC, n.133 (addressing autonomous aircraft and systems).

B. Pilots vs. Remote Pilots: Our use of the term "Pilots" mirrors usage of the term by certification authorities as discussed immediately above, and reflects acceptance of UAS aviators as members of the pilot community with commensurate responsibilities to adhere to applicable rules and embrace aviation safety culture.

C. Plural Non-possessive Form: The usage of "Aviators" or "Pilots" in the Aviators Code Initiative's title takes the plural, and non-possessive form, i.e., "Pilots", as opposed to "Pilot's". "Pilots" is here used as a modifier, as in "Air Line Pilots Association".

D. Pilots vs. Commercial Pilots: The term "Commercial" was considered to underscore that many of the UASPC's practices are geared to the comparatively rigorous requirements of commercial operations (in contrast to certain hobbyist or certain other types of operations). Nonetheless "Commercial" was rejected because: (1) much of the UASPC is extensible or relevant to non-commercial operations, (2) the UASPC's introduction describes its scope and audience, and (3) there is an editorial preference for a concise title.

"Code" -

Code vs Code of Conduct: The term "Code" is a more concise version of the phrase "Code of Conduct" used in the ACl's earlier documents. As used in this title, "Code" is not intended to connote a collection or compendium of laws.

Drafting Considerations: Further discussion regarding the titling of our codes of conduct is presented in $\mathrm{ACl}$, Commentary to the Title, http://secureav.com/Comment-AMCC-Title.pdf.

${ }^{4}$ See ACl, Commentary to AMCC 1.a - General Responsibilities, http://www.secureav.com/CommentAMCC-1.a-General-Responsibilities.pdf (addressing safety).

${ }^{5}$ See ACl, Commentary to AMCC 1.b - General Responsibilities, http://www.secureav.com/CommentAMCC-I.b-General-Responsibilities.pdf (addressing airmanship).

${ }^{6}$ All pilots share many attributes traditionally identified with aviation professionals, including: (1) a wide range of required specialized skills, (2) a need for good judgment, (3) a need for proficiency and ongoing training, (4) a direct responsibility for the well-being of others, and (5) serious consequences for 


\section{UAS Pilots Code -Annotated Version 1.0}

misfeasance or malfeasance. ACl, Commentary to AMCC 1.f-General Responsibilities, http://www.secureav.com/Comment-AMCC-I.f-General-Responsibilities.pdf (addressing professionalism).

${ }^{7}$ See UASPC, § I.d, and associated Sample Recommended Practices (SRPs) (addressing risk management). Two paradigms have emerged in the practice of risk management. "One is related to hazard based risk analysis driven by technical professionals. The other [is] the precaution based risk analysis driven by the legal system." Tracy Lamb, Risk Management for a Booming Drone Industry - ALARP VS SFAIRP who cares anyway? (Oct. 6, 2016), available at https://www.linkedin.com/pulse/risk-managment-booming-droneindustry-alarp-vs-sfairp-tracy-lamb/ (considering retrospective vs forward-looking proactive risk analysis in the UAS industry). Note the European Commission's embrace of the precautionary principle. Euro. Comm., Press Release, IP/00/96 (Feb. 2, 2000), http://europa.eu/rapid/press-release IP-00-96 en.htm; and EASA, 'Prototype' Commission Regulation on Unmanned Aircraft Operations, Art. II.34 (Aug. 22, 2016), https://www.easa.europa.eu/system/files/dfu/UAS\%20Prototype\%20Regulation\%20final.pdf (includes the precautionary principle).

The FAA uses the term Safety Risk Management (SRM) as a primary component of safety management systems (SMS) throughout the aviation industry as well as in FAA operations. "The objective of SRM is to provide information regarding hazards, safety risk, and safety risk controls/mitigations to decision makers and to enhance the FAA's ability to address safety risk in the aerospace system. SRM consists of conducting a system analysis; identifying hazards; and analyzing, assessing, and controlling safety risk associated with the identified hazards." FAA, Order 8040.4B, Safety Risk Management Policy, p.1 (May 2, 2017), https://www.faa.gov/documentLibrary/media/Order/FAA Order 8040.4B.pdf. These principles are consistent with the general concept of "risk management," the terminology used in the UASPC.

Cf., U.S. 14 C.F.R. Part 5, g 5.51 (required for part 121 air carriers) also specifies Safety Risk Management processes to be performed prior to implementation of new systems or revision of existing systems, including processes for system analysis, identification of potential hazards, analysis and assessment of risk, and, where necessary, development of risk controls.

${ }^{8}$ FAA, Remote Pilot - Small Unmanned Aircraft Systems Airman Certification Standards, FAA-S-ACS-10 (July 2016), https://www.faa.gov/training testing/testing/acs/media/uas acs.pdf ("The FAA views the ACS as the foundation to an integrated and systematic approach to airman certification. The ACS is part of the safety management system (SMS) framework . . ." Foreword). See FAA Order 8900.1 CHG 477, vol. 16, Unmanned Aircraft Systems, ch. 3, Airmen Certification, § 1, Remote Pilots (Oct. 17, 2016), http://fsims.faa.gov/wdocs/8900.1/v16\%20unmanned\%20aircraft\%20systems/chapter\%2003/16 003001. htm (presenting UAS pilot certification requirements and procedures).

${ }^{9}$ Standards - Voluntary standards organizations and nongovernmental organizations (NGOs) developing UAS standards include, but are not limited to: the Am. Nat'I Standards Institute (ANSI), ANSI Unmanned Aircraft Systems Standardization Collaborative (UASSC),

https://www.ansi.org/standards activities/standards boards panels/uassc/overview?menuid=3; ASTM Int'I, Comm. F38 on Unmanned Aircraft Systems, https://www.astm.org/COMMITTEE/F38.htm; AUVSI, http://www.auvsi.org/rpc-top; Consumer Technology Ass'n, R6WG23 - Small Unmanned Aerial Systems, www.cta.org; Int'I Civil Aviation Org. (ICAO) RPAS Panel, www.icao.int; Int'I Org. for Stds. (ISO), www.iso.org; Joint Authorities for Rulemaking on Unmanned Systems (JARUS), http://jarus-rpas.org; RTCA, SC-228, Minimum Operational Performance Standards for Unmanned Aircraft Systems, www.rtca.org; and Society of Automotive Engineers (SAE), Technical Committee AS-4, Unmanned Systems, http://www.sae.org. 


\section{UAS Pilots Code -Annotated Version 1.0}

${ }^{10}$ Ideally, individuals adhere to codes for their own good reasons. Such deferential adherence may occur in part as a result of deliberate organizational or cultural encouragement. And, individuals may seek rules more stringent than their status requires.

The UASPC is informed by the US FAA's Small Unmanned Aircraft Systems rule (as codified in 14 C.F.R. § 107) and applicable rules and guidance of other jurisdictions and intergovernmental organizations, including, but not limited to:

- Australia (CASA) - https://www.casa.gov.au/standard-page/casr-part-101-unmanned-aircraft-androcket-operations

- Canada (DoT) - https://www.unmannedsystems.ca/download/usc-small-rpas-bvlos-best-practices/

- Europe (EASA) https://www.easa.europa.eu/system/files/dfu/UAS\%20Prototype\%20Regulation\%20final.pdf

- ICAO - https://www4.icao.int/uastoolkit/Home/Narrative\#background

- JARUS - http://jarus-rpas.org/publications

- UK - http://www.legislation.gov.uk/uksi/2016/765/contents/made; http://www.caa.co.uk/Consumers/Unmanned-aircraft-and-drones/

While the scope of the UASPC is primarily applicable to U.S. operators, the recommended guidance and best practices may have applicability in other jurisdictions. Consequently, the annotations selectively include supporting or comparative references to relevant rules and guidance from these (and where helpful, other) entities.

${ }^{11}$ For example, because UAS pilot certification (in the United States) does not require the involvement of an instructor, the need for non-regulatory or operational guidance is heightened.

Diminished Regulation - A current trend towards diminished regulation and oversight may also bolster the need for voluntary practices such as a code of conduct. See, e.g., Wheeler, et al., Trump signs '2-for-1' order to reduce regulations, The Hill (Jan. 30, 2017), http://thehill.com/homenews/administration/316839trump-to-sign-order-reducing-regulations ("The executive order [No. 13771, Reducing Regulation and Controlling Regulatory Costs] is aimed at dramatically rolling back federal regulations."); and Andy Pasztor, Some Drone Regulations Delayed, Others Postponed Indefinitely: Highly anticipated rules await government approval, but timeline is pushed back to late 2018 or early 2019, WSJ (Sept. 17, 2017), available (fee) at www.wsj.com, and (free) at http://www.kathrynsreport.com/2017/09/some-drone-regulations-delayedothers.html; and Mark Dombroff, Dentons US LLP ("It seems in many respects everything has come to a halt .... There's almost a resignation that has set in."). Cf., Jan Pie, Chairman, Int'l Coordinating Council of Aerospace Indus. Ass'ns (ICCAIA), Presentation at RPAS2017, ICAO, Montréal (Sept. 19, 2017) (asserting that regulations are essential to safely integrating UAS into existing aviation systems; and that without appropriate regulation, the operation of UAS business would be premature. "No regulatory framework, no business.").

Diminished Federal Preemption - "[T]he FAA will address preemption issues on a case-by-case basis rather than doing so in a rule of general applicability.... Rather than asserting preemption, the FAA in Part 107, indicated many areas where state and local regulation may be appropriate." N. DuPuis, et al., Cities \& Drones: What Cities Need to Know About Unmanned Aerial Vehicles, National League of Cities, pp. 5, 8 (2016), http://www.nlc.org/sites/default/files/2016-12/NLC\%20Drone\%20Report.pdf. See UASPC, n.82 (regarding Federal preemption).

${ }^{12}$ Drafting Considerations: The scope of the UASPC includes civil UAS operations and does not distinguish between commercial vs. non-commercial operations, as the 14 C.F.R. 1.1 definition of civil aircraft 


\section{UAS Pilots Code -Annotated Version 1.0}

inclusively contains both types of operations. Moreover, the decision to limit the scope to civil UAS operations is not to suggest that some elements or recommendations may not apply to governmental operations, but rather to acknowledge the inadequacy of the UASPC in fully addressing the unique regulatory and operational framework of governmental UAS operations under military authority or state aircraft rules.

"Other interested or responsible parties" is inclusive and intended to include anyone planning to work with or hire UAS pilots.

Hobbyist/recreational users who typically operate under the Special Rule for Model Aircraft (14 C.F.R. Part 101, Subpart E, Special Rule for Model Aircraft, available at https://www.eC.F.R..gov/cgi-bin/textidx?SID=5a94599c486631fe22f2127461f38a26\&mc=true\&node=pt14.2.101\&rgn=div5\#sp14.2.101.e) may either choose to operate under the more stringent Small Unmanned Aircraft Systems rules (14 C.F.R. Part 107), or will be subject to Part 107 if their operations are noncompliant with Part 101. See FAA, Advisory Circular, AC 00-1.1A, Subj. Public Aircraft Operations (Feb. 12, 2014), https://www.faa.gov/documentLibrary/media/Advisory Circular/AC 00-1 1 A.pdf (defining civil and public aircraft operations).

${ }^{13}$ Limitations - The UASPC's general, foundational guidance should inform any UAS operation although many of its specific provisions may not address operations beyond the scope of 14 C.F.R. Part 107, such as Beyond Visual Line of Sight (BVLOS) operations or UAS carriage of people.

Part 107 is, however, just "the first step in the process of integrating small UAS operations into the NAS." Final Rule, 81 Fed. Reg. 42,063 (June 28, 2016). "With this new rule [14 C.F.R. Part 107], we are taking a careful and deliberate approach that balances the need to deploy this new technology with the FAA's mission to protect public safety. But this is just our first step. We're already working on additional rules that will expand the range of operations.", Fmr. FAA Adm'r Michael Huerta (June 21, 2016).

https://www.faa.gov/news/press releases/news story.cfm?newsld=20515. Integration developments are evolving quickly.

${ }^{14}$ See ACl, Commentary Addressing Code of Conduct Model, Length, and Organization, http://secureav.com/Comment-AMCC-General.pdf; and UASPC, n.3 (title).

${ }^{15}$ The Code is founded on codifying best practices, which include professional procedures that are industry benchmarks, or otherwise accepted as being the most correct or most effective in achieving identified desirable effects. Nonetheless, the UASPC could become a model for standards development. See ASTM Int'I, Form and Style for ASTM Standards, § C15.1A, https://www.astm.org/FormStyle for_ASTM STDS.html\#definitions (defining "standard practice" as "an accepted procedure for the performance of one or more operations or functions.").

${ }^{16} \mathrm{See} \mathrm{ACl}$, Commentary to the Title, http://secureav.com/Comment-AMCC-Title.pdf.

17 "SRPs" are distinct from ICAO's Standards and Recommended Practices ("SARPs"). See www.ICAO.int.

18 "Integrating the responsibility for management and oversight of all sUAS operations in a company under a flight department can provide improved compliance, operational safety and effectiveness, standardization, economies of scale and collaborative benefit." NBAA, Integrated Operational Management and Oversight for sUAS (May 13, 2016), https://www.nbaa.org/ops/uas/integrated-operationalmanagement-and-oversight-for-suas/NBAA-Resource-Integrated-Operational-Management-and-Oversightfor-sUAS.pdf. 


\section{UAS Pilots Code -Annotated Version 1.0}

${ }^{19}$ In addition, the UASPC may be helpful to civil aviation authorities for their development of associated practices.

${ }^{20}$ As noted above, the FAA has not developed or adopted standards for the qualification and certification of UAS pilot instructors. Consequently, the UASPC emphasizes establishing a meaningful self-training program, aided by experienced UAS pilots or other knowledgeable mentors. See UASPC, § III. Training and Proficiency. The individual UAS pilot retains responsibility for assessing their own skill, comfort level, and personal minimums associated with the UAS platform, mission, and operational environment, and should adapt their training plan appropriately. Cf., ICAO, Manual on RPAS, $\S 8.5$ (presenting general prerequisites and requirements for instructors).

${ }^{21}$ As is often the case with an emergent technology, unmanned aircraft are likely to pose new ethical and regulatory challenges. "As always, we must welcome innovation and the benefits it brings us. But, we must also remain committed to sustainable development, taking into account issues of inequality, human dignity, and inclusiveness." Nayef Al-Rodhan, Scientific American (Mar. 13, 2015), https://www.scientificamerican.com/article/the-many-ethical-implications-of-emerging-technologies/ (addressing ethical implications of emerging technologies); and Alisa M. Dolan, et al., Integration of Drones into Domestic Airspace: Selected Legal Issues, Rpt. 7-5700, Cong. Research Service (Apr. 4, 2013), available at https://fas.org/sgp/crs/natsec/R42940.pdf. Ethical behavior underlies and is integrated into the UASPC. See, e.g., UASPC, § VII.e \& n.133 (Autonomous Systems \& Ethical Considerations).

${ }^{22}$ See ACl, Commentary to AMCC 1.a-General Responsibilities; UASPC, n.8 (addressing safety risk management); FAA Adm'r Michael Huerta, Preface to FAA, Integration of Civil Unmanned Aircraft Systems (UAS) in the National Airspace System (NAS) Roadmap, p. i (Nov. 7, 2013), https://www.faa.gov/uas/media/uas roadmap 2013.pdf ("The FAA is committed to the safe and efficient integration of UAS into the NAS. However, as safety is our top priority, UAS integration must be accomplished without reducing existing capacity, decreasing safety, impacting current operators, or placing other airspace users or persons and property on the ground at increased risk.") (emphasis added). Cf., JARUS, JARUS OPS, Recommendations for Unmanned Aircraft Systems (UAS), Operations for Category A and B, JAR_DEL_WG2_D.03, Art. 4-Principles for UA operations, g 1 (Oct. 7, 2017), available at http://apant.pt/wp-content/uploads/2017/10/jar doc 14 draft d3 ops cat a extcons 251017.pdf ("The operator of a UA shall be responsible for its safe operation."); Australian Ass'n for Unmanned Systems, Code of Conduct, v1.0 (Aug 19, 2016), http://aaus.org.au/resources/Documents/Documents/AAUS\%20Code\%20of\%20Conduct.pdf ("The safety of your operations is paramount to any other concern."); Gur Kimchi, VP, Amazon Prime Air, Presentation at ICAO, DRONE ENABLE 2017, Montréal (Sept. 22, 2017) ("The number one priority for our service is safety."); ICAO, Manual on RPAS, Ch. 1, § 10.1.5 ("[Unmanned aircraft] will have to be as safe as, or safer than, present manned operations."); and Email from Michael Gadd, UK (Jan. 21, 2018) (urging "tests of reasonableness").

Consider the following perspective from Don Arendt, Ph.D., FAA (Dec. 2016):

It is common to say that safety is the top priority but this, arguably, may not be realistic. It could, at its extremes, imply that we can achieve absolute safety, which can only be achieved by eliminating the activity in which risk is incurred. We take on (or accept) risk when we engage in these activities, but this needs to be done in a context of effectively managing those risks - operating safely. People, particularly those who are innovators, don't enter into their enterprises to "be safe." Safety is one of the three things, mission, 


\section{UAS Pilots Code -Annotated Version 1.0}

money, and safety, that have to be balanced if we are to accomplish anything. Achievement necessitates survival in all three areas. Risk has to be managed by understanding the boundaries that have to be observed to stay in balance. We have to be sure that people recognize these margins and not dismiss them with what can easily become empty rhetoric. While it's good rhetoric to place a high, if not the highest priority on safety, I caution that it's easy to compartmentalize safety into its own domain and lose the fact that risks mostly exist as byproducts of operations - the real purpose(s) behind what we're doing. (emphasis added).

Drafting Considerations: Implementers may prefer alternative formulation of UASPC §1.a, ("make safety a top priority") such as: "make safety the top priority", "make safety of operations the highest priority", or "make risk management the priority".

${ }^{23}$ Adherence to good airmanship and aeronautical decision-making practices is necessary to ensuring safe flight operations. See ICAO, Manual on RPAS, § 8.4.36 (“. . . demonstrate the ability to: d) exercise good judgement and airmanship"). "The remote pilot in command is directly responsible for and is the final authority as to the operation of the small unmanned aircraft system." 14 C.F.R. § 107.19(b).

24 "Building upon the foundation of conventional decision-making, ADM enhances the process to decrease the probability of human error and increase the probability of a safe flight. ADM provides a structured, systematic approach to analyzing changes that occur during a flight and how these changes might affect the safe outcome of a flight." FAA, Remote Pilot - Small Unmanned Aircraft Systems Study Guide, FAA-G-808222 (2016), Ch. 10, p. 52, https://www.faa.gov/regulations policies/handbooks manuals/aviation/media/remote pilot study guide. pdf. See FAA, Pilot's Handbook of Aeronautical Knowledge, FAA-H-8030-25B, Ch. 2, Aeronautical DecisionMaking, available at https://www.faa.gov/regulations policies/handbooks manuals/aviation/phak/media/04 phak ch2.pdf; FAA, Aeronautical Decision Making, FAA-P-8740-69, AFS-8 (2008), available at https://www.faasafety.gov/files/gslac/library/documents/2011/Aug/56413/FAA\%20P-874069\%20Aeronautical\%20Decision\%20Making\%20[hi-res]\%20branded.pdf (pamphlet addressing ADM); and FAA, The Art of Aeronautical Decision-Making, available at https://www.faasafety.gov/files/gslac/courses/content/28/216/The\%20Art\%20of\%20Aeronautical\%20Deci sion.pdf (a brief ADM course).

${ }^{25}$ See Michael Huerta, Fmr. FAA Adm'r, Speech at AirVenture, Oshkosh, WI, EAA AirVenture (July 28, 2016), available at https://www.faa.gov/news/speeches/news story.cfm?newsld=20575. ("[T]here's a lot more to flying than just knowing the rules and pushing buttons. It takes good judgment. It requires discipline. And it demands a true sense of professionalism that's rooted in a deep, unwavering commitment to doing the right thing.").

26 "The goal of risk management is to proactively identify safety-related hazards and mitigate the associated risks. Risk management is an important component of ADM." FAA, Pilot's Handbook of Aeronautical Knowledge, FAA-H-8030-25B, Ch. 2, p. 3.

"Aircraft operating without a pilot on board present a wide array of hazards to the civil aviation system. These hazards must be identified and the safety risks mitigated, just as with introduction of an airspace redesign, new equipment, or procedures." ICAO, Unmanned Aircraft Systems, ICAO Cir. 328, § 2.17 (2011), https://www.icao.int/Meetings/UAS/Documents/Circular\%20328 en.pdf. 


\section{UAS Pilots Code -Annotated Version 1.0}

See generally R. A. Clothier, et al., Safety risk management of Unmanned Aircraft Systems; Handbook of Unmanned Aerial Vehicles, Netherlands: Springer Science (2014), (fee) http://www.springer.com/us/book/9789048197064\#otherversion=9789048197088 (providing in-depth discussion of risk management applicable to UAS); FAA, Advisory Circular, AC 107-2, App. A., RIsk Assessment Tools (June 21, 2016), https://www.faa.gov/uas/media/AC 107-2 AFS-1 Signed.pdf; ASTM Int'I, F3178, Standard Practice for Operational Risk Assessment of Small Unmanned Aircraft Systems (sUAS), available (fee) at https://www.astm.org/COMMITTEE/F38.htm. Cf., Sec'y of the Air Force, Air Force Instruction 90-802, Risk Management (May 15, 2017), available at http://static.epublishing.af.mil/production/1/af se/publication/afi90-802/afi90-802.pdf (excising references to operational risk management and replacing with risk management "to emphasize the important of hazard and risk mitigation and management in all aspects of the [Air Force], not just Operations."). See also JARUS guidelines on Specific Operations Risk Assessment (SORA), Doc. JAR-DEL-WG6-D.04 (June 26, 2017), available at http://rpas-regulations.com/wp-content/uploads/2017/07/170626 JARUS SpecificOperations-Risk-Assessment SORA v1.0.pdf.

${ }^{27}$ Situational Awareness - "Maintaining situational awareness requires an understanding of the relative significance of all flight related factors and their future impact on the flight. When a pilot understands what is going on and has an overview of the total operation, he or she is not fixated on one perceived significant factor. Not only is it important for a pilot to know the aircraft's geographical location, it is also important he or she understand what is happening." FAA, Aeronautical Decision-Making and Judgement, Remote Pilot Small Unmanned Aircraft Systems Study Guide, FAA-G-8082-22 (2016) Ch. 10, p. 63. See FAA, Pilot's Handbook of Aeronautical Knowledge, FAA-H-8030-25B, Ch. 2-24, Aeronautical Decision-Making, https://www.faa.gov/regulations policies/handbooks manuals/aviation/phak/, and FAA, Airplane Flying Handbook, FAA-H-8083-3B (2016), Ch. 2-11.

The reader will note that we have adopted the US FAA's standard usage of the phrase "situational awareness," as opposed to "situation awareness". Cf., Mica R. Endsley, Toward a Theory of Situation Awareness in Dynamic Systems, Human Factors, vol. 37(1), pp. 32-64 (1995), available at https://doi.org/10.1518/001872095779049543.

Perceptual Illusions - "The pilot of an RPAS may be exposed to a range of perceptual illusions and conflicts that do not occur in conventional aviation [for example:]

Control-consequence incompatibility. [In VLOS, where] the track of the aircraft is not aligned with the pilot's point of view, for example, if the aircraft is flying towards a visual pilot, or a map display is not aligned with track up, then control inputs may result in the aircraft turning in a manner that is inconsistent with the pilot's point of view.

Depth cues.... Camera views can produce misleading depth cues, some of which may be related to the lack of binocular cues....

Camera direction. If a moveable camera located on board an RPA [Remotely Piloted Aircraft] is not aligned as expected by the pilot, there may be an illusion of yaw, disorientation or other undesired aircraft state."

R. Jay Shively, NASA Ames Research Center, et al., Human Performance Considerations for Remotely Piloted Aircraft Systems (RPAS), ICAO, Remotely Piloted Aircraft Systems Panel (RPASP), Second Mtg. (RPASP/2),

Montréal (June 15-19, 2015), § 2.2.2, pp. 18-19, available at

https://ntrs.nasa.gov/archive/nasa/casi.ntrs.nasa.gov/20150011435.pdf. 


\section{UAS Pilots Code -Annotated Version 1.0}

${ }^{28}$ See M. W. McFarland, The papers of Wilbur and Orville Wright, including the Chanute-Wright Papers: 1899-1905, McGraw Hill (2000), p. 62 ("The history of past investigation demonstrates that greater prudence is needed rather than greater skill." Wilbur Wright, 1901). Cf., Fischer v. S/Y Neraida, 508 F.3d 586 (11th Cir. 2007), available at https://www.leagle.com/decision/20071094508f3d58611092 (in maritime practice, holding vessel owners to a "prudent seamanship" standard) (emphasis added).

${ }^{29} \mathrm{See} \mathrm{ACl}$, Commentary to AMCC 1.f - General Responsibilities (Nov. 14, 2005), http://www.secureav.com/Comment-AMCC-I.f-General-Responsibilities.pdf (addressing professionalism); and Fmr. FAA Adm'r Randy Babbitt, Statement before the House Comm. on Transp. and Infrastructure, Subcomm. on Aviation, An Update: The FAA's Call to Action on Airline Safety and Pilot Training (Feb. 4, 2010), https://www.transportation.gov/content/update-faa\%E2\%80\%99s-call-action-airline-safety-andpilot-training ("Professionalism is not something we can regulate ... it is something we can encourage and urge pilots and flight crews to aspire to.").

30 No such code can ever create an exhaustive list of what it takes to be healthy, and the same holds for ethics. The character of both morality and health is organic. And, if someone seeking a reference for either encounters a list of behaviors, they might be misled into taking a "checklist" approach to a matter that no checklist can describe. The whole is greater than the sum of its parts. How to think and the objects of thought occupy radically distinct categories. This issue pervades education, professional development, strategy ... maybe most fields concerned with humanity.

Email from Bill Rhodes, PhD., PEB Member, ACI (Oct. 27, 2017). Checklists are considered in UASPC, n.76.

"Ethics and integrity aren't just buzzwords--they are an integral part of our culture." NBAA, Business Aviation Mgt. Comm., Promoting Ethics \& Integrity, Business Aviation Insider (Sept./Oct. 2017), https://www.nbaa.org/admin/leadership/promoting-ethics-and-integrity-in-business-aviation.php. See Australian Association for Unmanned Systems, Code of Conduct, http://aaus.org.au/resources/Documents/Documents/AAUS\%20Code\%20of\%20Conduct.pdf ("[D]emonstrate: The principles of justice, dignity, humanity, equanimity and moral balance while carrying out an assignment under the UIS Program."); R. I. Baron, Do the right thing, Flight Safety Foundation (2011), https://flightsafety.org/asw-article/do-the-right-thing/; and C. White, How is a pilot 'professional'? No to backpacks, yes to integrity., Forbes (2010), https://www.forbes.com/sites/wheelsup/2010/06/18/how-is-apilot-professional-no-to-backpacks-yes-to-integrity/\#12e0141b130c.

${ }^{31}$ See UASPC, n.82 (addressing state/local vs. Federal rules, and federalism). See generally, FAA, Unmanned Aircraft Systems (UAS) Regulations \& Policies, https://www.faa.gov/uas/resources/uas regulations policy/. Also, consider the implications of the FAA's compliance philosophy. "Regulatory compliance represents the minimum standards by which an operator can achieve a minimal degree of safety." According to the FAA, "Traditional oversight relies on the assumption that if an airman/organization is fully compliant with the applicable regulatory requirements, then an adequate level of safety is achieved. However, the aviation environment has reached a level of complexity where further safety improvements cannot be achieved by simple compliance with prescriptive rules." FAA, FSIMS, 8900.1 Chg 422, 14-1-1-5B,

http://fsims.faa.gov/PICResults.aspx?mode=EBookContents\&restricttocategory=all menu (describing evolution of the FAA's compliance philosophy).

There is an important trend towards safety risk management oversight based upon data-driven, "performance-based" metrics, including within design standards. For example, 14 CFR Part 107 is widely steeped in performance-based requirements. And, use of performance-based metrics in rule-making transcend the FAA. Indeed, the U.S. Office of Management and Budget has stated that focusing on 


\section{UAS Pilots Code-Annotated Version 1.0}

"outcomes rather than specifying the means to those ends .... are generally superior ...", OMB, Circular A-4 (Sept. 7, 2013), available at

https://www.transportation.gov/sites/dot.gov/files/docs/OMB\%20Circular\%20No.\%20A-4.pdf (emphasis added); and FAA, FSIMS, 8900.1 CHG 422 (Dec. 4, 2016), Ch. 14-1-1-7, Compliance Philosophy, http://fsims.faa.gov/wdocs/8900.1/v14\%20compliance\%20\&\%20enforcement/chapter\%2001/14 001001. $\underline{\mathrm{htm}}$ (considering that "[t]he greatest systemic safety risk is not from a specific operational event or its outcome, but rather from an airman or organization's unwillingness or inability to comply with safety standards and, most importantly, operating contrary to the core principles of Safety Risk Management (SRM)").

${ }^{32}$ See generally FAA, Safety Management System (SMS), https://www.faa.gov/about/initiatives/sms/; ICAO, Manual on RPAS, Ch. 7.4.1 (requirement to implement a SMS); and ICAO, Safety Management Manual, Doc. 9859, AN/474, ch. 5 (3rd ed. 2013),

https://www.icao.int/safety/SafetyManagement/Documents/Doc.9859.3rd\%20Edition.alltext.en.pdf(Safety Management Systems).

${ }^{33}$ Visual Observers - Many organizations and UAS standards recommend or mandate use of a visual observers. The effectiveness of visual observers is dependent on many factors, including: training and competence, communication delays, simultaneous or failed communications from multiple visual observers, or failure to "determine the optimum collision avoidance manoeuvre." ICAO, Manual on RPAS, § 9.5.6. See Public Safety Aviation Accreditation Comm., Standards for Small Unmanned Aircraft System (sUAS) Programs (2017), Draft Ver. June 5, 2017, § 02.02 .03 (Min. Crew Composition for UAS Ops), available at http://alea.org/images/Standards/tab 16 c - UAS Stds Draft 6-5-17.pdf (requiring preflight brief underscoring effective communications between crew members, "clear definition of launch and recovery location," and scanning for aircraft); Kevin Williams, et al., A Review of Research Related to Unmanned Aircraft System Visual Observers, DOT/FAA/AM-14/9 (Oct. 2014), https://www.faa.gov/data research/research/med humanfacs/oamtechreports/2010s/media/201409.pdf; and Arthur C. Poe, III, A model for visual detection of aircraft by ground observers, Tech Report: RD75-30, Nat'l Tech. Info. Service (1974), available at http://www.dtic.mil/dtic/tr/fulltext/u2/a017599.pdf. Note that visual observers may not apply to BVLOS operations.

Cf., S. M. Vance \& R. J. Wallace, et al., Detecting and assessing collision potential of aircraft and small unmanned aircraft systems (sUAS) by visual observers, IAAA, vol. 4(4) (2017), available at https://doi.org/10.15394/ijaaa.2017.1188 ("The use of visual observers is one of many tools available to remote pilots to comply with aviation regulations and ensure safety of flight. [Recognize] the important human performance limitations associated with visual observer performance . . . . and be wary of relying solely on this fallible modality of hazard detection.").

First-Person View (FPV) - While FPV devices are commonly used for flying some UAS (such as for drone racing activities), they do not satisfy the requirements of 14 C.F.R. § 107.31(a), Visual Line of Sight Aircraft Operation. The FAA has not addressed FPV usage under 14 C.F.R. Part 107, however, 14 C.F.R. Part 101 may support such use provided such operations are conducted under the auspices of programming of a national community-based organization. If operating under FPV, it is highly recommended to use a visual observer to assist in maintaining situational awareness.

${ }^{34} \mathrm{~A}$ hazardous payload may increase risks associated with UAS operation .... Wherever there are shared resources or interactions between the payload and the air vehicle, there is a need to analyze and manage this sharing of resources to ensure that all hazards have been mitigated." Kelly J. Hayhurst, et al., Unmanned aircraft hazards and their implications for regulation, pp. 5B1-1, -12, Proc. of the 25th Digital 


\section{UAS Pilots Code -Annotated Version 1.0}

Avionics Sys. Conf. (2006), available at https://shemesh.larc.nasa.gov/people/imm/5B1 201hayhu.pdf. Hazardous payloads may also include the carriage of hazardous materials, or HAZMAT prohibited by 14 C.F.R. § 107.36 ("A small unmanned aircraft may not carry hazardous material. [T]he term hazardous material is defined in 49 C.F.R. 171.8.").

${ }^{35}$ FAA, UAS Facility Maps, available at https://www.faa.gov/uas/request waiver/uas facility maps/ ("the maps are for "airspace authorizations and waivers in controlled airspace" - not for navigation). See FAA ATO, Low Altitude Authorization and Notification Capability (LAANC) Concept of Operations, DRAFT v0.93 (Feb. 14, 2017), available at https://faaco.faa.gov/index.cfm/attachment/download/75780 (describing the limitations of LAANC utilizing UAS Facility Maps).

The UAS Facility Maps are designed to identify permissible altitudes (above ground level) at which UAS, operating under the Small UAS Rule (14 C.F.R. § 107), can be authorized to fly within the surface areas of controlled airspace. These altitude parameters, provided by the respective air traffic control facilities, are criteria used to evaluate airspace authorization requests (14 C.F.R. § 107.41), submitted via FAA.GOV/UAS. Airspace authorization requests for altitudes in excess of the predetermined map parameters will require a lengthy coordination process. This dataset will be continually updated and expanded to include UAS Facility Maps for all controlled airspace by Fall 2017. This map is not updated in real time. Neither the map nor the information provided herein is guaranteed to be current or accurate. Reliance on this map constitutes neither FAA authorization to operate nor evidence of compliance with applicable aviation regulations in or during enforcement proceedings before the National Transportation Safety Board or any other forum.

FAA, UAS Facility Map Data: Description, http://uas-faa.opendata.arcgis.com/.

${ }^{36}$ Confirm that an "emergency response plan is coordinated with the emergency response plan of those organizations with which it would interface." ICAO, Manual on RPAS, § 7.7.1. Develop and maintain a current emergency/contingency checklist and an emergency contact list. See Global Aerospace, et al., Unmanned Aircraft Systems: An Introductory Guide to Emergency Response (2016), available at http://ctsaonline.org/wp-content/uploads/2013/08/UAS-Emergency-Response-

Guide GA.55 Watermarked.pdf (considerations for UAS emergency response planning). Consider unique response requirements for each type of UAS operation.

${ }^{37}$ Be prepared for flight termination, including the loss/destruction of the UAS, and understand procedures to mitigate loss or injury to life and damage to property. See flight termination, and lost link, UASPC, App. 2, Definitions.

${ }^{38}$ See FAA, Advisory Circular, AC 107-2, Subj. Small Unmanned Aircraft Systems (sUAS), Ch. B.2., sUAS Loading and Its Effects on Performance (June 21, 2016), https://www.faa.gov/documentLibrary/media/Advisory Circular/AC 107-2.pdf; Unmanned Systems Canada, Small RPAS Best Practices for BVLOS, v1.1, App. 2, § 5XX.3.5, p. 43 (Oct. 2016), https://www.unmannedsystems.ca/download/usc-small-rpas-bvlos-best-practices/ ("A centre of gravity envelope, where the RPA remains safely controllable, shall be established. The RPA centre of gravity, including all modifications, consumables, configurations and payloads, shall remain within this envelope during flight."); and FAA, Remote Pilot - Small Unmanned Aircraft Systems Airman Certification Standards, FAA-S-ACS-10, Task A. Loading and Performance, p. 10 (July 2016), https://www.faa.gov/training testing/testing/acs/media/uas acs.pdf. 


\section{UAS Pilots Code -Annotated Version 1.0}

${ }^{39}$ UAS pilots should perform a brief stability and controllability test immediately after launch to ensure the craft appropriately responds as expected to operator inputs, flight controllability is not adversely affected by UAS payloads or weight distribution loading, and the craft demonstrates characteristics of positive static and dynamic stability. See FAA, Pilot's Handbook of Aeronautical Knowledge, FAA-H-80-8335B, pp. 5-14,15 (2016), https://www.faa.gov/regulations policies/handbooks manuals/aviation/phak/. For non-standard payloads, uncertain weight and balance, or where UAS controllability is in question, recognize the enhanced need for such a test. Cf., FAA, ORDER 8130.34D, SUBJ. Airworthiness Certification of Unmanned Aircraft Systems and Optionally Piloted Aircraft, p. 3-2(4)(f) (Sept. 8, 2017), available at

https://www.faa.gov/documentLibrary/media/Order/FAA Order 8130.34D.pdf (“. ... the applicant must demonstrate control link and control station [and other associated elements] functionality by performing procedures such as turning on/off the aircraft lights, deflecting flight controls, and/ or conducting an engine run.").

${ }^{40}$ Consider the human factors implications of the belief harbored by some manned aircraft pilots that manned certification/training/experience alone is adequate for UAS operations.

${ }^{41}$ The UAS pilot may make aeronautical decisions that increase risk to other NAS users, but is unlikely to share in the actual risk like manned pilots. That is, the UAS pilot's decisions are influenced by being "safe, on the ground" rather than assuming the personal risks of flight. Indeed, training standards in development recognize the absence of the UAS pilot's "shared fate" with the UAS. See ASTM Int'I, Comm. F38, https://www.astm.org/COMMITTEE/F38.htm.

${ }^{42}$ See K. W. Williams, et al., A review of research related to unmanned aircraft system visual observers, FAA, Office of Aerospace Medicine Report: DOT/FAA/AM-14/9, p. 5 (Oct. 2014), https://www.faa.gov/data research/research/med humanfacs/oamtechreports/2010s/media/201409.pdf (citing, e.g., Crognale: "participants were relatively poor at judging both distance and altitude of the UA"). Ascertaining altitude from the ground may require visual slant angle estimation which is inherently inaccurate. See Marcus Johnson, et al., Flight Test Evaluation of a Unmanned Aircraft System Traffic Management (UTM) Concept for Multiple Beyond-Visual-Line-of-Sight Operations, NASA Ames, Twelfth USA/Europe Air Traffic Mgt. Research and Devel. Seminar (ATM2017), available at https://utm.arc.nasa.gov/docs/2017-Johnson_12th_ATM2017-Seminar.pdf (“Measurement and reporting of vehicle altitude was not consistent among airspace users."); S. M. Vance \& Ryan J. Wallace, et al., Detecting and Assessing Collision Potential of Aircraft and Small Unmanned Aircraft Systems (sUAS) by Visual Observers (2017), Int'I J. of Aviation, Aeronautics, and Aerospace, vol. 4(4), p. 14, available at https://doi.org/10.15394/ijaaa.2017.1188 (Discerning altitude differences and collision potential was difficult, in part because of size differential between manned aircraft and sUAS platforms.); and Igor Dolgov, Moving towards Unmanned Aircraft System Integration into the National Airspace System: Evaluating Visual Observers' Imminent Collision Anticipation during Day, Dusk, and Night sUAS Operations, Int'I J. of Aviation Sciences, vol. 1(1), pp. 41-56 (2016), https://www.ijas.us/index.php/issues/current-issues/issue-i-volume1 /articles/moving-towards-unmanned-aircraft-systems-integration-into-the-national-airspace-systemevaluating-visual-observers-imminent-collision-anticipation-during-day-dusk-and-night-suas-operationsigor-dolgov.

${ }^{43}$ Threat and Error Management (TEM) - See FAA Advisory Circular, AC 120-9, Subj. Line Operations Safety Audits, Appendix 1, Threat and Error Management (Apr. 26, 2006), https://www.faa.gov/documentlibrary/media/advisory circular/ac 120-90.pdf; D. Maurino, Threat and Error Management, Canadian Aviation Safety Seminar (CASS), Vancouver, B.C. (Apr. 18-20, 2005), available at 


\section{UAS Pilots Code -Annotated Version 1.0}

https://www.faa.gov/about/initiatives/maintenance hf/losa/publications/media/maurino (2005) tem.pdf ("Flight crews must, as part of the normal discharge of their operational duties, employ countermeasures to keep threats, errors and undesired aircraft states from reducing margins of safety in flight operations."); and European Helicopter Safety Team (EHEST), The Principles of Threat and Error Management (TEM) for Helicopter Pilots, Instructors and Training Organisations, HE8, https://www.easa.europa.eu/system/files/dfu/HE8.pdf (tutorial on TEM principles and training for helicopter operations providing general aid to understanding TEM fundamentals).

${ }^{44}$ Application of Threat \& Error Management in UAS Operations - Voluntary standards are in development within ASTM Int'l, Comm. F38 that recognize and advance CRM and TEM principles using skill sets that include planning, decision-making, leadership and effectiveness, situation awareness, communications, monitor/cross-check, workload management, automation management, and general aeronautical decision making.

${ }^{45}$ Crew Resource Management (CRM) - See FAA, Advisory Circular, AC 107-2, Subj. Small Unmanned Aircraft Systems (sUAS) (June 21, 2016),

]https://www.faa.gov/documentLibrary/media/Advisory Circular/AC 107-2.pdf ("CRM is a component of ADM, where the pilot of sUAS makes effective use of all available resources: human resources, hardware, and information."), and FAA, Advisory Circular, AC 120-51E, Subj. Crew Resource Management Training (2004), https://www.faa.gov/documentLibrary/media/Advisory Circular/AC120-51e.pdf.

${ }^{46}$ Power Reserve - The original proposal for 14 C.F.R. Part 107 included a requirement that the remote pilot ensure that the sUAS had sufficient power to operate for its intended operational time plus an additional five-minute reserve. In the Final Rule, however, "the FAA retains the requirement that the small UAS has enough power to operate for its intended operational time, but has eliminated the additional five minute requirement. ... The FAA concurs with commenters who suggest that a small UAS should have enough power to operate for its intended operational time and land safely. ... As such, a requirement for an additional five minutes of power is unnecessary." Operation and Certification of Small Unmanned Aircraft Systems, 81 Fed. Reg. 42,155 (June 28, 2016) (amending 14 C.F.R. Part 107), https://www.gpo.gov/fdsys/pkg/FR-2016-06-28/pdf/2016-15079.pdf. Cf., Unmanned Systems Canada, Small RPAS Best Practices for BVLOS, v1.1, § 4.2, p. 22 (Feb. 16, 2017), https://www.unmannedsystems.ca/download/usc-small-rpas-bvlos-best-practices/ (recommending "a 15\% of flight time (up to 30 minutes) fuel/energy reserve be planned for VFR BVLOS operations.").

Temperature Effect on Lithium-Ion Batteries - For electric aircraft, cold temperatures may dramatically diminish battery capacity. See, e.g., Sony, Lithium Ion Rechargeable Batteries Technical Handbook, Fig. 7, p. 21 (undated), available at http://dlnmh9ip6v2uc.cloudfront.net/datasheets/Prototyping/Lithium\%20lon\%20Battery\%20MSDS.pdf (presenting discharge curve demonstrating material reduction of power as a function of decreasing temperatures).

${ }^{47}$ See FAA, FSIMS 8900.1, Vol. 16, Unmanned Aircraft Systems, § 2A, http://fsims.faa.gov/PICDetail.aspx?docld=8900.1,Vol.16,Ch2,Sec2 ("require[ment] to establish maintenance and inspection criteria that support safe operations" absent an airworthiness certification requirement under Part 107). See UASPC, n.76 (addressing checklists), and UASPC, n.229 (addressing airworthiness and conditions for safe operation). 


\section{UAS Pilots Code -Annotated Version 1.0}

${ }^{48}$ See ICAO, Manual on RPAS, § 10.2.2 (“For a single hazard, two risk analyses may be needed, one for manned aircraft and one for unmanned aircraft. One should not assume that the hazard, the severity of the risk or the mitigation strategies will be the same."). See UASPC, n. 26 (on risk management).

${ }^{49}$ See UASPC n.204 (addressing well clear regarding aircraft-to-aircraft separation and DAA). The FAA expects that most remote PICs will avoid operating in the vicinity of airports because their aircraft generally do not require airport infrastructure.

Drafting Considerations: "well clear" has many non-aircraft usages in aviation. See, e.g., FAA, Advisory Circular, AC 90-66A, Subj. Recommended Standards Traffic Patterns for Aeronautical Operations at Airports without Operating Control Towers, § 9.2.1 (Aug. 26, 1993),

https://www.faa.gov/regulations policies/advisory circulars/index.cfm/go/document.information/docume ntID/23093 (a "point well clear of the pattern"); FAA, Pilots Handbook of Aeronautical Knowledge (2016), p. $14-3$,

https://www.fa.gov/regulations policies/handbooks manuals/aviation/phak/media/16 phak ch14.pdf ("Well clear of the pattern"); and many usages of "well clear" concerning obstructions, and other nonaircraft objects, such as in Chart Supplements. See, e.g., FAA, Chart Supplement, NE, Oct. 12, 2017 - Dec. 7, 2017, Troy Airport (5B7), http://aeronav.faa.gov/afd/07dec2017/ne 248 07DEC2017.pdf ("use best angle of climb speed until well clear of residential area").

Notification - Unlike operations under 14 C.F.R. Part 101, commercial and other pilots operating under 14 C.F.R. Part 107 are not generally required to notify airports (including heliports and other types of aerodromes). Instead, their notification and authorization responsibilities are well-defined and directed to ATC. It may nonetheless be prudent to voluntarily provide airport authorities with such notice. As a practical matter, ATC and airport management sometimes neither have effective information sharing/reporting procedures nor do they necessarily coordinate safety management systems. See also UASPC, n.35 (addressing LAANC).

${ }^{50}$ See, e.g., 14 C.F.R. § 107.43, Operation in the vicinity of airports; and 14 C.F.R. $\S 107.41$, Operation in certain airspace. Sensitivity to operations near airports is also manifest in legislative initiatives such as the proposed Drone Operator Safety Act of 2017, H.R.3644 - 115th Congress (2017-2018), https://www.congress.gov/bill/115th-congress/housebill/3644/text?q=\%7B\%22search\%22\%3A\%5B\%22unmanned+aircraft\%22\%5D\%7D\&r=1 (prohibiting unauthorized flight operations within a rectangular runway exclusion zone extending one sm from each end of the runway with a $1 / 2$ sm width). See also UASPC, n. 35 (addressing LAANC); and UASPC, n.49 (addressing notification).

${ }^{51}$ The primary hazard in urban environments are operations over humans. See 14 C.F.R. § 107.39, Operation over human beings, "No person may operate a small unmanned aircraft over a human being unless that human being is: (a) Directly participating in the operation of the small unmanned aircraft; or (b) Located under a covered structure or inside a stationary vehicle that can provide reasonable protection from a falling small unmanned aircraft."

See ICAO, Manual on RPAS, § 9.5.16 ("Operations over heavily populated areas or over open air assemblies of people may require special considerations [including]: a) altitudes for safe operations, b) uncontrolled landings, c) obstructions, d) proximity to airports/emergency landing fields, e) local restrictions ... and f) the emergency termination of an RPA flight."). 


\section{UAS Pilots Code -Annotated Version 1.0}

${ }^{52}$ See Public Safety Aviation Accreditation Comm., Standards for Small Unmanned Aircraft System (suas) Programs, Draft Ver. 6/5/17, § 02.03.06 (Over Water Operations), available at http://alea.org/images/Standards/tab 16 c - UAS Stds Draft 6-5-17.pdf:

Standard: If missions are routinely flown over water the UAS should be equipped for a water recovery.

Commentary: Programs that operate over water should have the ability to safely recover the UAS in the event that it lands in the water. As such, UAS should float or should be equipped with external flotation equipment.

In some cases certain systems will not function effectively in some environments and RPs need to understand those limitations and the subsequent risks they incur by proceeding.

${ }^{53}$ See John Croft, NASA and industry tackle the next phase of drone flight, AviationWeek (Nov. 18, 2017), http://m.aviationweek.com/aircraft-design/nasa-anomalies-drive-uas-traffic-management ("vehicle performance degradations caused by hot and high conditions").

${ }^{54}$ See UASPC, n.80 (operations exceeding the standard limitations of 14 C.F.R. Part 107 that may require a waiver per 14 C.F.R. § 107.200, Subpart D-Waivers).

${ }^{55}$ See ICAO, Manual on RPAS, § 6.8.1 (“[E]nsure that operational and emergency equipment necessary for the intended flight are serviceable.").

${ }^{56}$ Consider that aeronautical sectional charts do not include man-made obstructions below $200 \mathrm{ft}$. AGL. See FAA, FAA Aeronautical Chart User's Guide, https://www.faa.gov/air traffic/flight info/aeronav/digital products/aero guide/. See email from Rex Alexander, Uber (Jan. 17, 2018) ("There may be errors in the FAA Airport Master Record database and some airports and heliport may be incorrectly located."). Aeronautical products are generally updated on a 28- or 56-day cycle. Effective dates are listed on applicable charts and aeronautical products. Users can also consult the FAA's Dates of Latest Editions webpage to determine chart currency and subsequent edition publication dates, at https://www.faa.gov/air traffic/flight info/aeronav/productcatalog/doles/.

${ }^{57}$ Remote Pilots should consult a variety of map resources to better understand the layout, topography, obstructions, and other site hazards prior to commencing UAS operations. Such resources may include but are not limited to Google (satellite or street view) Maps, digital terrain elevation data charts, and other resources. See National Geospatial-Intelligence Agency, https://www.nga.mil/ProductsServices/TopographicalTerrestrial/Pages/DigitalTerrainElevationData.aspx.

${ }^{58}$ Preventing Distraction - Such practices are widely recognized as maintaining a sterile cockpit. The concept of a sterile cockpit prohibits manned aircraft pilots from engaging in non-essential tasks or conversation during critical phases of flight such as taxi, takeoff, climb, descent and landing, i.e., high-task load or high-risk events. Remote pilots are also required to effectively manage similar critical, high task-load operations and must avoid unnecessary communication or activity that could cause distractions leading to human errors, and potentially, an incident or accident. See FAA, Order 8900.1 CHG 477, vol. 16-5-2-17, F. Mission and Operations (Oct. 17, 2016), http://fsims.faa.gov/wdocs/8900.1/v16\%20unmanned\%20aircraft\%20systems/chapter\%2005/16 005002. htm ("It is important to observe the ... 'sterile cockpit concept'"); NTSB, Safety Recommendation A-06-7 (Jan. 24, 2006), https://www.ntsb.gov/news/events/Pages/Collision with Trees and Crash Short of the Runway Corpo rate Airlines Flight 5966 British Aerospace BAE-J3201 N875JX Kirks.aspx (importance of strict 


\section{UAS Pilots Code -Annotated Version 1.0}

compliance with the sterile flight deck rule); 14 C.F.R. $\S \S 121.542,135.100$ (sterile cockpit rule for commercial manned aircraft); and S. A. Shappell, et al., The Human Factors Analysis and Classification System--HFACS, DOT/FAA/AM-00/7 (2000), available at https://www.nifc.gov/firelnfo/firelnfo documents/humanfactors classAnly.pdf (categorizing relevant "Adverse Mental States" including loss of situational awareness, task fixation, distraction, and mental fatigue).

UAS Application - Public Safety Aviation Accreditation Comm., Standards for Small Unmanned Aircraft System (sUAS) Programs (2017), Draft ver. June 5, 2017, § 02.02.04, Crew Coordination and Communications, available at http://alea.org/images/Standards/tab 16 c - UAS Stds Draft 6-5-17.pdf (urging "the aviation equivalent of a 'sterile cockpit' during launch and recovery where non-essential communications are prohibited to avoid distracting the crew." And, UAS "operator procedures must not allow remote flight crew members to perform any activities during critical phases of flight other than those required for the safe operation of the [UAS]."); ICAO, Manual on RPAS, § 6.2.5; ICAO, Doc 9870, Manual on the Prevention of Runway Incursions, AN/463 (2007),

http://cfapp.icao.int/fsix/ Library/Runway\%20Incursion\%20Manual-final full fsix.pdf (promoting a "sterile flight deck"); and Sec. of the Air Force, Air Force Instruction 11-2MQ-1\&9, vol. 3 (Nov. 1, 2012), available at https://www.google.com/url?q=http://static.e-publishing.af.mil/production/1/af a3/publication/afi112mq-1\%269v3/afi11-2mq1\%269v3.pdf\&sa=D\&ust=1506525802382000\&usg=AFQjCNEzIHMF3FDclymK2czccZLP 9yUxA (maintaining sterile cockpit regarding ground control station).

${ }^{59}$ Conspicuity - See ICAO, Manual on RPAS, § 9.5.4 (VLOS operation conspicuity "dependent on their colour, size, speed, lighting, etc."); and J. M. Loffi, et al., Seeing the threat: Pilot visual detection of small unmanned aircraft systems in visual meteorological conditions, Int'I J. of Aviation, Aeronautics, and Aerospace, vol. 3.3, p. 19 (2016), available at http://commons.erau.edu/ijaaa/vol3/iss3/13/ (While not specifically studied during the experiment, $80 \%$ of the participants indicated that the white (contrasting) color of the UAS platforms aided in their detection. Conversely, $10 \%$ of the participants found the white color made the UAS more difficult to spot.).

Night Vision - "Bright lighting and strobes may impair vision and control of the aircraft in low lighting conditions. Before flight, limit use of strobes and other bright lights that may impair your night vision." Interview with Brandon Montellato, DJI (Palo Alto, Dec. 2, 2017). See FAA, Airplane Flying Handbook, FAAH-8083-3B, ch. 10 (2016), https://www.faa.gov/regulations policies/handbooks manuals/aviation/airplane handbook/media/12 afh ch10.pdf (addressing night vision); and 14 CFR § 107.29(b), Daylight operation (permitting operations during civil twilight; and permitting the RP to "reduce the intensity of the anti-collision lighting if ... in the interest of safety"); and a standard inclusion in night-flight waivers - FAA, Waiver Safety Explanation Guidelines for Part 107 Waiver Applications, https://www.faa.gov/uas/request waiver/waiver safety explanation guidelines/.

${ }^{60}$ See-and-Avoid - Recognize that even manned aircraft can be very challenging to see. See ICAO, Manual on RPAS, § 10-3-1 ("If a very small RPA is to be integrated into non-segregated airspace, it is doubtful that it will be visible to manned aircraft."), § 14-3-1 ("Owing to the relatively small size and low conspicuity of some [UAS], it may be difficult for pilots of manned aircraft and other remote pilots to visually acquire the [UAS]."); NTSB, Safety Alert, No. SA-058 (Nov. 2016), https://www.ntsb.gov/safety/safetyalerts/Pages/default.aspx ("[T]he inherent limitations of this [see-and-avoid] concept, including human limitations, environmental conditions, aircraft blind spots, and operational distractions, leave even the most 


\section{UAS Pilots Code -Annotated Version 1.0}

diligent pilot vulnerable to the threat of a midair collision with an unseen aircraft."); and UASPC, § VI. Use of Technology (addressing detect and avoid technology).

See generally ACl, Flight Safety in the Drone Age, v1.0, n.15, http://www.secureav.com/DroneAgeTechPaper-v1.0.pdf (highlighting challenges associated with manned aircraft using see and avoid procedures for UAS detection and evasion):

a. Too Small to See: Manned aircraft are typically at least an order of magnitude bigger than many small drones, and small drones cannot effectively be seen by pilots. As an analogy, consider the extent of helicopter wire-strikes which occur with unacceptable frequency even where there are multiple observers on-board.

b. Half the Eyes: As a practical matter, see-and-avoid for small drones has the benefit of only half the eyes watching effectively for other aircraft (that is, only the drone operator or observer, not the manned pilot can see-and-avoid). This arguably might make it only half as effective.

c. Degraded Visual Environments: Drone operator see-and-avoid is handicapped by degraded visual environments, obstacles, varying altitudes (between drone and operator), and slopes that may reduce the ability to see approaching aircraft.

d. Reduced Safety Margins: The ability of drone operators to see-and-avoid other traffic decreases with distance between operator and drone.

e. Areas of Reduced Buffer: There is a safety gap beyond the extreme edge of line-of-sight operation, precluding effectiveness of see-and-avoid.

${ }^{61}$ Drafting Considerations: The term "mission" is used throughout the UASPC to denote flight operations performed with a specific operational objective or purpose. This usage is not necessarily synonymous with its recognized use in a military context.

Collision Risks - See David Arterburn, et al., FAA study Final Report for the FAA UAS COE Task 4A: UAS Ground Collision Severity Evaluation, Rev. 2, p. 145 (2017), available at http://pr.cirlot.com/wpcontent/uploads/2017/04/assure_a4 final_report uas ground_collisionseverity evaluation rev 220170428 final.pdf (presenting conclusions); and Military Avi Auth., BALPA, UK DoT, Small Remotely Piloted Aircraft systems (drones) Mid-Air Collision Study (2016), p. 5, https://www.gov.uk/government/publications/drones-and-manned-aircraft-collisions-test-results (asserting "drone components used can cause significantly more damage than birds of equivalent masses at speeds lower than required to meet birdstrike certification standards").

${ }^{62}$ Recognize that not all manned aircraft operate above 500 AGL. Even below 500 AGL, helicopters, agricultural applicators and other manned aircraft operate frequently-both in the airport environment and beyond. See 14 C.F.R. § 91.119(d), Minimum safe altitudes: General (helicopters, powered parachutes, and weight-shift-control aircraft "may be operated at less than the minimums prescribed [altitude]"). See Keith C. Heidorn, Winds of the City (2005), http://www.islandnet.com/ see/weather/elements/citywind.htm (urban canyon winds).

${ }^{63}$ See FAA, Risk Management Handbook, FAA-H-8083-2, Ch. 3, p. 3-3, Identifying Hazards and Mitigating Risk (2009, 2016), https://www.faa.gov/regulations policies/handbooks manuals/aviation/media/risk management hb cha nge 1.pdf; and 14 C.F.R. § 91.17, Alcohol or drugs. 


\section{UAS Pilots Code -Annotated Version 1.0}

${ }^{64}$ See FAA, Best Practices for Mentoring in Aviation Education, v.1.2 (2016),

https://www.faa.gov/training testing/training/media/mentoring best practices.pdf. Emergency scenarios that are recommended for practice include: control surface failures, landing gear failures, engine failure for rotorcraft and fixed-wing, and loss of VLOS.

${ }^{65}$ Radio Communication - E.g., ERAU UAS Flight Operations require the operator to monitor air traffic with a hand-held VHF radio and to be able to make calls to notify manned aircraft in proximity to the UAS in an emergency. Conversation with Scott Burgess, PhD., ERAU (San Jose, CA, Oct. 3, 2017). See Marcus Johnson, et al., Flight Test Evaluation of a Unmanned Aircraft System Traffic Management (UTM) Concept for Multiple Beyond-Visual-Line-of-Sight Operations, NASA Ames, Twelfth USA/Europe Air Traffic Mgt. Research and Development Seminar (ATM2017), available at https://utm.arc.nasa.gov/docs/2017-

Johnson 12th_ATM2017-Seminar.pdf ("the ability to communicate with other operators during off-nominal conditions would greatly improve an operator's ability to react to hazardous conditions caused by other users of the airspace"); FAA, Small Unmanned Aircraft System Study Guide (FAA-G-8082-22), Ch. 7, Radio Communications Procedures, pp. 39-42 (Aug. 2016),

https://www.faa.gov/regulations policies/handbooks manuals/aviation/media/remote pilot study guide. pdf (addressing traffic advisories). See also ICAO, Manual on RPAS, § 12.4, Voice and Data To/From the RPS Without A Relay Via the RPA (addressing both VHF and telephonic communications with ATC), § 12.5, Specific Communication Requirements for Operations in VLOS, and $\S 12.5$ (implications of non-standard communication methods on the overall traffic situation).

66 "A remote pilot is not expected to communicate with other aircraft in the vicinity of an airport, and should not do so unless there is an emergency situation." FAA, Remote Pilot - Small Unmanned Aircraft Systems Study Guide (2016), FAA-G-8082-22, p. 42,

https://www.faa.gov/regulations policies/handbooks manuals/aviation/media/remote pilot study guide. pdf. But see, 47 C.F.R. § 87.43, Operation during emergency, https://www.ecfr.gov/cgi-bin/textidx?SID=f587a3bf77b94dcc8f18c5714ac4367e\&mc=true\&node=se47.5.87 143\&rgn=div8 ("A station may be used for emergency communications in a manner other than that specified in the station license or in the operating rules when normal communication facilities are disrupted."); and 14 C.F.R. § 107.21 (specifying that the remote pilot may deviate from regulations in an in-flight emergency requiring immediate action).

Remote pilots who wish to transmit on an aviation frequency must hold an FCC ground station authorization in accordance with 14 C.F.R. Part 87 (radio station licensure for aviation services). "Ground station authorizations are usually only issued to aviation service organizations located on airports, businesses engaged in pilot training, aircraft manufacturers, or persons engaged in chase activities related to soaring and ballooning." www.fcc.gov/wireless/bureau-divisions/mobility-division/aviation-radioservices/ground-stations.

${ }^{67}$ A distance that is within the formal airport environment, restricted by Part 107, that may create an unsafe condition, or that is otherwise imprudent.

${ }^{68}$ See FAA, Chart Supplements Basic Search, https://www.faa.gov/air traffic/flight info/aeronav/digital_products/dafd/search/. Consider that many private airports and heliports (such as hospitals) may not be listed in the Chart Supplements.

${ }^{69}$ See Kathy Yodice, Esq., Legal Briefing, AOPA (July 5, 2004), available at https://www.google.com/url?q=https://www.aopa.org/news-and-media/all-news/2004/july/flight-training$\underline{\text { magazine/legal-briefing\&sa=D\&ust=1504204565982000\&usg=AFQjCNGwKr Ae5mvxtXQ4N1YR3sbE0xXUQ }}$ 


\section{UAS Pilots Code -Annotated Version 1.0}

(Pilots ". . must check notams as often as feasible, including immediately before takeoff and en route, too."); and FAA, Advisory Circular, AC 107-2, Subj. Small Unmanned Aircraft Systems (2016), https://www.faa.gov/documentLibrary/media/Advisory Circular/AC 107-2.pdf (addressing NOTAMs).

${ }^{70}$ See FAA, TFR Map, http://tfr.faa.gov/tfr_map ims/html/index.html.

${ }^{71}$ See Leidos Flight Service, 1800wxbrief, https://www.1800wxbrief.com/Website/\#!/, and https://www.1800wxbrief.com/Website/resources/help.pdf;isessionid=CD7FB706FAA3E4C6EAA7336FDBA BE4A9 (presenting Unmanned Operating Areas (UOAs), planning, filing, activating, NOTAMs features, and access to an associated Web User Guide, § 10, UAS).

${ }^{72}$ See FAA, Advisory Circular, AC 107-2, Subj. Small Unmanned Aircraft Systems (June 21, 2016), ch. 5.5, https://www.faa.gov/uas/media/AC 107-2 AFS-1 Signed.pdf (requiring preflight inspection to verify aircraft is in a safe condition for flight), ch. 7.4 (listing recommended preflight inspection items), and app. C (sUAS maintenance and inspection best practices); and ICAO, Manual on RPAS, § 6.7.1 (before flight "ascertain[] by every reasonable means available that [facilities are available for] safe operation") (emphasis added). See also Check3GPS, http://www.check3gps.com/ (providing a "quick and easy method to assess any activity or event for possible hazards and allow mitigation when required" -- Gear, Plan, Skills).

${ }^{73}$ See, e.g., Mavic Pilots Web Forum, Domain Block List for Firmware Update Check on DJI Go 4, https://mavicpilots.com/threads/domain-block-list-for-firmware-update-check-on-dji-go-4.20394/ (a description of how one user blocked automatic UAS firmware updates); Aaron Luo, Drones Hijacking, multidimensional attack vectors and countermeasures, https://media.defcon.org/DEF\%20CON\%2024/DEF\%20CON\%2024\%20presentations/DEFCON-24-AaronLuo-Drones-Hijacking-Multi-Dimensional-Attack-Vectors-And-Countermeasures-UPDATED.pdf (addressing hijacking vulnerabilities, and by implication the importance of keeping firmware current. Note that the subject manufacturer subsequently issued firmware updates that materially resolved the identified vulnerabilities); Ben Sullivan, DJI is Locking Down its Drones Against a Growing Army of DIY Hackers, Motherboard (July 7, 2017), https://motherboard.vice.com/en us/article/3knkgn/dji-is-locking-down-itsdrones-against-a-growing-army-of-diy-hackers (summarizing diverse firmware exploits and manufacturer response mandating firmware updates-or losing functionality); and Gary Mortimer, DJI to restrict noncompliant drones at next software update, sUAS News (Aug. 22, 2017), https://www.suasnews.com/2017/05/dii-restrict-non-compliant-drones-next-update/amp/.

${ }^{74}$ Additionally, understand any firmware/software updates before implementation-read the release notes. Consider performing a functional flight test following any system modifications.

${ }^{75}$ See ICAO, Manual on RPAS, § 9.5.28, Diversion to alternate aerodromes (Among other factors in choosing an emergency landing site, consider fuel reserves, C2 reliability, and field conditions.), § 9.7, Emergencies and Contingencies; and NASA, Safe2Ditch, available at https://www.youtube.com/watch?v=kM FFWgPV Q (demonstrating autonomous crash management technology and emergency landing location resolution). See also ASTM Int'l, Operational Risk Assessment standard, F3178; and UASPC, n.26).

${ }^{76}$ Checklists provide safety benefit for all phases of flight. See Atul Gawande, The Checklist Manifesto, Picador, p. 72 (2011):

For generations after the first aviation checklist went into use, a lesson is emerging: checklists seem able to defend anyone, even the experienced, against failure in many more tasks than we realized... They provide a kind of cognitive net. They catch mental flaws inherent in all of us-flaws of memory and attention and thoroughness. 


\section{UAS Pilots Code -Annotated Version 1.0}

See Asaf Degani \& Earl L. Wiener, NASA, Human Factors of Flight-Deck Checklists, The Normal Checklist, esp. App. A (1990), available at https://ntrs.nasa.gov/archive/nasa/casi.ntrs.nasa.gov/19910017830.pdf (on incorporating modern human factors research into new principles for cockpit checklist design and usage); and FAA, SAFO 17006, Subj. Safety Concerns with Using Commercial Off-the-Shelf (COTS) or Personally Developed Checklists (Apr. 10, 2017), https://content.govdelivery.com/attachments/USAFAA/2017/04/27/file attachments/808068/SAFO17006. pdf (highlighting risks of commercially and personally-developed checklists "in lieu of using the checklist contained in the manufacturer 's Pilot Operating Handbook (POH)/Airplane Flight Manual (AFM)"; urging meticulous comparison with "manufacturer's checklist and placards contained in the POH/AFM").

Nonetheless, many sUAS may not provide manufacturers checklists; and homebuilt or UAS with optional equipment or modifications may render "standard" checklists ineffective or inadequate. Also, there are important limitations to the efficacy of checklists, see UASPC n. 30 .

${ }^{77}$ See FAA, Advisory Circular, AC 107-2, Subj. Small Unmanned Aircraft Systems, § 5.9.1, Prior to Flight (June 21, 2016), https://www.faa.gov/uas/media/AC 107-2_AFS-1 Signed.pdf. Also, identify areas where your visibility may be obscured by structures or sun glare.

${ }^{78}$ Drafting Considerations: The UASPC adopted "limitations" rather than "minimums" reflecting that some parametric values will be maximums rather than minimums.

${ }^{79}$ See 14 C.F.R. $\S 107.19$ (c) (RP in command must ensure sUA poses no undue hazard to people, aircraft or property).

${ }^{80}$ See 14 C.F.R. Part 107, Subpart D-Waivers; 14 C.F.R. § 107.200, Waiver policy and requirements; 14 C.F.R. $\S 107.205$, List of regulations subject to waiver; the FAA online portal, FAADroneZone, https://faadronezone.faa.gov/\#/ (including for submission of waiver requests); and https://www.faa.gov/uas/request waiver/waivers granted/ (Part 107 waivers granted).

81 "[O]perating location" may include, inter alia, droneports and vertiports. See, e.g., the charted Dallas Cbd Vertiport (49T), https://nfdc.faa.gov/nfdcApps/services/ajv5/airportDisplay.jsp?airportld=49T. See also 14 C.F.R. Part 77, Safe, Efficient Use and Preservation of the Navigable Airspace; 14 C.F.R. Part 157, Notice of Construction, Alteration, Activation and Deactivation; FAA Order JO 7400.2L, Procedures for Handling Airspace Matters; and FAA, FSIMS, vol. 16 (on UAS criteria); and ASTM Int'l, Comm. F38, https://www.astm.org/COMMITTEE/F38.htm (developing a vertiport standard).

${ }^{82}$ State, Local, and Tribal Rules - See generally N. DuPuis, et al., Cities and drones: What Cities Need To Know About Unmanned Aerial Vehicles (UAVs), National League of Cities, (2016), http://www.nlc.org/sites/default/files/2016-12/NLC\%20Drone\%20Report.pdf; Institute for Nat'l Security and Counterterrorism, Syracuse Univ., Domesticating the Drone, http://uavs.insct.org/local-regulation/ (providing, inter alia, an interactive map of UAV legislation); U.S. Dept. of Transp., FAA, State and Local Regulation of Unmanned Aircraft Systems (UAS) Fact Sheet, p. 3 (Dec. 17, 2015), https://www.faa.gov/uas/resources/uas regulations policy/media/uas fact sheet final.pdf (state and local police power laws "including land use, zoning, privacy, trespass, and law enforcement operationsgenerally are not subject to federal regulation"); Nat'I Conf. of State Legislatures, Current Unmanned Aircraft State Law Landscape (July 2017), http://www.ncsl.org/research/transportation/current-unmannedaircraft-state-law-landscape.aspx; and Rupprecht Law, US Drone Laws (2017) - Drone Laws by State, https://jrupprechtlaw.com/drone-laws-state.

Federalism; Federal Preemption - Federalism is a system of government that (in the US) bifurcates governance between the states (including its subdivisions) and national government. See New York v. US, 


\section{UAS Pilots Code -Annotated Version 1.0}

505 U.S. 144 (1992), available at https://supreme.justia.com/cases/federal/us/505/144/case.html (anthology of federalism's underpinnings). Federal preemption is premised on Art. VI, cl. 2 (the Supremacy Clause) of the U.S. Constitution: "This Constitution, and the Laws of the United States which shall be made in Pursuance thereof; and all Treaties made ... shall be the supreme Law of the Land; and the Judges in every State shall be bound thereby, any Thing in the Constitution or Laws of any state to the Contrary notwithstanding." Available at https://www.archives.gov/founding-docs/constitution. It grants Congress power to preempt, or override state law that interferes with or are contrary to powers granted Congress. See McCulloch v. Maryland, 17 U.S. 316 (1819), available at https://www.law.cornell.edu/supremecourt/text/17/316 ("The Government of the Union, though limited in its powers, is supreme within its sphere of action, and its laws, when made in pursuance of the Constitution, form the supreme law of the land."). The extent of federal preemption depends on Congress's intent: field preemption arises where Congress intends to preempt an entire field; whereas conflict preemption arises where state-federal law conflicts to the extent of physical impossibility. Federal preemption affecting UAS operations is undergoing scrutiny. See, e.g., Singer v. City of Newton, Case No. 1:17-CV-10071-WGY (Sept. 21, 2017), available at https://www.ecfr.gov/cgibin/retrieveECFR?gp=\&SID=5a94599c486631fe22f2127461f38a26\&mc=true \& $n=s p 14.2 .107 . b \& r=S U B P A R T \&$ ty=HTML\#se14.2.107 123 (conflict preemption).

Federal authority over navigable airspace appears in 49 U.S.C. § 40103(a), Sovereignty and use of airspace, available at https://www.law.cornell.edu/uscode/text/49/40103 (exclusive sovereignty; public right of transit through navigable airspace); and 49 U.S.C. § 40103(b) (FAA authorization; prescription of air navigation regulation). See Brian P. Wynne, Pres. and CEO, AUVSI, Letter to Pres. Donald J. Trump (Oct. 11, 2017) ("Federal control of the airspace is a bedrock principle of aviation law that dates back over 50 years, and is the primary reason the United States maintains an aviation safety record that is the envy of the world. Maintaining the FAA's authority helps keep the skies safe for all aircraft - manned and unmanned."). Nonetheless, the FAA recognizes limitations to federal preemption with regard to sUAS:

The FAA is not persuaded that including a preemption provision in the final rule is warranted at this time. Preemption issues involving small UAS necessitate a case-specific analysis that is not appropriate in a rule of general applicability. Additionally, certain legal aspects concerning small UAS use may be best addressed at the State or local level. For example, State law and other legal protections for individual privacy may provide recourse for a person whose privacy may be affected through another person's use of a UAS.

FAA, Operation and Certification of Small Unmanned Aircraft Systems (RIN 2120-AJ60), (NPRM at 9552) (effective Aug. 29, 2016), available at https://www.regulations.gov/document?D=FAA-2015-0150-4721, and 81 Fed. Reg. 42,064, 42,194 (June 28, 2016) ("Final Rule").

Also, consider Fmr. FAA Adm'r Huerta's acknowledgment of Federalist principles, suggesting the efficacy of certain limited local control on UAS: “. . . in addition to the FAA's rules, there are existing state and local laws in areas of reckless endangerment, trespass, and privacy that could apply." Statement by the Hon. Michael Huerta, Fmr. FAA Adm'r, Before the U.S. Senate Appropriations Subcomm. on Transp., Housing and Urban Dev., and Related Agencies (Oct. 28, 2015),

https://www.appropriations.senate.gov/imo/media/doc/102815-Huerta-Testimony.pdf. See Drone Innovation Act of 2017, HR 2930, available at https://www.congress.gov/bill/115th-congress/housebill/2930? q=\%7B\%22search\%22\%3A\%5B\%22unmanned+aerial\%22\%5D\%7D\&r=2 (requiring development of a policy framework that, inter alia, "preserve[s] the legitimate interests of State, local, and Tribal 


\section{UAS Pilots Code -Annotated Version 1.0}

governments including-(1) Protecting public safety; (2) protecting personal privacy; (3) protecting property rights; (4) managing land use; and (5) restricting nuisances and noise pollution." And other limitations intended to advance such rights); and Sen. Feinstein's introduction of the Drone Federalism Act of 2017, available at https://www.feinstein.senate.gov/public/ cache/files/d/b/dbfod059-09d2-43ae-9e173ca960592798/88CC2E3D7D090130DE655B22BEA674C7.ros17470.pdf.

The erosion of support for Federal preemption of the airspace was noted by Steven J. Brown, COO, NBAA, Presentation to NBAA's Access Comm. (Oct. 9, 2017): “I've never before seen a time when local government had such an open disregard for Federal provisions. ... This type of assertiveness and disregard is clearly a pattern that has been in place for a couple of years and is metastasizing." As stated above, the limits of Federal authority over low-altitude airspace remain a work in progress.

There is a disconnect between preemption (which bars local municipalities from regulating) and the P.L. 112-95 limits imposed in Section 336 (which bars the FAA from rulemaking for model aircraft). Some model aircraft operators argue that preemption means local governments cannot create binding ordinances because the FAA has responsibility for regulating aviation. They then argue that enjoining the FAA from rulemaking means, in effect, that no one can create binding ordinances.

Aviation Apps Informing State/Local Rule Compliance - Separately, consider the extent to which aviation apps provide sufficient actionable local rule content. For example, the B4UFLY application (available at https://www.faa.gov/uas/where to fly/b4ufly/) is designed primarily to assist operator compliance with Federal airspace rules-not state and local rules. Operators should independently become familiar with available resources to ascertain applicable state and local rules.

${ }^{83}$ See 14 C.F.R. § 107.9, Accident reporting, available at the FAADroneZone Portal, https://faadronezone.faa.gov/ (UAS pilots must report accidents no later than 10 days after occurrence that meet designated criteria. UAS accidents are defined as any operation of a UAS involving at least: (a) serious injury or loss of consciousness, (b) or property damages greater than \$500). And, FAA Hotline, https://hotline.faa.gov/ (for reports related to the safety of the NAS, violations of FAA regulations, safety issues, and FAA employees or facilities). Conversely, the NTSB defines an unmanned aircraft accident as "an occurrence associated with the operation of any public or civil unmanned aircraft system that takes place between the time that the system is activated with the purpose of flight and the time that the system is deactivated at the conclusion of its mission, in which (1) Any person suffers death or serious injury; or (2) The aircraft has a maximum gross takeoff weight of 300 pounds or greater and sustains substantial damage." Events that do not meet the criteria for classification as accidents are considered incidents. NTSB, Notification and Reporting of Aircraft Accidents or Incidents and Overdue Aircraft, and Preservation of Aircraft Wreckage, Mail, Cargo, and Records, 49 C.F.R. § 830.2.

All accidents are required to be reported, whereas only some incidents-depending on the type-require reporting. See also FAA, Accident and Incident Reporting FAQs, https://www.faa.gov/uas/faqs/\#air. Where practicable, preserve UAS data for accident or incident investigation purposes. ICAO, Manual on RPAS, § 9.10.8.

${ }^{84}$ FAA, Near Mid Air Collision System (NMACS), FAA Aviation Safety Information Analysis and Sharing (ASIAS), http://www.asias.faa.gov/pls/apex/f?p=100:33:0::NO. See FAA, Order 8900.1 vol. 7, ch. 4, § 1 (sUAS NMAC are to be processed with current aircraft NMAC report forms, pilot bill of rights and added sUAS items that address determining ownership of the UAS; the order references vol. 16, Unmanned Aircraft Systems, and FAA, Advisory Circular, AC 107-2, Subj. Small Unmanned Aircraft Systems). 


\title{
UAS Pilots Code -Annotated Version 1.0
}

\begin{abstract}
Aircraft Registry and Investigation - If the investigation process involves a sUAS and the aircraft cannot be found in the aircraft registry (see FAA, Aircraft Registry, http://registry.faa.gov/aircraftinquiry/), it may have been registered per 14 C.F.R. Part 48, Registration and Marking Requirements for Small Unmanned Aircraft. The investigating office is to contact the Law Enforcement Assistance Program (LEAP), at http://www.faa.gov/about/office org/headquarters offices/ash/ash programs/investigations/leap/. See generally Unmanned Aircraft System Handbook and Accident/Incident Investigation Guidelines, Int'I Society of Air Safety Investigators (2015),

http://www.isasi.org/Documents/ISASI\%20Unmanned\%20Aircraft\%20System\%20Handbook\%20and\%20Acc ident Incident\%20Investigation\%20Guidelines.pdf.
\end{abstract}

See Jeff Guzzetti, Why it Makes a Difference to Report and Investigate UAS Incidents ... Even When They Don't Really Happen, Int'I Society of Air Safety Investigators, Submission for the 2017 ISASI Seminar, San Diego, http://www.isasi.org/Documents/library/technicalpapers/2017/Wed/9.\%20Why\%20it\%20Makes\%20a\%20Difference\%20to\%20Report\%20and\%20Investigate \%20UAS\%20Incidents.docx ("investigation of UAS sightings and, when warranted, root cause analysis of incidents [where UAS/human-piloted aircraft] have come in close proximity, are essential to validate the effectiveness of the safety controls in place today for preventing accidents [and] help guide the industry's ongoing research into the development of future safety controls related to the operation and design of UAS.").

NTSB Accident Reporting - NTSB accident reporting is not required for hobbyists, per FAA Modernization and Reform Act of 2012, §336. See NTSB, Advisory to Operators of Civil Unmanned Aircraft Systems in the United States (“NTSB Advisory”) (July 29, 2016),

https://www.ntsb.gov/investigations/process/Documents/NTSB-Advisory-Drones.pdf. The NTSB requires all other UAS operators to provide immediate notification of any accident involving serious injury or death, or if the aircraft has a maximum takeoff weight of 300 pounds or greater, and sustains substantial damage, or any serious incident involving UAS of any weight that meets the following criteria: flight control system malfunction or failure, inability of any required flight crewmember to perform normal flight duties as a result of injury or illness, inflight fire, aircraft collision in flight, More than $\$ 25,000$ in damage to objects other than the aircraft, Release of all or a portion of a propeller blade from an aircraft, excluding release caused solely by ground contact, Damage to helicopter tail or main rotor blades, including ground damage, that requires major repair or replacement of the blade(s), or an aircraft is overdue and is believed to have been involved in an accident. See 49 C.F.R. $\S \S 830.2,830.5$, and NTSB Advisory, above. See generally https://www.ntsb.gov/investigations/process/Documents/NTSB-Advisory-Drones.pdf.

${ }^{85}$ Aviation Safety Reporting (ASRS) - See ASRS, https://asrs.arc.nasa.gov/ (NASA's cooperative safety reporting program encourages reporting actual or potential discrepancies or deficiencies involving the safety of aviation operations); and FAA, Advisory Circular, AC-00-46E, Subj. Aviation Safety Reporting Program, p. 1 (Dec. 16, 2011), available at http://www.faa.gov/documentLibrary/media/Advisory Circular/AC\%2000-46E.pdf (explaining the ASRS reporting system and that "[t]he FAA considers the filing of a report with NASA concerning an incident of occurrences ... to be indicative of a constructive attitude [that] will tend to prevent future violations" and may preclude civil penalty or certificate suspension); and 14 C.F.R. § 91.25, Aviation Safety Reporting Program: Prohibition against use of reports for enforcement purposes ("The Administrator of the FAA will not use reports submitted to the National Aeronautics and Space Administration under the Aviation Safety Reporting Program (or information derived therefrom) in any enforcement action except information concerning accidents or criminal offenses which are wholly excluded from the Program."). Cf., 14 C.F.R. § 13 (investigative and enforcement actions); and 14 C.F.R. § 13.19, Certificate Action. See also R. S. Sharma, 


\section{UAS Pilots Code -Annotated Version 1.0}

Investigation into Unmanned Aircraft System Incidents in the National Airspace System, Int'l J. of Aviation, Aeronautics, and Aerospace, vol. 3(4) (Dec. 2, 2016), available at https://doi.org/10.15394/ijaaa.2016.1146 (summarizing FAA reports); and ASRS references, UASPC, n.121.

${ }^{86}$ Maintenance Program - See FAA, Advisory Circular, AC 107-2, Subj. Small UAS Systems § 7.2-3 (2016), available at https://www.faa.gov/documentLibrary/media/Advisory Circular/AC 107-2.pdf (addressing sUAS maintenance and inspection):

Whenever possible, the operator should maintain the sUAS and its components in accordance with manufacturer's instructions. The aircraft manufacturer may provide the maintenance program, or, if one is not provided, the applicant may choose to develop one.... There may be components of the sUAS that are identified by the manufacturer to undergo scheduled periodic maintenance or replacement based on time-in-service limits (such as flight hours, cycles, and/or the calendar-days). All manufacturer scheduled maintenance instructions should be followed in the interest of achieving the longest and safest service....

Maintenance Practices - See ASTM Int'I, Standard Practice for Maintenance and Continued Airworthiness of Small Unmanned Aircraft Systems (sUAS), F2909, https://www.astm.org/COMMITTEE/F38.htm. ASTM Int'I is also developing a guide for UAS maintenance qualification and certification. See also ACl, Aviation Maintenance Technicians Model Code of Conduct, http://www.secureav.com/AMTMCC-Listings-Page.html.

Product Registration/Warranty and Alerts - Laws such as the Consumer Product Safety Act (CPSA), 5 U.S.C. $\S \S$ 2051-2089, available at https://www.law.cornell.edu/uscode/text/15/chapter-47), provide for product registration by consumers and notification in the event of a product recall or safety alert. However, the CPSA expressly excludes "aircraft, aircraft engines, propellers, or appliances (as defined in section 101 of the Federal Aviation Act of 1958, section 40102(a) of title 49)," CPSA § 2052(A)(5)(F). Also, aircraft are not considered consumer products under the Magnuson-Moss Warranty Act, 15 U.S.C. § 2301, et seq. (available at https://www.law.cornell.edu/uscode/text/15/2301), a policy formulated on the premise that "no appreciable portion of new aircraft are sold to consumers, for personal, household or family purposes." Modification of Implementation and Enforcement Policy, 41 Fed. Reg. 26,757 (1976). Given the dramatic proliferation of sUAS, and their substantial application for personal, household and family use, this policy should be reconsidered. Or, the FAA could qualify its definition for an "aircraft", providing that sUAS weighing less than a weight threshold for registration would no longer be considered aircraft, thereby (presumably) invoking the CPSA.

Importantly, many sUAS do not undergo formal airworthiness certification, and thus may not benefit from direct notification of Airworthiness Directives (ADs) (14 C.F.R. Part 39, https://www.ecfr.gov/cgibin/retrieveECFR?n=pt14.1.39), and particularly by Emergency ADs. See https://www.faa.gov/aircraft/air cert/continued operation/ad/type pub/type emerg/. See UASPC, nn. 120 and 229 (airworthiness).

In sum, most UAS are neither subject to Airworthiness Directives, nor subject to product recall under the Consumer Product Safety Act. Thus UAS owners and operators should maintain a direct relationship with sUAS and component manufacturers and dealers by: (1) signing-up for product announcements on their websites, (2) configuring and updating sUAS apps, and (3) submitting product registration cards (and any updates to reflect change of address).

${ }^{87}$ Navigation Database Discrepancy Reporting - Recognize that navigation and other database discrepancies may warrant reporting. The FAA encourages submission of charting error reports regarding 


\section{UAS Pilots Code -Annotated Version 1.0}

FAA Aeronautical products. FAA, FAQ, https://www.faa.gov/air traffic/flight info/aeronav/faq/\#q6a ("Chart Discrepancies How can I report chart discrepancies?"). The ASRS also encourages reporting such discrepancies to the ASRS. See UASPC, n.85. Additionally, navigation product manufacturers solicit database error reports. See, e.g., Garmin, Report a Database Error, https://my.garmin.com/mapErrors/report.faces?type=aviation. Cf., Reporting of consumer database errors: GPS.GOV, How to Report a Mapping Problem Affecting GPS Devices, Apps, and Maps, https://www.gps.gov/support/user/mapfix/devices-and-maps/ ("UU]nderstand that the U.S. government cannot correct mapping errors in consumer devices and apps" - rather, it is the responsibility of the commercial map provider.).

${ }^{88}$ FAA, Advisory Circular, AC 107-2, Subj. Small UAS Systems, $\S 7.3 .5$ (June 21, 2016) (addressing benefits of recordkeeping). Cf., ICAO, Manual on RPAS, §§ 6.6.3 d-f (requiring "Journey log book for the RPA ... maintenance log book and technical log for the RPA," and remote pilot stations), and $\S 6.4 .5 \mathrm{f}$ (recordkeeping items "covering at a minimum: ... security management records.").

${ }^{89}$ Communication of safety issues should be directed by law, an organization's procedures, applicable SOPs and guidelines, and undertaken such that there is confidence of their communication to the intended recipient.

${ }^{90}$ See, e.g., Richard M. Lusk, et al., An Early Survey of Best Practices for the Use of Small Unmanned Aerial Systems by the Electric Utility Industry, Oak Ridge Nat'I Lab., ORNL/TM-2017/93, § 4.3.30, p. 54 (Feb. 2017), http://nias-uas.com/wp-content/uploads/2017/02/An-Early-Survey-of-Best-Practices-for-the-Use-of-SmallUnmanned-Aerial-Systems-by-the-Electric-Utility-Industry-RM-Lusk-Feb-2017.pdf (recommending anemometer and wind sock); Unmanned Systems Canada, Small RPAS Best Practices for BVLOS, v1.1, § 4.6.2(e), p. 26 (Oct. 2016), https://www.unmannedsystems.ca/download/usc-small-rpas-bvlos-bestpractices/ (recommending timepiece readily available to each flight crew member); and Scott Burgess, PhD., ERAU (Oct. 3, 2017) (urging spectrum analyzer to assess C2 reliability near electrical transmission and high-power radio antenna). See The Application of Handheld Spectrum Analyzers in Interference Testing, Techi-Tools, reprinted by Agilent Technologies, http://www.techni-

tool.com/site/ARTICLE LIBRARY/Agilent\%20\%20The\%20Application\%200f\%20Handheld\%20Spectrum\%20Analyzers\%20in\%20Interference\%20Testing.p df (RFI prediction tool).

${ }^{91}$ C2 Link Loss and Latency - Lost link involves two failures: a control link failure, followed by the unmanned aircraft's failure to follow its lost link programming. These are unpredictable, potentially hazardous, and outside current certification thinking. Even lost links that follow their profiles represent autonomous operations until re-captured or terminated, and those are prohibited because of the inherent risk associated with them. Pilots should read and understand manufacturer's documentation addressing lost link functionality, and that lost link protocols may vary greatly among each aircraft and operation. Such familiarity should include understanding any redundancy, timing/latency in lost link initiation, annunciations of lost link and lost link protocols, how the aircraft is programmed to function upon lost link, and how/whether to modify lost link factory settings. See R. Jay Shively, NASA Ames Research Center, et al., Human Performance Considerations for Remotely Piloted Aircraft Systems (RPAS), ICAO, Remotely Piloted Aircraft Systems Panel (RPASP), Second Mtg. (RPASP/2), Montréal, Human performance considerations for Remotely Piloted Aircraft Systems (RPAS) (June 15-19, 2015), § 2.4, p. 43-47, https://ntrs.nasa.gov/archive/nasa/casi.ntrs.nasa.gov/20150011435.pdf (addressing C2 latency and its human factors affects). 


\section{UAS Pilots Code -Annotated Version 1.0}

Recognize that C2 latency may diminish RP ability to respond timely to DAA alerts where such response requires RP inputs; and understand all surveillance system error and bias. Id., § 2.5, pp. 53-54. Additionally, RP SOPs should define the criteria triggering link loss protocol. See Unmanned Systems Canada, Small Remotely Piloted Aircraft System (RPAS) Best Practices for BVLOS Operations, v1.1, § 4.7.2.1(3), p. 28 (Feb. 16, 2017), https://www.unmannedsystems.ca/download-usc-small-rpas-best-practices-document/ ("Unless otherwise authorized, alternative contingency planning measures must allow for safe termination of the flight under any circumstances during all phases of flight.") (emphasis added). Id., § 4.7.2.3.5 (Lost link procedures when flying VFR in uncontrolled airspace include: executing lost link procedure, remaining in VMC and uncontrolled airspace, advising ATC as soon as possible, squawking appropriate lost link code if transponder equipped, where practicable broadcasting location and intent in plain language at regular intervals to advise local traffic, and landing as soon as practicable at nearest safe suitable site.). See UASPC, n.66 (regarding emergency reporting).

C2 Link Security - Consider "the security of the C2 link against hacking, spoofing and other forms of interference or malicious hijack, as well as unintentional interference. Mitigations must be implemented to prevent the C2 link from connecting the RPS [Remote Pilot Station] to an unintended RPA [Remotely Piloted Aircraft] or vice versa." ICAO, Manual on RPAS, § 4.5.5. See UASPC, § IV. Security and Privacy (addressing C2 security).

Drafting Considerations: The UASPC contains a number of principles and SRPs that could have been placed in sections other than where they appear. For example, this SRP relating to learning lost control link and other automation failure procedures could have been placed in Section III. Training and Proficiency, or in Section VI. Use of Technology. The Drafting Team recognized that there would be overlap of subject matter across the UASPC's sections and resolved questions of placement on the basis of context and intended meaning.

${ }^{92}$ See ICAO, Manual on RPAS, $\S 4.3$ Governing Principles, 4.3.1 d) ("the remote PIC is expected to have continuous control over the RPA under normal operating conditions."); FAA, Order JO 7110.65X, § 5-2-9, Unmanned Aircraft Systems (UAS) Lost Link (Oct. 12, 2017), available at

https://www.faa.gov/documentLibrary/media/Order/JO 7110.65X Air Traffic Control.pdf. For larger (and some small) UAS, understand "lostlink route of flight, lost link orbit points, lost link altitudes, communications procedures and pre-planned flight termination points if the event recovery of the UAS is deemed unfeasible."); and FAA, ORDER 8900.1 CHG 468, Ch. 16-4-8-7, Contingency Planning, http://fsims.faa.gov/PICDetail.aspx?docld=8900.1,Vol.16,Ch4,Sec8 (addressing risk mitigation and lost link procedures).

${ }^{93}$ See ASTM Int'I, F3005 Specification for Batteries for Use in Small Unmanned Aircraft Systems (sUAS), available (fee) at https://www.astm.org/search/fullsite-search.html?query=f3005\& (re discharge, § 8.1.3 Storage, requiring "charge [ ] / discharge [] to a level that is optimal for storage based on the particular chemistry ... stored at approximately one-half capacity or at the supplier-specified charge level for long term storage any time a pack is out of service for more than one month"); and UASPC, § V. Environmental Issues (environmental considerations regarding batteries). See also n.175 (addressing batteries), and UASPC, § V.c (addressing hazards and special handling procedures for batteries and other fuels).

${ }^{94}$ See 14 C.F.R. § 107.19(c) ("The remote pilot in command must ensure that the small unmanned aircraft will pose no undue hazard to other people, other aircraft, or other property ..."); Parimal Kopardekar, et al., Unmanned Aircraft System Traffic Management (UTM) Concept of Operations, p. 3 (June 2016), https://utm.arc.nasa.gov/docs/Kopardekar 2016-3292 ATIO.pdf ("The biggest risk is to people and assets on the ground and to manned aviation ... ."); Gerardo Olivares, et al., ASSURE, Volume III-UAS Airborne 


\section{UAS Pilots Code -Annotated Version 1.0}

Collision Severity Evaluation-Fixed-Wing, § 8.2.1, p. 176 (July 2017),

http://www.assureuas.org/projects/deliverables/a3/Volume\%201II\%20-

\%20UAS\%20Airborne\%20Collision\%20Severity\%20Evaluation\%20-\%20Fixed-wing.pdf ("UAS operations may pose unique hazards to other aircraft and people on the ground."); and UK, Civil Aviation Auth., CAP 1627, Drone Safety Risk: An Assessment, http://publicapps.caa.co.uk/modalapplication.aspx?catid=1\&pagetype=65\&appid=11\&mode=list\&type=sea rch\&search=CAP1627.

${ }^{95}$ Drafting Consideration: The term "surface" is adopted rather than "ground" to include both bodies of water as well as solid land. See, e.g., 14 C.F.R. § 91.119(a) (addressing "hazard to persons or property on the surface").

${ }^{96}$ See 14 C.F.R. § 107.37, Operation near aircraft; right-of-way rules (“(a) Each small unmanned aircraft must yield the right of way to all aircraft, airborne vehicles, and launch and reentry vehicles. Yielding the right of way means that the small unmanned aircraft must give way to the aircraft or vehicle and may not pass over, under, or ahead of it unless well clear."); 14 C.F.R. § 91.113(b) (general right-of-way rule); and FAA, Advisory Circular, AC 107-2, Subj. Small Unmanned Aircraft Systems (sUAS), § 5.8.1 (June 21, 2016), https://www.faa.gov/uas/media/AC 107-2 AFS-1 Signed.pdf ("the remote PIC must yield right-of-way to all other aircraft, including aircraft operating on the surface of the airport.").

${ }^{97}$ See 14 C.F.R. § 107.39(b), Operation over human beings, available at https://www.law.cornell.edu/cfr/text/14/107.39 (requiring "covered structure" or "a stationary vehicle" providing "reasonable protection" from a falling sUAS). Also, ASTM Int'l, Comm. F38 is developing a specification for operations over people that includes possible equipment-based risk mitigations, such as ballistic parachutes, digital flight data recorders, braking motors, geo-fencing, battery redundancy, enhanced C2, and functional hold capability. See UASPC, n. 98.

${ }^{98}$ See Academy of Model Aeronautics, AMA National Model Aircraft Safety Code, § B.3. (Jan. 1, 2014), https://www.modelaircraft.org/files/105.pdf (addressing safety lines); and AMA, Recommended RC Flying Site Specifications, Doc\# 706, http://www.modelaircraft.org/files/706.pdf.

${ }^{99}$ Understand that use of UAS non-manufacturer aftermarket devices may void warranties, potentially create unacceptable safety risks, or possibly lead to an accident.

${ }^{100}$ See generally David Arterburn, et al., Final Report for the FAA UAS Center of Excellence Task A4: UAS Ground Collision Severity Evaluation, Rev. 2 (2017), available at http://pr.cirlot.com/wpcontent/uploads/2017/04/assure a4 final report uas ground collisionseverity evaluation_rev_2 20170428 final.pdf (and particularly the Report's conclusions, p. 145).

Drafting Considerations: This SRP is relevant even when operations over people are not anticipated. Recognize that operations over people generally require explicit approval.

101 Jason Maddocks, et al., Avian, Colo. Ag. Avi. Ass'n, p. 1 (2015) available (upon request) at http://coagav.org/ (During the subject experiment "all pilots were easily able to see the prototype ground crew markings." Pilots were less likely to see the actual drone in flight and more likely to see the crew or high-visibility markers indicating UAS operations were being conducted). See FAA, InFo 17018, Subj. Use of Reflective Vests by Small Unmanned Aircraft Systems (sUAS) Remote Pilots (Nov. 27, 2017), https://www.faa.gov/other visit/aviation industry/airline_operators/airline safety/info/all infos/media/2 017/InF017018.pdf (urging use of reflective vests with suggested warning against distracting pilot, e.g., "Drone Pilot Please Do Not Disturb" or "Drone Pilot Stand Clear"). 


\section{UAS Pilots Code -Annotated Version 1.0}

102 Insurance - Although not included in 14 C.F.R. Part 107, commentators to the proposed sUAS Rule (NPRM for Part 107) urged an insurance requirement because: "(1) other countries require liability insurance for small UAS operations; (2) liability insurance would incentivize safe operations and encourage operators to keep pace with technological developments; and (3) small UAS operations are analogous to automobile operations, which require liability insurance." FAA, Operation and Certification of Small Unmanned Aircraft Systems, Final Rule, K. Misc. Provisions, 1. Mandatory Insurance, p. 497, available at https://www.faa.gov/uas/media/RIN 2120-AJ60 Clean Signed.pdf. See NBAA, Integrated Operational Management and Oversight for sUAS (May 13, 2016), https://www.nbaa.org/ops/uas/integratedoperational-management-and-oversight-for-suas/NBAA-Resource-Integrated-Operational-Managementand-Oversight-for-sUAS.pdf (suggesting aviation liability coverage of at least \$2 million per occurrence, and professional liability/errors and omissions insurance with limits of at least \$1 million for each claim or wrongful act). Cf., AMA, 2017 Insurance Summary,

https://www.modelaircraft.org/files/insurancesummarymembers.pdf (providing per occurrence coverage for members of “\$2,500,000 involving bodily injury and/or property damage”). Separately, where indicated, urge [potential] customers to obtain non-owned UAS coverage in excess of the operator's coverage limits.

${ }^{103}$ Operations Manual - See, e.g., ICAO, Manual on RPAS, § 9.3, RPAS Manuals; HK Civil Aviation Dept., Application for UAS Operations Manual Template,

http://www.cad.gov.hk/reports/UAS operations manual.pdf (outlining areas that should be in a UAS operations manual); and Unmanned Systems Canada, Small RPAS Best Practices for BVLOS, v1.1, App. 2, §

5XX.13.2, p. 58 (Oct. 2016), https://www.unmannedsystems.ca/download/usc-small-rpas-bvlos-bestpractices/ (suggested Basic Structure of a Small RPAS Operating Manual).

Concept of Operations - Consider review of applicable concept of operations to inform drafting of operations manuals. See FAA, Integration of Unmanned Aircraft Systems into the National Airspace System, ver. 2 (Sept. 28, 2012), available at https://www.suasnews.com/wp-content/uploads/2012/10/FAA-UASConops-Version-2-0-1.pdf; EASA, Concept of Operations for Drones, https://www.easa.europa.eu/system/files/dfu/204696 EASA concept drone brochure web.pdf; Parimal Kopardekar, et al., Unmanned Aircraft System Traffic Management (UTM) Concept of Operations, NASA (June 2016), https://utm.arc.nasa.gov/docs/Kopardekar 2016-3292 ATIO.pdf; and EUROCONTROL, RPAS ATM CONOPS, Ed. 4.0 (2017), https://www.eurocontrol.int/sites/default/files/publication/files/rpas-atmcocept-of-operations-2017.pdf.

${ }^{104}$ Consider establishing minimum standoff distances. See, e.g., Public Safety Aviation Accreditation Commission, Standards for Small Unmanned Aircraft System (sUAS) Programs (2017), Draft Ver. June 5, 2017, § 02.02.3, Minimum Standoff Distances and Maximum Altitudes, available at https://publicsafetyaviation.org/images/Standards/tab 16 c - UAS Stds Draft 6-5-17.pdf ("Minimum standoff distances from people and objects and maximum altitudes shall be established to ensure safe operations....).

105 Recognize your legal and ethical obligations to avoid injuring others and their property.

${ }^{106}$ Drafting Considerations: The Drafting Team adopted the term "proficiency" over prescribed specific recurrency or recency requirements, acknowledging that proficiency is highly individualistic and encompasses elements of both recent experience and recurrent training and practice.

See ICAO, Manual on RPAS, § 6.9.8 (training programme "should include: knowledge and skills related to the RPA operational procedures for the intended area of operations . . remote flight crew coordination ... . abnormal and emergency situations ... methods to maintain situational awareness ... human performance 


\section{UAS Pilots Code -Annotated Version 1.0}

aspects [re CRM], threat and error management (TEM), and automation or human-machine interface (HMI) which are unique to unmanned aviation."); R. Jay Shively, NASA Ames Research Center, et al., Human Performance Considerations for Remotely Piloted Aircraft Systems (RPAS), Report of the ICAO, Remotely Piloted Aircraft Systems Panel (RPASP), Second Mtg. (RPASP/2), Montréal (June 15-19, 2015), § 2.1.6, p. 13, available at https://ntrs.nasa.gov/archive/nasa/casi.ntrs.nasa.gov/20150011435.pdf ("Retention of knowledge and skills is dependent on the level of expertise of the pilot when they are first developed, the frequency at which they are used in daily activities, the importance that is placed on retention during the training process, and other factors.").

107 "Minimum requirements" that meet or exceed applicable law may be fashioned via private organization SOPs or other non-regulatory instrument. Minimum requirements are presented in 14 C.F.R. Parts 91, 101, 107, and elsewhere. See e.g., nn.8, 20, 115 \& 122, and corresponding text (addressing minimum requirements and the ACS).

${ }^{108}$ See UASPC, n.103 (operations manuals).

${ }^{109}$ Securing payloads includes ensuring slung or towed payloads do not adversely affect unmanned aircraft control or flight stability, and are not susceptible to unintended payload release. Payloads should also create no unsafe electromagnetic radiation. See UASPC, n.34 (addressing hazardous payloads).

${ }^{110}$ Placards provide necessary information to aid in the safe operation of UAS. See, e.g., ASTM Int'l, Committee F38, https://www.astm.org/COMMITTEE/F38.htm (developing standards assuring that placards are prominently available to the UAS pilot).

${ }^{111}$ Some unmanned aircraft are equipped with orientation or system status lighting. For example, DJI platforms are equipped with front LED lights that provide the remote pilot with flight orientation information, and aft color-coded aircraft status lights indicating system status, operational limitations, or malfunctions. Users can reference the meaning of various lighting colors and flash patterns in the manufacturer's UAS user manual.

Some sUAS may utilize position lighting modeled after manned aircraft. If seeking issuance of a special airworthiness certificate in the experimental category, UAS operators must present evidence of aircraft visibility acceptable for integration in the NAS. This may include high visibility paint, anti-collision lighting, or position lighting. See FAA, Order 8130.34D, App. D, Airworthiness Certification for Unmanned Aircraft Systems and Optionally Piloted Aircraft (9/8/2017), available at https://www.faa.gov/documentLibrary/media/Order/FAA Order 8130.34D.pdf.

${ }^{112}$ See, e.g., FAA, ALC Content, ALC-42: Airspace, Special Use Airspace and TFRs, shttps://www.faasafety.gov/gslac/ALC/course content.aspx?cID=42\&sID=505\&preview=true.

${ }^{113}$ See UASPC, n.133 (addressing autonomous aircraft).

${ }^{114}$ See, e.g., Tom Haritos, et al., The Use of High Fidelity Simulators to Train Pilot and Sensor Operator Skills for Unmanned Aerial Systems (2012), available at https://www.researchgate.net/publication/271837225 The Use of High Fidelity Simulators to Train Pil ot and Sensor Operator Skills for Unmanned Aerial Systems; Paul Cianciolo, Simulating your Drone Flight, FAA Safety Briefing, p. 29 (Nov./Dec. 2017), https://www.faa.gov/news/safety briefing/2017/media/NovDec2017.pdf (benefits of UAS simulation); and Deonna Neal \& William Rhodes, Failure Predicts Success: Professional Ethical Decision-Making in Aviation Simulators, J. of Character \& Leadership Integration (Winter 2017), available at https://icli.scholasticahq.com/article/1307-failure-predicts-success-professional-ethical-decision-making-in- 


\section{UAS Pilots Code -Annotated Version 1.0}

aviation-simulators (benefits of "real time" decision-making training). See also SRP corresponding to UASPC, n.114 ("use flight simulators and other training devices...").

${ }^{115}$ Standards in development for the design, construction and verification of various types of UAS recognize the efficacy of emergency training, where the standard requires the UAS to remain controllable, predictable or capable of performing a safe recovery maneuver following certain anomalies. See, e.g., ASTM Int'l, Comm. F38, https://www.astm.org/COMMITTEE/F38.htm.

${ }^{116}$ See FAA, Airman Information Manual (AIM), § 7-5-3(c), available at https://www.faa.gov/air traffic/publications/ ("[M]any power lines do not require notice to the FAA and, therefore, are not marked and/or lighted. Many of those that do require notice do not exceed 200 feet AGL or meet the Obstruction Standard of 14 C.F.R. Part 77 and, therefore, are not marked and/or lighted."). See, e.g., Jason Green, Drone crash knocks out power to 1,600 in Mountain View, The Mercury News (June 9, 2017), http://www.mercurynews.com/2017/06/09/drone-crash-knocks-out-power-to-1600-in-mountainview/. With or without a pilot in the aircraft, there are preflight actions that may mitigate wire strikes. See FAA, SAFO, Subj. Flying in the Wire Environment (Aug. 6, 2010), available at https://www.faa.gov/other visit/aviation industry/airline operators/airline safety/safo/all safos/media/2 010/SAF010015.pdf (referenced in the FAA's Remote Pilot ACS); and News 9, Wire Strike Story (Aug. 28, 2017), http://m.news9.com/story.aspx?story=36233805\&catld=112032.

${ }^{117}$ Where applicable, train for mission-specific skills, those uniquely germane to particular vertical market applications, and, e.g., long-duration flights requiring RP handover. See R. Jay Shively, NASA Ames Research Center, et al., Human Performance Considerations for Remotely Piloted Aircraft Systems (RPAS), Report of the ICAO, Remotely Piloted Aircraft Systems Panel (RPASP), Second Mtg. (RPASP/2), Montréal (June 15-19, 2015), § 1.2, p. 7, https://ntrs.nasa.gov/archive/nasa/casi.ntrs.nasa.gov/20150011435.pdf (“While more [frequently applicable to] larger UAS, '[h]andovers can be a time of particular risk, associated with system mode errors and coordination breakdowns'."); Unmanned Systems Canada, Small RPAS Best Practices for BVLOS, v1.1, § 3.2.1, p. 16 (Oct. 2016), https://www.unmannedsystems.ca/download/usc-small-rpas-bvlosbest-practices/ ("During pilot handovers, there shall be a means to synchronize and positively transfer control between control stations and/or pilots.").

${ }^{118}$ See 14 C.F.R. $\S 107.49$ (a)(1), Preflight familiarization, inspection, and actions for aircraft operation (re local weather conditions); 14 C.F.R. § 91.103, Preflight action (requirement to "become familiar with all available information"); NOAA, Aviation Weather Center, https://www.aviationweather.gov/; FAA, Advisory Circular, AC 00-6B, Subj. Aviation Weather (Aug. 23, 2016), https://www.faa.gov/documentLibrary/media/Advisory Circular/AC 00-6B.pdf; FAA, Order 8900.1 CHG 447, vol. 3, ch. 26, Safety Assurance System: Regulatory Sources of Aviation Weather Information and Aviation Weather Information Systems (Mar. 2, 2016), http://fsims.faa.gov/wdocs/8900.1/v03\%20tech\%20admin/chapter\%2026/03 026 002.pdf; ICAO, Manual on RPAS, § 9.4.1 ("pilot should review all available meteorological information pertaining to the operation"). Cf., 14 C.F.R. § 135.213, Weather reports and forecasts (requirement to use "a weather report or forecast ... of the U.S. National Weather Service, a source approved by the U.S. National Weather Service, or a source approved by the Administrator" except for VFR operations if such report is unavailable).

119 "Water" may confuse optical or sonar-based stabilization sensors; and "urban areas" are recognized for pockets of poor GPS reception. See UASPC, n.62 (regarding "urban canyons").

${ }^{120}$ See 14 C.F.R. $\S 107.15$, Condition for safe operation, 14 C.F.R. $\S 107.49$, Preflight familiarization, inspection, and actions for aircraft operation, FAA, Advisory Circular, AC 107-2, Subj. Small Unmanned 


\section{UAS Pilots Code -Annotated Version 1.0}

Aircraft Systems (sUAS), App. C. sUAS Maintenance and Inspection Best Practices (June 21, 2016), https://www.faa.gov/uas/media/AC 107-2 AFS-1 Signed.pdf; and ICAO, Manual on RPAS, § 6.8.1 ("operator responsible for ensuring that all components of the RPAS are maintained in an airworthy condition"). See "Airworthy" Definition, UASPC, n.229.

${ }^{121}$ See, e.g., Aviation Safety Reporting System (ASRS), Report Sets/Unmanned Aerial Vehicle, https://asrs.arc.nasa.gov/search/reportsets.html (most recent 50 reports, updated semi-annually). See UASPC n.85 (on ASRS).

${ }^{122}$ FAA, Remote Pilot - Small Unmanned Aircraft Systems, Airman Certification Standards, FAA-S-ACS-10 (July 2016), https://www.faa.gov/training testing/testing/acs/media/uas acs.pdf.

${ }^{123}$ See Academy of Model Aeronautics, Charter Club Search, http://www.modelaircraft.org/clubsearch.aspx (providing a query search by zip code or city/state of available flying sites; and UASPC, §IV, addressing security and privacy issues.

${ }^{124}$ Any simulated mission training for any size and type of UAS is valuable to rehearse and revise procedures and emergency situations. See David C. Ison, et al., Designing Simulation to Meet UAS Training Needs, Int'I Conf. on Human Interface and the Mgt. of Info., Springer-Berlin Heidelberg (2013), https://link.springer.com/chapter/10.1007/978-3-642-39215-3 67 (in part, describing best practices for simulation-based training); and ICAO, Manual on RPAS, § 8.4.38 (applicants for RPAS "license should have appropriate experience flying an RPA in actual or simulated flight") (emphasis added).

${ }^{125}$ FAA, Aviation Instructor's Handbook, FAA-H-8083-9A, p. 2-23, https://www.faa.gov/regulations policies/handbooks manuals/aviation/aviation instructors handbook/m edia/FAA-H-8083-9A.pdf ("The student profits by having someone watch the performance and provide constructive criticism to help eliminate errors .... Allowing the student to critique his or her performance enhances student-centered learning.").

${ }^{126}$ See "Additional Resources" (providing information that includes UAS education).

${ }^{127}$ WINGS offers many sUAS-relevant safety courses as well as training material on diverse general aeronautical knowledge subjects applicable to UAS operations. See, e.g., FAA, FAASafety Document Resources, https://www.faasafety.gov/search/default.aspx?keywords=unmanned\&submit=Search. Although sUAS pilots do not require flight reviews, and therefore WINGS credits do not provide such incentives, the FAA offers UAS-centric WINGS training courses. Accordingly, the SRP adopts "Attend" rather than "Participate". See Ryan J. Wallace, EdD, Position Paper: Safety Culture: Why the FAA Should Consider Adapting the WINGS Pilot Proficiency Program as a Method of Remote Pilot Recertification, vol. 3(3), IJAAA (Aug. 2016), available at http://commons.erau.edu/cgi/viewcontent.cgi?article=1138\&context=ijaaa.

${ }^{128}$ Such organizations include UAS industry associations, advocacy, and user groups.

${ }^{129}$ Such publications may include but are not limited to: Advisory Circulars, Chart Supplements U.S., and the extensive guidance on UAS provided at FAA, Unmanned Aircraft Systems (UAS) Regulations \& Policies, https://www.faa.gov/uas/resources/uas regulations policy/.

${ }^{130}$ New UAS models may have different flight or control characteristics and configurations, and automation features that, without familiarization, could adversely affect the safety of flight. See also UASPC, n.111 (differences in aircraft status lighting), and UASPC, n.133 (automation and autonomy).

${ }^{131}$ Such training may also enhance discipline, and improved situational awareness. See, e.g., ACl, Flight Safety in the Drone Age, http://www.secureav.com/Drone-Listings-Page.html (describing challenges and 


\section{UAS Pilots Code -Annotated Version 1.0}

suggested flight safety responses by manned aircraft pilots operating in the presence of UAS). See, e.g., PrecisionHawk, PrecisionHawk Research Outlines Operations Risk for Drones Flying Beyond Line of Sight (Dec. 13, 2016), http://www.precisionhawk.com/media/topic/precisionhawk-releases-faa-pathfinderphase-2-data-at-uas-taac/ (In FAA Pathfinder Program research, manned aircraft pilots could typically detect intruding aircraft at a distance of 2-3 nautical miles compared to 1-2 nautical miles for non-pilots.).

${ }^{132}$ See generally Douglas M. Marshall, et al., Introduction to Unmanned Aircraft Systems, 2nd Ed., ch.12, Communications Systems, pp. 333, et seq., CRC Press (2016), available at http://tinyurl.com/v7h86spc (addressing C2); and UASPC, n.134.

${ }^{133}$ Autonomous Aircraft/Operations - See ICAO, Unmanned Aircraft Systems (UAS), Cir 328 AN/190 (2011), https://www.icao.int/Meetings/UAS/Documents/Circular\%20328 en.pdf (defining "autonomous aircraft" as: "[a]n unmanned aircraft that does not allow pilot intervention in the management of the flight."); ICAO, Working Paper, Remotely Piloted Aircraft Systems Panel (RPASP), Autonomy and Automation (Mar. 13-17, 2017), available at https://ntrs.nasa.gov/archive/nasa/casi.ntrs.nasa.gov/20170002271.pdf (considering pilot "in," "on" and "out of the loop"). Cf., FAA, Advisory Circular, AC 107-2, Subj. Small Unmanned Aircraft Systems, § 5.2.3, Autonomous Operations (June 21, 2016), https://www.faa.gov/uas/media/AC 107-2 AFS1 Signed.pdf ("An autonomous operation is generally considered an operation in which the remote pilot inputs a flight plan into the CS, which sends it to the autopilot onboard the small UA. During automated flight, flight control inputs are made by components onboard the aircraft, not from a CS."); Kristine M. Kiernan, PhD, Human factors considerations in autonomous lethal unmanned aerial systems, Abstract, A3IRCON (2015), available at https://commons.erau.edu/aircon/2015/Friday/22/. See generally Am. Institute of Aeronautics and Astronautics (AIAA) Intelligent Systems Tech Comm. (ISTC), Roadmap for Intelligent Systems in Aerospace (June 6, 2016), https://info.aiaa.org/tac/isg/ISTC/Shared\%20Documents/Roadmap\%20for\%20Intelligent\%20Systems\%20in \%20Aerospace/AIAA Roadmap for Intelligent Systems-v1.0 14Jun2016.pdf; NIST, Autonomy Levels for Unmanned Systems, https://www.nist.gov/el/intelligent-systems-division-73500/cognition-andcollaboration-systems/autonomy-levels-unmanned (portal for framework, terminology, publications); and Andrew Lasher, et al., MITRE, A Framework for Discussing Trust in Increasingly Autonomous Systems (June 2017), https://www.mitre.org/sites/default/files/publications/17-2432-framework-discussing-trustincreasingly-autonomous-systems.pdf (trustworthiness as the "real competency of a system"). Also, consider the effects of autonomous operations on complacency. John Markoff, Robot Cars Can't Count on Us in an Emergency, NYT (June 7, 2017), https://www.nytimes.com/2017/06/07/technology/google-selfdriving-cars-handoff-problem.html?smprod=nytcore-ipad\&smid=nytcore-ipad-share (human as a reliable backup a "fallacy").

Autonomous Systems \& Ethical Considerations - Autonomous systems increasingly rely on artificial intelligence (Al) or machine learning to give the appearance of intelligence. The algorithms underlying these systems, and the machines' decisions, are generally opaque to their users-yet the algorithms may raise ethical issues. See U.S. Dep't of Transp. \& Nat'I Highway Traffic Safety Admin., Federal Automated Vehicles Policy: Accelerating the next Revolution in Roadway Safety, p. 26 (2016),

https://www.transportation.gov/sites/dot.gov/files/docs/AV\%20policy\%20guidance\%20PDF.pdf ("Even in instances in which no explicit ethical rule or preference is intended, the programming of a [highly 


\section{UAS Pilots Code -Annotated Version 1.0}

automated vehicle] may establish an implicit or inherent decision rule with significant ethical consequences."); Markus Christen, et al., An Evaluation Schema for the Ethical Use of Autonomous Robotic Systems in Security Applications (Oct. 2017), UZH Digital Society Initiative, U. of Zurich, available at https://ssrn.com/abstract=3063617 (framework for and survey of ethical issues affecting autonomous UAS); NASA Selects Three Aeronautics Teams to Explore an Autonomous Future, UAS Vision (June 8, 2017), http://www.uasvision.com/2017/06/08/nasa-selects-three-aeronautics-teams-to-explore-an-autonomousfuture/; IEEE Standards Ass'n, The IEEE Global initiative for Ethical Considerations in Artificial Intelligence and Autonomous Systems, https://standards.ieee.org/develop/indconn/ec/autonomous systems.html; and United Nations Office in Geneva (UNOG), Group of Governmental Experts on Lethal Autonomous Weapons Systems, https://www.unog.ch/80256EE600585943/(httpPages)/8FA3C2562A60FF81C1257CE600393DF6?OpenDocu ment (materials addressing ethical considerations).

${ }^{134}$ Additional issues deserving of attention in training may include: electrical load management, heat thresholds, controllers, battery performance, RF interference, frequency spectrum challenges, and satellite latency. See generally FAA, Remote Pilot - Small Unmanned Aircraft Systems Study Guide, FAA-G-8082-22 (Aug. 2016), https://www.faa.gov/regulations_policies/handbooks manuals/aviation/media/remote pilot study guide. pdf, and JARUS, RPAS "Required C2 Performance" (RLP) concept, Doc. JAR_DEL_WG5_D.04, § 3.3.1, p. 22, http://jarus-rpas.org/sites/jarus-rpas.org/files/storage/Library-

Documents/iar doc $13 \mathrm{rpl}$ concept upgraded.pdf ("[T]he RPAS C2 function is dependent on the C2 system design, including but not limited to transmission protocols, automation levels, message error correction, performance of the flight and ground computers and message criticality prioritization." And, § 2.1.2, "Poor performance in the communications between the RPIL [Remote Pilot] and the RPA would for example lead to increased separation and reduced airspace capacity to maintain the current safety levels."). Thus, training and understanding their limitations is essential.

${ }^{135}$ See, e.g., Vampire ${ }^{\circledR}$ for Unmanned Air Systems, available at https://www.youtube.com/watch?v=tzEk1kOuvMk (simulation and related UAS training video); and UASPC, n.124 (addressing simulation).

${ }^{136}$ See 14 C.F.R. § 107.49(c) ("Ensure that all control links between ground control station and the [sUAS] are working properly."). Consider that some UAS do communicate cautions and warnings to ground stations. Be attentive to, and proactively and appropriately responsive to such cautions and warnings. See also ICAO, Manual on RPAS, § 13.4.3 ("All warnings and alerts currently provided for manned aircraft should be considered for inclusion in the RPS.").

Implement procedures for real-time monitoring of the control link, and awareness of its quality-and minimum acceptable quality. Many UAS control stations display (at least) signal strength graphicallytypically as the corresponding number of "bars". See Kerry Williamson, et al., FAA Interim Technical Report, Radio Line of Sight (RLOS) Coverage Field Tests with a 900 MHz Antenna (100mW), p. 23 (Feb. 2, 2017), http://www.assureuas.org/projects/deliverables/a2/FAA Progress Deliverable RLOS Testing.pdf (manufacturer radio specifications under ideal conditions may overestimate the RLOS link distance in realworld conditions; significant link margin ( $15 \mathrm{dBm}$ or greater) as a closer estimate of a "safe" RLOS coverage area due to complexity / variability of RF signal attenuation at low AGLs; variability of battery life a factor; maintenance critical). Some experienced UAS operators propose a rule-of-thumb for signal strength: links should be capable of a reliable signal over a minimum range equivalent to twice the visible distance of the aircraft for VLOS operation. 


\section{UAS Pilots Code -Annotated Version 1.0}

${ }^{137}$ Both UAS and manned aircraft pilots take responsibility for safety of the NAS.

Drafting Considerations: The Drafting Team sought to avoid the principle from being misinterpreted to mean that if the UAS operator observes anything suspicious or illegal via the UAS sensors, the UAS operator should report it. That is, the provision and associated SRPs do not imply "deputizing" UAS operators to report illegal activities based on their UAS feed monitoring or otherwise impinging on privacy rights. Instead, the intent is to cover activities that tend to threaten aviation safety. For example, if a UAS pilot becomes aware of someone pointing lasers at aircraft, or maliciously using an aviation transceiver, or other activities that may compromise the safety of the NAS, it should be reported immediately.

${ }^{138}$ The UASPC embraces immutable elements of the proposed FAA Reauthorization Act of 2017, particularly:

It is the policy of the United States that the operation of any unmanned aircraft or unmanned aircraft system shall be carried out in a manner that respects and protects personal privacy consistent with the United States Constitution and Federal, State, and local law.

FAA Reauthorization Act of 2017 (Senate Bill), Title II, Part I-Privacy and Transparency (§ 2101), available at https://www.commerce.senate.gov/public/ cache/files/1e5fb629-5fde-49da-9e09e7bfce702c99/FDA7993A27A984DBEC38510A5DA60E58.s.-1405---faa-bill.pdf. See NTIA, Voluntary Best Practices for UAS Privacy, Transparency, and Accountability, § 4(a) (May 18, 2016), https://www.ntia.doc.gov/other-publication/2016/multistakeholder-process-unmanned-aircraft-systems (regarding "Secure Covered Data"):

UAS operators should take measures to manage security risks of covered data by implementing a program that contains reasonable administrative, technical, and physical safeguards appropriate to the operator's size and complexity, the nature and scope of its activities, and the sensitivity of the covered data.

Examples of appropriate administrative, technical, and physical safeguards include those described in guidance from the Federal Trade Commission, the National Institute of Standards and Technology (NIST) Cybersecurity Framework, https://www.nist.gov/cyberframework, and the International Organization for Standardization's 27001 standard for information security management, https://www.iso.org/isoiec-27001-information-security.html.

For example, UAS operators engaging in commercial activity should consider taking the following actions to secure covered data:

- Having a written security policy with respect to the collection, use, storage, and dissemination of covered data appropriate to the size and complexity of the operator and the sensitivity of the data collected and retained.

- Making a reasonable effort to regularly monitor systems for breach and data security risks.

- Making a reasonable effort to provide security training to employees with access to covered data.

- Making a reasonable effort to permit only authorized individuals to access covered data. 


\section{UAS Pilots Code -Annotated Version 1.0}

Internet-of-Things - sUAS can also be viewed as a specie of the Internet of things (IoT)-with corresponding security and privacy implications - and that its "evolution will be constrained until safety and security requirements can be proven in flight operations." WIND, The Internet of Things in Commercial Aviation, White Paper, p. 6 (2015), http://events.windriver.com/wrcd01/wrcm/2016/08/WP-loT-the-internet-ofthings-for-commercial-aviation.pdf. See FTC, Internet of Things: Privacy \& Security in a Connected World, Staff Report, pp. 27-46 (Jan. 27, 2015), https://www.ftc.gov/system/files/documents/reports/federaltrade-commission-staff-report-november-2013-workshop-entitled-internet-things-privacy/150127iotrpt.pdf (presenting FTC Comm'n Staff's views and recommendations for loT data security and data minimization/privacy best practices); NIST, Cyber-Physical Systems, https://www.nist.gov/el/cyber-physicalsystems (addressing cyber-physical systems); and Tim Polk, et al., Mitigating loT-Based Distributed Denial of Service (DDOS, ) NIST (Nov. 2017), https://nccoe.nist.gov/sites/default/files/library/project-descriptions/iotddos-project-description-final.pdf.

As a practical matter, information security of UAS as IoT endpoints is largely the realm of equipment manufacturers and possibly network operators as more begin to use mobile networks for C2 and/or payload communications. From the remote pilot's perspective, any kind of attack that renders the UAV unresponsive is the same as a lost link condition. Nonetheless, UAS pilots and operators should become aware of the attendant security threats to inform their overall flight risk decisions and mitigation strategies.

${ }^{139}$ Special Use Airspace (SUA) is a subset of Special Activity Airspace (SAA), defined as "[a]ny airspace with defined dimensions within the National Airspace System wherein limitations may be imposed upon aircraft operations. ..." Cf., SUA is defined as "[a]irspace of defined dimensions identified by an area on the surface of the earth wherein activities must be confined because of their nature and/or wherein limitations may be imposed upon aircraft operations that are not a part of those activities ..." FAA, Pilot/Controller Glossary (Aug. 25, 2011), http://tfmlearning.faa.gov/Publications/atpubs/PCG/S.HTM (defining SUA).

140 ICAO, Manual on RPAS, § 9.11 .1 ("Security is a vital issue for [RPAS]").

${ }^{141}$ See, e.g., Gov't of India, Office of the Dir. Gen. of Civil Avi., Civil Avi. Regs., § 3, Series X, Part 1, Sub. 8.1, http://www.dgca.nic.in/misc/draft\%20cars/CAR\%20-\%20UAS\%20(Draft Nov2017).pdf ("The owner/operator shall be responsible for the safe custody, security and access control of the RPAS.").

${ }^{142}$ The permissibility of flight over property-whether public or private-remains a contentious and developing issue. See, e.g., Boggs. v. Merideth, Case 3:16-CV-00006-DJH (W. Dist. KY Ct, 2016), available at https://assets.documentcloud.org/documents/2674191/001-Complaint-for-Declaratory-Judgment-and.pdf (supporting the practice of seeking permission); U.S. v. Causby, 328 U.S. 256, 264 (1946), available at https://supreme.justia.com/cases/federal/us/328/256/case.html (property owner's right to control "at least as much of the space above the ground as he can occupy or use in connection with the land.").

${ }^{143}$ There is an impetus to restrict UAS pilot access to certain safety and security features, such as those designed to limit unmanned aircraft to within line of sight and "return to home" functions. See UAS-ID ARC, ARC Recommendations, Final Report, p. 3 (dated Sept. 30, 2017, released Dec. 19, 2017). Additionally, many sUAS make use of a smartphone or tablet device, certain settings of which may adversely affect flight operations. Pilots should consider disabling screen auto-lock, and setting the device to airplane mode to avoid receiving phone or text messages on the device, which may interrupt critical flight operations or impede C2. Consult your UAS user guide, operating handbook or manual for additional information.

${ }^{144}$ Some practical pilot actions may include, but are not limited to contacting and introducing yourself to nearby people to explain the intended mission, dressing professionally, carrying/wearing credentials, 


\section{UAS Pilots Code -Annotated Version 1.0}

posting signage near the intended mission, and presenting a postcard with the pilots (or, where applicable, operators) credentials and mission description.

Drafting Consideration: The Drafting Team sought to recommend practices that would not unreasonably constrain the legal rights and scope of legitimate UAS operations. "[A]voiding even the appearance of a security threat," although a subjective determination, is intended to yield the most prudent course of action.

${ }^{145}$ Counter-UAS - "The Small Unmanned Aircraft System (sUAS) is a disruptive commercial technology that poses a unique and currently undefined threat to U.S. national security. Although, as with any new technology, the parameters of the capabilities regarding military uses have yet to be fully discovered, recent events highlight the potential danger. . . To effectively counter sUASs it will be necessary to refine and practice procedures and doctrine, while developing the capability to effectively detect, track, and positively identify the threat." Anthony Tingle \& David Tyree, The Rise of the Commercial Threat: Countering the Small Unmanned Aircraft System, JFQ 85 2nd Ed., pp. 30-31 (2nd Qtr 2017), available at http://ndupress.ndu.edu/Portals/68/Documents/ifq/ifq-85/ifq-85 30-35 Tingle-Tyree.pdf.

Perceived Threats Precipitating Shoot-downs - The perceived threats by the public extend from privacy (see below) to the existential, perhaps exacerbated by widespread media focus on weaponized UAS. See, e.g., U.S. Dep't of Homeland Security (DHS), National Terrorism Advisory System Bulletin (Nov. 9, 2017), https://www.dhs.gov/ntas/advisory/ntas 1711090001 ("Some terrorist groups overseas are using battlefield experiences to pursue new technologies and tactics, such as unmanned aerial systems and chemical agents that could be used outside the conflict zones.").

Perceived privacy threats and vigilante shoot-downs are increasing, as reflected in case law and the media. See, e.g., Boggs v. Merideth, No. 3:2016cv00006 - Doc. 20 (W.D. Ky. 2017), available at https://law.justia.com/cases/federal/district-courts/kentucky/kywdce/3:2016cv00006/96944/20/; WDRB, Judge dismisses charges for man who shot down drone (Oct. 26, 2015), http://www.wdrb.com/story/30354128/judge-dismisses-charges-for-man-who-shot-down-drone; Julie Carey, et al., Virginia Woman Says She Shot Down Drone Near Actor Robert Duvall's Home, NBC Wash., http://www.nbcwashington.com/news/local/Virginia-Woman-Shoots-Down-Drone-Near-Actor-RobertDuvalls-Home-391423411.html; and Cyrus Farivar, Man takes drone out for a sunset flight, drone gets shot down, ARS Technica (Apr. 25, 2017), https://arstechnica.com/tech-policy/2017/04/man-takes-drone-outfor-a-sunset-flight-drone-gets-shot-down/; http://www.popsci.com/it-is-federal-crime-to-shoot-downdrone-says-faa.

${ }^{146}$ UAS Registration - Registration is required in the United States for all commercial and recreational UAS greater than $.55 \mathrm{lbs}$. See FAA, Getting Started, https://www.faa.gov/uas/getting started/; 14 C.F.R. $\S$ 107.13, Registration (requiring compliance with § 91.203(a)(2)); and the Nat'l Defense Auth. Act for Fiscal Year 2018, § 1092(s) (enacted Dec. 12, 2017), restoring a UAS registration requirement for model aircraft:

(d) RESTORATION OF RULES FOR REGISTRATION AND MARKING OF UNMANNED AIRCRAFT.-The rules adopted by the Administrator of the Federal Aviation Administration in the matter of registration and marking requirements for small unmanned aircraft (FAA-2015-7396; published on December 16, 2015) that were vacated by the United States Court of Appeals for the District of Columbia Circuit in Taylor v.

Huerta (No. 15-1495), [dec. May 19, 2017, available at https://scholar.google.com/scholar_case?case=15932350315687343901\&hl=en\&as sdt= 2006] shall be restored to effect on the date of enactment of this Act. 


\section{UAS Pilots Code -Annotated Version 1.0}

http://docs.house.gov/billsthisweek/20171113/HRPT-115-HR2810.pdf. Registration for small UAS platforms can be accomplished online via FAADroneZone, https://faadronezone.faa.gov/\#/. See 14 C.F.R. Parts 47 and 48 (prescribing general aircraft and sUAS registration requirements). As of January 2018, "more than a million UAS have been registered with the FAA." Elaine Chow, US Secy. of Transp., Presentation at CES, Las Vegas (Jan. 11, 2018). Cf., JARUS, JARUS OPS, Recommendations for Unmanned Aircraft Systems (UAS), Operations for Category A and B, JAR_DEL_WG2_D.03, Art. 5-Registrations and identification, g 1 (Oct. 7, 2017), available at http://apant.pt/wpcontent/uploads/2017/10/jar_doc 14 draft d3 ops cat_a extcons 251017.pdf ("The operator of an UA. .. shall register in the manner established by the NAA ...").

The following highlights a few proposals by industry, government, and NGOs that may contribute to effective UAS registration infrastructure and practices, and also interface and support identification, authorization and other security services addressed in UASPC, nn.146-7. See UAS-ID ARC Final Report, https://www.faa.gov/regulations policies/rulemaking/committees/documents/media/UAS\%20ID\%20ARC\% 20Final\%20Report\%20with\%20Appendices.pdf.

Global Registry - ICAO has proposed a registry concept for drones to facilitate state interoperability for international drone use; "provide a plug-and-play option for States without an existing drone registry, or enable API integration with a State's existing drone registry." Stephen Creamer, Dir., Air Nav. Bureau, ICAO, Presentation at DRONE ENABLE 2017 (Sept. 22, 2017), https://www.icao.int/Meetings/UAS2017/Documents/Drone\%20Registry\%20Presentation\%20Dro ne\%20Enable FINAL.pdf (also noting ICAO's experience operating the Aircraft Registration System integrating with the Int'l Registry of Commercial Aircraft). See ICAO, Aircraft Nationality And Registration Marks, Annex 7 (4th ed. 1981), available at https://www.highergraphics.com/hg docs/ICAO\%20Annex\%207.pdf; and Int'I Registry of Mobile Assets, https://www.internationalregistry.aero/ir-web/ (global registry example for interests in aircraft assets).

Domain Name System (DNS) - The Domain Name System (DNS), the internet's hierarchical, decentralized naming system may in part enable UAS registration (in coordination with the ICAO registry initiative), recognizing the DNS' extensible, scalable, and ubiquitous nature. See Hillman Mitchell Pres., Critical Infrastructure Cyber Security Consultants, Presentation at ICAO, DRONE ENABLE 2017, Cyber Threats: Initiatives to assist industry in building resilient system (Sept. 22, 2017), https://www.youtube.com/watch?v=TJJJbaqsPyc ("We think the addressable entities within aviation in the future need to actually be scaled . . . up to 10 billion entities." emphasis added. Identifying namespace conventions and schemes are essential to a UAS ecosystem.). See also ICANN, Global UAS Registry initiative, https://www.icann.org/resources/pages/registries/registries-en; and loT, Air: The Next Frontier for the IoT (Oct. 7, 2016), available at https://ipv6. net/news/air-the-next-frontier-for-the-iot/; and UASPC, n.138 (regarding loT).

Legacy Services - Various traditional manned aviation service providers have proposed using aviation-centric databases and related capabilities to support UAS registration.

${ }^{147}$ Identification, Tracking, and Authorization - The remote identification, tracking, and authorization (for specific privileges such as entry to particular airspace) requires use of diverse technologies. The choice of such technologies may impact flight safety, cost, operational efficiency/effectiveness/ease-of-use, interoperability, mission and equipment, national security, public safety, and technology 


\section{UAS Pilots Code -Annotated Version 1.0}

availability/readiness. Pilots and operators must have at least a basic understand of the applicable technologies and their associated limitations, recognizing that each may affect flight safety, operations, and efficiency.

The FAA is considering new identification and tracking rules that will be informed by the Final Report of the Unmanned Aircraft Systems (UAS) Identification (ID) and Tracking Aviation Rulemaking Committee (ARC) (“UAS-ID ARC"), ARC Recommendations, Final Report (dated Sept. 30, 2017, released Dec. 19, 2017) (“UASID Final Report"),

https://www.faa.gov/regulations policies/rulemaking/committees/documents/media/UAS\%20ID\%20ARC\% 20Final\%20Report\%20with\%20Appendices.pdf. Key recommendations include: "two methods for UAS to provide remote ID and tracking information -- (1) direct broadcast (locally, e.g., ADS-B, Low-Power Direct $\mathrm{RF}$, Unlicensed Integrated C2, and Visual Light Encoding); and (2) network publishing (e.g., Networked Cellular, Satellite, and SW [software]-based Flight Notification w/ Telemetry) to an FAA-approved internetbased database," UAS-ID Final Report, § 6.2, p. 33; "a tiered approach" to direct broadcast and network publishing requirements, UAS-ID Final Report, $\S 6.3$, p. 35; and minimum data requirements, UAS-ID Final Report, $\S 6.5$, p. 39. The ARC's recommendations did not include a third option (or means) that would have provided for proven, developed, or designed systems fitting safely into the existing or a future version of an ATM framework.

There is an expectation for robust interoperability of an ID and tracking system with ATC. UAS-ID Final Report, § 6.6, p. 44. And yet, there may be limitations on interoperability with ATC that may not fit the autonomous UTM framework. To this extent, perhaps UAS flight operations should remain entirely invisible to ATC.

A schema to manage personally identifiable information is also proposed, UAS-ID Final Report, § 7.1, p. 46. And, it was recognized that "it is important to protect the privacy of UAS owners and operators," UAS-ID Final Report, § 6.5.3, p. 41; and recommending three levels of data access, UAS-ID Final Report, § 7.1.

The UAS-ID Final Report states that the committee failed to reach consensus on certain ID and tracking threshold requirements, such as exemptions for model aircraft users. UAS-ID Final Report, § 5.2.3, pp. 2930. See, e.g., The Comm. Drone Alliance, The Comm. Drone Alliance Dissents from the Key Recommendations of the UAS ID and Tracking Aviation Rulemaking Committee (Dec. 19, 2017), https://www.commercialdronealliance.org/newsarchive/2017/12/19/the-commercial-drone-alliancedissents-from-the-key-recommendations-of-the-uas-id-and-tracking-aviation-rulemaking-committee (in part, urging a weight threshold, "accommodating technological development", and eliminating the model aircraft exclusion).

One "direct broadcast (locally)" or non-network, localized approach is described in DJI, "What's In a Name?" A Call for a Balanced Remote Identification Approach, A DJI Technology Whitepaper (Mar. 22, 2017), available at http://tinyurl.com/yaqdvth9; and Walter Stockwell, PhD, Dir. Tech. Stds., DJI, Presentation at ICAO, DRONE ENABLE 2017, Montréal (Sept. 22, 2017) (utilizing existing UAS radios, embedding ID data in the C2 link, thereby facilitating scaling \& int'I compliance, without an internet connection: AeroScope https://www.dji.com/newsroom/news/understanding-dji-aeroscope-solution).

Another "direct broadcast" technology facilitating network publishing is Automatic Dependent Surveillance Broadcast (ADS-B) that uses GPS signals and aircraft avionics to transmit aircraft location to ATC and aircraft receivers to support aircraft separation and traffic flow mgt. FAA, Fact Sheet-Automatic Dependent Surveillance-Broadcast (ADS-B), https://www.faa.gov/news/fact sheets/news story.cfm?newsld=7131; and FAA, ORDER 8200.85, Subj: Automatic Dependent Surveillance-Broadcast (ADS-B) Flight Inspection (Oct. 19, 


\section{UAS Pilots Code -Annotated Version 1.0}

2014), https://www.faa.gov/documentLibrary/media/Order/8200 45 ADS-B.pdf. ADS-B transceivers increasingly provide cost, form-factor, etc. and ID message protocol extension can enable sUAS - still, its practical implementation will require low power ADS-B approval. See uAvionix, Concept for Remote Identification (Mar. 22, 2017), http://www.uavionix.com/downloads/whitepapers/uavionix-remoteidentification-white-paper.pdf; and R. Michael Guterres, et al., Small UAS Automatic Dependent Surveillance-Broadcast (ADS-B) Like Surveillance Concept of Operations: A Path Forward for Small UAS Operations Surveillance (2017), https://www.mitre.org/sites/default/files/publications/16-4497-AlAA-2017ADS-B.pdf. ADS-B transmission power and traffic density parameters can be balanced to provide safety/utility sUAS operation). See generally RTCA, DO-317B, Minimum Operational Performance Standards (MOPS) for Aircraft Surveillance Applications (ASA) System (June 17, 2014), available (fee) at www.rtca.org.

The UAS-ID Final Report's discussion of "Network publishing (to an FAA-approved internet-based database)", and, among other recommendations, urges that the "FAA should leverage internet-based database infrastructure that exists or that is already under development and that could integrate with the FAA's future UTM roadmap... [and] could result in the rapid deployment of internet-based database publishing capability by leveraging technologies that already exist." Different or competing technologies could coexist so long as they could be published "to an API" and satisfy "the internet-based database publishing requirement." UAS-ID ARC Final Report, § 6.2.2, p. 34.

Public Key Infrastructure (PKI) - PKI is an extensible/scalable technology that can support transportable identities and provide diverse security services by deploying trusted digital certificates. Its use for UAS registration, authentication, and privacy has been proposed. See, e.g., FAA, Rob Segers, Info. Sec. Sys. Engr, FAA, NextGen Security Branch, Presentation at ICAO, Second Global Air Nav. Industry Symposium (GANIS/2), Cyber Threats: Initiatives to assist industry in building resilient system (Dec. 13, 2017), https://www.youtube.com/watch?feature=youtu.be\&v=TJJJbaqsPyc\&app=desktop (proposing a PKI-based ICAO "Trust" Bridge); Patrick Mana, EUROCONTROL, SWIM Common PKI and policies \& procedures for establishing a Trust Framework (Nov. 29, 2017), https://www.sesardeploymentmanager.eu/wpcontent/uploads/2017/12/3.-Common-PKI-INEA-2017-Kick-off.ppt; and Jared Ablon, Presentation at ICAO, DRONE ENABLE 2017, Montréal (Sept. 22, 2017) ("We believe the digital identity should be in the form of a digital certificate ... based on public key cryptography.").

The UAS-ID ARC Final Report, § 5.1.2.3, p. 18, sought a technology security solution providing three attributes: "Spoofing Security", "Tamper Proof", and "Tracking Verification". PKI can provide such services. Digital certificates are broadcast-method independent, can support diverse identity and privacy policy requirements, and be embedded in diverse schemes, architectures, and registries. See generally Michael S. Baum, Federal Certification Authority Liability and Policy, MITRE Corp. under Contract \#50SBN1C6732 (1992), available at https://www.dropbox.com/s/rvgwyev058gy2r9/Fed-Cert-Auth.pdf?dl=0; and Warwick Ford \& Michael S. Baum, Secure Electronic Commerce, Building the Infrastructure for Digital Signatures and Encryption, 2nd Ed., Prentice Hall (2000).

${ }^{148}$ See 49 C.F.R. § 171.8, available at https://www.gpo.gov/fdsys/pkg/CFR-2011-title49-vol2/pdf/CFR-2011title49-vol2-sec171-8.pdf (defining hazardous material as "a substance or material [including] hazardous substances, hazardous wastes, marine pollutants, elevated temperature materials, materials designated as hazardous in the Hazardous Materials Table (see 49 CFR 172.101) ..."); and 14 C.F.R. § 107.36, Carriage of hazardous materials (prohibiting the carriage of certain agricultural materials, such as pesticides or other products by small unmanned aircraft systems). This provision is not eligible for waiver under 14 C.F.R. $\S$ 107.205, List of regulations subject to waiver. 49 C.F.R. § 171.8, Hazardous material means a substance or material that the Secretary of Transportation has determined is capable of posing an unreasonable risk to 


\section{UAS Pilots Code -Annotated Version 1.0}

health, safety, and property when transported in commerce, and has designated as hazardous under section 5103 of Federal hazardous materials transportation law (49 U.S.C. § 5103).

${ }^{149}$ See, e.g., ASTM Int'I, F3201, Standard Practice for Ensuring Dependability of Software Used in Unmanned Aircraft Systems (UAS), available (fee) at https://www.astm.org/COMMITTEE/F38.htm; RTCA SC-228, Minimum Operational Performance Standards for Unmanned Aircraft Systems, available (fee) at www.rtca.org; and JARUS, RPAS "Required C2 Performance" (RLP) concept, Doc JAR_DEL_WG5_D.04, § 2.1.2 (Jan. 5, 2016), http://jarus-rpas.org/sites/jarus-rpas.org/files/storage/Library-

Documents/jar doc $13 \mathrm{rpl}$ concept upgraded.pdf ("Poor performance in the communications between the RPIL [Remote Pilot not co-located] and the RPA would for example lead to increased separation and reduced airspace capacity to maintain the current safety levels."; and presenting possible safety requirements, including time stamping. Table B-4 Safety reqs., pp. 45-46). See also Richard M. Lusk, et al., An Early Survey of Best Practices for the Use of Small Unmanned Aerial Systems by the Electric Utility Industry, § 4.3.5 (asserting power line inspection industry best practices to "Encrypt Aircraft Control Signal Frequencies" and "Encrypt Datalink Frequencies"); and UASPC, n.147 (introducing PKI).

${ }^{150}$ Such requirements may derive from, among other sources, UAS operator / enterprise-client contract, regulation, standards, and industry best practices. See ICAO, Manual on RPAS, § 6.4.7 (“When contracting or purchasing service as part of its activity ... ensure that such services or products conform to the applicable requirements."). Security assurances extend to safety-critical service providers. See JARUS, JARUS OPS, Recommendations for Unmanned Aircraft Systems (UAS), Operations for Category A and B,

JAR_DEL_WG2_D.03, Art. 10.-Safety-critical services, 91 (Oct. 7, 2017), available at http://apant.pt/wpcontent/uploads/2017/10/jar doc 14 draft d3 ops cat a extcons 251017.pd ("The provider of any safety-critical services is responsible for the accuracy and integrity of the provided information and data, and for the quality of the services.").

Responsibility for security extends to third party service providers used by UAS operators, UAS manufacturers and their supporting service and product providers, and regulators. Indeed, the responsibility for security is shared; and, it cannot be provided unilaterally by government. See generally NIST, Framework for Improving Critical Infrastructure Cybersecurity, Draft Ver. 2 (Dec. 5, 2017), https://www.nist.gov/cybersecurity-framework/cybersecurity-framework-draft-version-11, pursuant to Executive Order 13636, Improving Critical Infrastructure Cybersecurity (Feb. 12, 2013), http://www.whitehouse.gov/the-press-office/2013/02/12/executive-order-improving-criticalinfrastructure-cybersecurity (directing NIST to publish a baseline framework that "promot[es] safety, security, business confidentiality, privacy, and civil liberties . . . and implement risk-based standards."), updated by the Cybersecurity Enhancement Act of 2014 (CEA), 15 U.S.C. § 272(e)(1)(A)(i) (enacted Dec.18, 2014), available at https://www.congress.gov/bill/113th-congress/senate-bill/1353/text.

${ }^{151}$ See, e.g., 49 C.F.R. § 1552.23, Security awareness training programs, https://www.ecfr.gov/cgi-bin/textidx?SID=cac873cb4523ff550f4dec504af03818\&mc=true\&node=se49.9.1552 123\&rgn=div8 (flight school

security awareness training). Cf., 49 C.F.R. $§ 1542.113$, Airport tenant security programs,

https://www.ecfr.gov/cgi-bin/text-

idx?SID=98e5059218489fbbca1fa21fa6526d34\&mc=true\&tpl=/ecfrbrowse/Title49/49cfr1542 main 02.tpl; and NTIA, Voluntary Best Practices for UAS Privacy, Transparency, and Accountability, § 4 (“Mak[e] a reasonable effort to provide security training to employees with access to covered data.").

152 Public agencies, operators with a Certificate of Authorization or Special Government Interest Addendum, or private commercial operators may issue NOTAMs to advise pilots of their activities. For NOTAMS defining 


\section{UAS Pilots Code -Annotated Version 1.0}

UAS operating areas (UOAs), see www.1800wxbrief.com; and may also be referred to as "DROTAMS". See Gen. Aviation News (Mar. 21, 2016), https://generalaviationnews.com/2016/03/21/skyvector-adds-realismto-drone-movie-adds-drotams/ (introducing DROTAMs).

${ }^{153}$ See 14 C.F.R. $\S 107.47$, Flight restrictions in the proximity of certain areas designated by notice to airmen (requiring compliance with: 14 C.F.R. §§91.137 Temporary flight restrictions in the vicinity of disaster/hazard areas, 91.138 Temporary flight restrictions in national disaster areas in the State of Hawaii, 91.139 Emergency air traffic rules, 91.141 Flight restrictions in the proximity of the Presidential and other parties, 91.143 Flight limitation in the proximity of space flight operations, 91.144 Temporary restriction on flight operations during abnormally high barometric pressure conditions, and 91.145 Management of aircraft operations in the vicinity of aerial demonstrations and major sporting events); and UASPC, n.139 (addressing Special Activity Airspace).

${ }^{154}$ See 14 C.F.R. § 99.7, Special security instructions, available at https://www.gpo.gov/fdsys/pkg/CFR-2012title14-vol2/pdf/CFR-2012-title14-vol2-sec99-7.pdf ("Each person operating an aircraft in an ADIZ or Defense Area must, in addition to the applicable rules of this part, comply with special security instructions issued by the Administrator in the interest of national security ..."); FAA, Sporting Event TFR, FDC NOTAM 4/3621, available at https://www.faa.gov/uas/resources/uas regulations policy/media/Sports TFRUAS Handout.pdf (re stadiums; large crowds); FAA, FAA Restricts Drone Operations Over Certain Military Bases, https://www.faa.gov/news/updates/?newsld=87865); and Nat'l Interagency Fire Center, https://www.nifc.gov/drones/ (prohibition on public lands to "[r]esist or interfere with the efforts of firefighter(s) to extinguish a fire." 43 C.F.R. § 9212.1(f)). See generally, FAA, Airspace Restrictions, https://www.faa.gov/uas/where to fly/airspace restrictions/ (Special Flight Rules Areas); and FAA, UAS Data Delivery System, https://uas-faa.opendata.arcgis.com (providing graphical UAS data, including for security restrictions).

${ }^{155}$ Critical Infrastructure - See FAA Extension, Safety, and Security Act of 2016, §2209, available at https://www.congress.gov/114/plaws/publ190/PLAW-114pub/190.pdf (facilitating petitions for FAA "to prohibit or restrict the operation of an unmanned aircraft in close proximity to a fixed site facility" that includes "critical infrastructure"); DHS, Unmanned Aircraft System (UAS) - Critical Infrastructure, https://www.dhs.gov/uas-ci; https://www.dhs.gov/what-critical-infrastructure (addressing, in part, "Why is the Threat Important to Critical Infrastructure?"; asserting UAS threats "will continue to expand in nature and increase in volume in the coming years"; and recognizing that "UAS can often evade detection and create challenges for the critical infrastructure community"); and FAA Restricts Drone Operations Over DOE Facilities, https://www.faa.gov/news/updates/?newsld=89365. Threats extend beyond unmanned aircraft themselves to the broader computing base used to process, communicate, and store UAS-related data, including flight log, UA performance, and UA sensor data. Regarding threats to the computing base, see, e.g., DHS, DHS Statement on the Issuance of Binding Operational Directive 17-01 (Sept. 13, 2017), https://www.dhs.gov/news/2017/09/13/dhs-statement-issuance-binding-operational-directive-17-01 (prohibiting Kaspersky Lab products and services, citing risk of Russian government compromise to infosystems implicating U.S. national security). Regarding threats from UAS, see, e.g., Paul Mozur, Drone Maker D.J.I. May Be Sending Data to China, U.S. Officials Say, NYT (Nov. 29, 2017), available at tinyurl.com/y8rtdybe (asserting "commercial drones and software may be sending sensitive information about American infrastructure abroad [and explaining] how consumer technology companies have become increasingly central to debates about national security"); and Michael Pehel, DJ Responds to the Army Ban with No-Internet Mode, Interdrone (Aug. 15, 2017), available at http://tinyurl.com/ya9hendh (DJI creates "local data mode" to prevent connection and transfer of data.). 


\section{UAS Pilots Code -Annotated Version 1.0}

${ }^{156}$ Trespass to Land - "One is subject to liability to another for trespass, irrespective of whether he thereby causes harm to any legally protected interest of the other, if he intentionally (a) enters land in the possession of the other, or causes a thing or a third person to do so, or (b) remains on the land, or (c) fails to remove from the land a thing which he is under a duty to remove." Restatement (Third) of Torts $\S 158$ (2013).

Aerial Trespass - "Flight by an aircraft in the air space above the land of another is trespass if [the aircraft] enters the immediate reaches of the air space next to the land, and (1) [it] interferes substantially with the other's use and enjoyment of the land." Restatement (Second) of Torts $\S 159(2)$. Unlike in surface land cases where "two-dimensional surface boundary lines are usually perfectly clear ... . [t] the analysis is far less straightforward in the murky realm of aerial trespass because the upper boundaries of landowners' airspace rights are largely undefined ... [and] courts must engage in subjective and unpredictable inquiries into whether the alleged aerial intrusion penetrated the amorphous 'immediate reaches' of the plaintiff's airspace and whether such intrusion substantially interfered with the plaintiff's 'use' of her land." Troy A. Rule, Airspace in an Age of Drones, B.U. L. Rev. vol. 95, pp. 155, 170 (2015), http://www.bu.edu/bulawreview/files/2015/02/RULE.pdf; and Hillary B. Farber, Keep Out! The Efficacy of Trespass, Nuisance and Privacy Torts as Applied to Drones, 33 Ga. St. U. L. Rev. 359 (2017), available at https://papers.ssrn.com/sol3/papers.cfm?abstract_id=2852083.

${ }^{157}$ Private Nuisance - "One is subject to liability for a private nuisance if, but only if, his conduct is a legal cause of an invasion of another's interest in the private use and enjoyment of land, and the invasion is either (a) intentional and unreasonable, or (b) unintentional and otherwise actionable under the rules controlling liability for negligent or reckless conduct, or for abnormally dangerous conditions or activities." Restatement (Third) of Torts (2013), § 822, General Rule.

Public Nuisance - See John E. Bryson, et al., Public Nuisance, the Restatement (Second) of Torts, and Environmental Law, Ecology L.Q., Vol. 2 Spring (1972), available at http://scholarship.law.berkeley.edu/cgi/viewcontent.cgi?article=1028\&context=elq. Trespass and private nuisance "may be distinguished by comparing the interest invaded; an actionable invasion of a possessor's interest in the exclusive possession of land is a trespass; an actionable invasion of a possessor's interest in the use and enjoyment of his land is a nuisance." Martin v. Reynolds Metals Co., 221 Or. 86, 342 P.2d 790, cert. denied, 362 U.S. 918 (1960), available at https://law.justia.com/cases/oregon/supremecourt/1959/221-or-86-0.html.

${ }^{158}$ Intrusion Upon Seclusion - "One who intentionally intrudes, physically or otherwise, upon the solitude or seclusion of another or his private affairs or concerns, is subject to liability to the other for invasion of his privacy, if the intrusion would be highly offensive to a reasonable person." Restatement (Third) Torts, $\S$ 652B, available at https://cyber.harvard.edu/privacy/Privacy R2d Torts Sections.htm. Such invasion may be physical or by "use of the defendant's senses, with or without mechanical aids, to oversee or overhear the plaintiff's private affairs." Id., Comments b.

159 See Troy A. Rule, Airspace in the age of drones, 95 B.U. L. Rev. vol. 95, p. 155 (2015), http://www.bu.edu/bulawreview/files/2015/02/RULE.pdf (There is unavoidable tension between the permissible scope of available airspace and the low-altitude rights of landowners - such rights are not yet clearly defined.). A uniform law is under development that might provide a measured, incremental extension of traditional trespass law addressing low altitude flight (most likely at or below $200 \mathrm{AGL}$ ) by the Nat'I Conf. of Comm. on Uniform State Laws (NCCUSL), http://www.uniformlaws.org/. 


\section{UAS Pilots Code -Annotated Version 1.0}

${ }^{160}$ See FAA, ORDER JO 7110.65x, Subj. Air Traffic Control ( Oct. 12, 2017), https://www.faa.gov/documentLibrary/media/Order/JO 7110.65X Air Traffic Control.pdf (§ 2-1-21, TRAFFIC ADVISORIES: describing general reporting instructions for ATC; and § 2-1-22, UNMANNED AIRCRAFT SYSTEM (UAS) ACTIVITY INFORMATION for ATC: "Issue UAS advisory information for known UAS activity, when in your judgment their proximity warrants it. If known, include position, distance, course, type of unmanned aircraft (UA), and altitude.... b. Issue UAS advisory information for pilot-reported or tower-observed activity, when in your judgment, their proximity warrants it. If known, include position, altitude, course, and type. Continue to issue advisories to potentially impacted aircraft for at least 15 minutes following the last report. .."); and FAA, Flight Service, https://www.faa.gov/about/office org/headquarters offices/ato/service units/systemops/fs/ (describing mission, services and use).

${ }^{161}$ See FAA, AIM, Pilot/Controller Glossary, Special Activity Airspace, http://www.faraim.org/faa/aim/aim705.html ("Any airspace with defined dimensions within the National Airspace System wherein limitations may be imposed upon aircraft operations.").

${ }^{162}$ See FAA, SUA, www.sua.faa.gov; FAA, TFR, http://tfr.faa.govl, and https://notams.aim.faa.gov/notamSearch/disclaimer.html; FAA, Map of FAA UAS Flight Data, http://uasfaa.opendata.arcgis.com; FAA, B4UFLY Mobile App, available at https://www.faa.gov/uas/where to fly/b4ufly/, and AIRMAP, App, https://www.airmap.com/.

${ }^{163}$ See FAA Modernization and Reform Act of 2012, § 333, 14 C.F.R. Part 107B, https://www.gpo.gov/fdsys/pkg/PLAW-112publ95/pdf/PLAW-112publ95.pdf; 14 C.F.R. §§ 107.200, 107.205; and UASPC, nn.112, 139 \& 154 (addressing airspace restrictions).

${ }^{164}$ Avoid or restrict operations that infringe on non-participants' right to privacy, particularly when operating in areas or vantage points where an individual has a public expectation of privacy. See, e.g., Katz v. U.S., 389 U.S. 347 (1967), available at https://www.law.cornell.edu/supremecourt/text/389/347 (individuals retain 4th Amendment protections where a reasonable expectation of privacy exists); Kyollo $\mathrm{v}$. U.S., 533 U.S. 27 (2001), available at http://caselaw.findlaw.com/us-supreme-court/533/27.html (certain sensors can violate 4th Amendment protections); Florida v. Riley, 488 U.S. 445 (1989), available at http://caselaw.findlaw.com/us-supreme-court/488/445.html (aerial observation of marijuana production; privacy would include areas such as the curtilage of one's home); California v. Ciraolo, 476 U.S. 207, 212-15 (May 19, 1986), available at https://www.law.cornell.edu/supremecourt/text/476/207\#writingUSSC CR 04760207 ZO (expectation of privacy unreasonable re police "naked eye" observation of marijuana from 1,000 AGL "within public navigable airspace [] in a physically nonintrusive manner"); Dow Chemical Co. v. US, 476 U.S. 227, 228 (1986), available at https://supreme.justia.com/cases/federal/us/476/227/case.html ("open areas of an industrial plant complex .... not analogous to the "curtilage" of a dwelling for purposes of aerial surveillance"); Florida Statutes, § 934.50, Searches and seizure using a drone, http://www.leg.state.fl.us/statutes/index.cfm?App mode=Display Statute\&URL=09000999/0934/Sections/0934.50.html (penal aspects); and NTIA, Voluntary Best Practices for UAS Privacy, Transparency, and Accountability, § 4(a) (May 18, 2016), https://www.ntia.doc.gov/files/ntia/publications/uas privacy best practices 6-21-16.pdf ("Mak[e] a reasonable effort to provide security training to employees with access to covered data.").

${ }^{165}$ Additionally, recognize that sophisticated sensors and other UAS payloads may dramatically and persistently enhance the capability of UAS to surveil people without their knowledge and consent. See, e.g., US v. Kyllo, 533 U.S. 27 (2001), available at http://caselaw.findlaw.com/us-supreme-court/533/27.html 


\section{UAS Pilots Code -Annotated Version 1.0}

(surveillance with a device not in general public use is a Fourth Amendment "search", presumptively unreasonable without a warrant). See also UK, ANO 2016 (CAP 393), § 167, Small unmanned surveillance aircraft, http://www.legislation.gov.uk/uksi/2016/765/contents/made (". . must not fly the aircraft . . . (a) over or within 150 meters of any congested area, (b) over or within 150 meters of an organization open-air assembly of more than 1,000 persons, (c) within 50 meters of any vessel, vehicle or structure which is not under the control of the person in charge of the aircraft, or (d) ... within 150 meters of any congested areas ..."); and UK, Dep't of Transp., Unlocking the UK's high tech economy: Consultation on the safe use of drones in the UK, p. 21 (2016),

https://www.gov.uk/government/uploads/system/uploads/attachment data/file/579562/consultation-onthe-safe-use-of-drones.pdf ("Whilst the rule was introduced for safety reasons, it also has benefits for privacy.").

${ }^{166}$ Minimizing data capture duration and location may prevent unintended privacy violations and optimize data storage use on the UAS. See UASPC n.167.

${ }^{167}$ See Int'I Ass' $n$ of Chiefs of Police, Aviation Comm., Recommended Guidelines for the use of Unmanned Aircraft (Aug. 2012), www.theiacp.org ("IMAGE RETENTION: 1. Unless required as evidence of a crime, as part of an ongoing investigation, for training, or required by law, images captured by a UA should not be retained by the agency. 2 . Unless exempt by law, retained images should be open for public inspection.").

168 "[P]ersonal data" here means information collected by a UAS that identifies a particular person. $C f$., NTIA, Voluntary Best Practices for UAS Privacy, Transparency, and Accountability, § III. Definitions (May 18, 2016), https://www.ntia.doc.gov/files/ntia/publications/uas privacy best practices 6-21-16.pdf (defining "covered data").

${ }^{169}$ See NTIA, Voluntary Best Practices for UAS Privacy, Transparency, and Accountability, § 1(b) (addressing privacy policy and its recommended content).

${ }^{170}$ Despite their typically smaller footprint than manned aircraft, UAS' potential environmental impacts require assessment.

Noise - "To date, there have not been any objective studies published to gain even a coarse view of annoyance due to sUAS noise specifically. Further, it is clear that the noise of these machines does not resemble, qualitatively, the noise of contemporary aircraft. This difference in sound quality introduces an unknown factor into the prediction of the resultant annoyance." Andrew Christian, et al., NASA Langley Research Center, Initial Investigation into the Psychoacoustic Properties of Small Unmanned Aerial System Noise, Am. Inst. of Aeronautics and Astronautics (2017), available at https://ntrs.nasa.gov/archive/nasa/casi.ntrs.nasa.gov/20170005870.pdf.

"[T]he FAA is measuring noise of different UAS to help determine an appropriate certification plan." FAA, Environment and Energy, https://www.faa.gov/nextgen/where we are now/nextgen update/progress and plans/environment/.

Internationally, ICAO's Committee on Aviation Environmental Protection (CAEP) has investigated "the current state of noise certification for remotely piloted aircraft systems (RPAS) and will continue monitoring certification issues in this fast-growing sector." ICAO, CAEP, Annual Report (2015), https://www.icao.int/annual-report-2015/Pages/progress-on-icaos-strategic-objectives-safetyenvironmental-protection-caep.aspx.

One helpful analogy (to UAS noise characteristics) is that presented by helicopters. Helicopter noise research found that helicopters tend to annoy people differently than straight-wing aircraft, both in terms 


\section{UAS Pilots Code -Annotated Version 1.0}

of frequency and operational characteristics. See HAI, Fly Neighborly/Noise Abatement Training, https://www.rotor.org/Operations/FlyNeighborly/NoiseAbatementTrainingCD.aspx. Consider also that UAS will operate in more environments than do manned aircraft since they are not confined to aerodromesand thus may impact a broader scope of environments that have not been the subject of current research. These differences suggest that in the future, separate UAS requirements or recommendations for noise may deserve consideration, whether via certification, or voluntary industry standards, e.g., ASTM Int'l, Comm. F38, www.astm.org. "The FAA is gathering data for all UAS on which it may base future certification standards .... At this time, however, the FAA does not believe there is sufficient evidence to warrant such a standard. . . . For similar reasons, the FAA lacks sufficient evidence at this time to justify imposing operating noise limits on small UAS." Final Rule, Discussion, 81 Fed. Reg. 42,186-7 (June 28, 2016).

FAA's UAS Rules Excluded From Environmental Assessment - The Final Rule asserts that the Dept. of Transp. determined that the proposed action (enacting Part 107, etc.) qualifies for a categorical exclusion (CATEX) under the National Environmental Policy Act (DoT ORDER 5610.1C, Para 4.c.5, https://www.transportation.gov/office-policy/transportation-policy/procedures-consideringenvironmental-impacts-dot-order-56101c), Final Rule, p. 510, thus precluding the need for an Environmental Impact Statement. See FAA Order 1050.1F, g 5-6.5(f), Categorical Exclusions for Procedural Actions, https://www.faa.gov/documentLibrary/media/Order/FAA Order 1050 1F.pdf (determining that the Final Rule is covered by the CATEX). See, e.g., U.S. Dept. of Energy, Office of Legacy Mgt., List of Recent Categorically Excluded Actions, https://energy.gov/Im/services/ioint-environmental-management-systemems/national-environmental-policy-act-nepa-0 (includes multiple categorical exclusions for UAS).

The lack of a comprehensive regulatory response reflects the unprecedented/unexpected growth of UAS, a lack of data and modeling, and government personnel resource constraints. Notwithstanding, the FAA's internal work plan for the next fiscal year anticipates further research and response. The FAA's primary office on environmental issues is the Environmental Policy and Operations Division, Office of Environment and Energy, Environmental Policy and Operations Division, https://www.faa.gov/about/office org/headquarters offices/apl/research/.

Other Environmental Considerations - See Chris Wargo, et al., UAS Industry Growth: Forecasting Impact on Regional Infrastructure, Environment, and Economy, p. 5 (2016), https://utm.arc.nasa.gov/docs/Wargo DASC 1570263430.pdf (Massachusetts Institute of Technology studying UAS environmental factors; recognizing, inter alia, "many interrelated and non-linear factors"; and that "[t]here is no single model to predict environmental impact generally."). And, the U.S. military recognizes that UAS present unique environmental challenges. Unmanned Aircraft System (UAS) Service Demand 2015-2035, Tech. Rep. DOT-VNTSC-DoD-13-01, V. 0.1, Sec. 6.3 (2013),

https://fas.org/irp/program/collect/service.pdf ("The noise produced by the UAS could mean the difference between the success and failure of this type of [noise sensitive] mission. ... The fumes and gaseous emissions produced by the powerplants will be subject to the same scrutiny of all other transportation appliances and vehicles.").

${ }^{171}$ Among other protected/sensitive areas are national parks. See Sarah Gray, Drones banned from Yosemite National Park, for negative impact on environment and safety, Salon.com (May 5, 2014), http://www.salon.com/2014/05/05/drones banned from yosemite national_park for negative impact on environment and safety/ (describing Yosemite National Park's UAS prohibition, citing 36 C.F.R. § 2.17(a)(3), Resource Protection, Public Use And Recreation, Aircraft And Air Delivery, and noting an "impact [on] the natural soundscape" and "creating an environment that is not conducive to wilderness travel."); and NPS, Policy Memorandum, Unmanned Aircraft-Interim Policy 14-05 (June 19, 2014), 


\section{UAS Pilots Code -Annotated Version 1.0}

https://www.nps.gov/policy/PolMemos/PM 14-05.htm (recognizing "potential to cause unacceptable impacts such as harming visitors, interfering with rescue operations, causing excessive noise, impacting viewsheds, and disturbing wildlife").

${ }^{172}$ See Parimal Kopardekar, et al., Unmanned Aircraft System Traffic Management (UTM) Concept of

Operations, NASA (June 2016), p. 4, https://utm.arc.nasa.gov/docs/Kopardekar 2016-3292 ATIO.pdf ("The environmental considerations associated with noise stemming from vehicles in the low-altitude operations could influence large-scale acceptance."); and Andrew Christian, et al., Initial Investigation into the Psychoacoustic Properties of Small Unmanned Aerial System Noise, NASA Langley Research Ctr. (2017), UASPC, n. 170.

${ }^{173}$ See ACl, Commentary to AMCC V.a - Environmental Issues, p. 1, http://www.secureav.com/CommentAMCC-V.a-Environmental.pdf (also quoting Jane F. Garvey, fmr. FAA Adm'r, "Environmental protection is valued and is everyone's responsibility.").

${ }^{174}$ See Nat'l Fire Protection Ass'n (NFPA), Standard for Aircraft Fuel Servicing, NFPA 407 (2017), http://www.nfpa.org/Assets/files/AboutTheCodes/407/407 AlF-AAA A2016 PCResponses.pdf.

${ }^{175}$ See, e.g., FAA, Advisory Circular, AC 20-184, Subj. Guidance on Testing and Installation of Rechargeable Lithium Battery and Battery Systems on Aircraft (Oct. 15, 2015), available at http://www.faa.gov/documentLibrary/media/Advisory Circular/AC 20-184.pdf. Cf., UASPC SRP corresponding to UASPC, n.93 (addressing battery hazards to persons and property).

${ }^{176}$ See NOAA Fisheries, Unmanned Aircraft Systems: Responsible Use to Help Protect Marine Mammals, http://www.nmfs.noaa.gov/pr/uas.html; Capt. Philip Hall, Office of Marine and Aviation Operations, NOAA, HQ Perspectives and Impacts of other Federal Regulations Related to UAS Operations (Oct. 26, 2016), https://swfsc.noaa.gov/uploadedFiles/Events/Meetings/UAS 2016/Pr... (the FAA has underscored that the Final Rule, p. 526, "does not authorize the harassment, harming, or killing of wildlife, and remote pilots of small UAS remain subject to environmental and wildlife laws ..."); The National Marine Sanctuaries Act, Title 16, Ch. 32, § 1431, et seq., available at https://nmssanctuaries.blob.core.windows.net/sanctuaries$\mathrm{prod} / \mathrm{media} /$ archive/library/national/nmsa.pdf (unlawful to "destroy, cause the loss of, or injure any sanctuary resource managed under law or regulations for that sanctuary," 16 U.S.C. § 1436); and asso. regulations, available at https://www.eC.F.R..gov/cgi-bin/text-

idx?tpl=/eC.F.R.browse/Title15/15C.F.R.922 main 02.tpl (includes sanctuary-specific overflight altitude restrictions).

${ }^{177}$ See Chelsea Harvey, Drones could be stressing out wildlife, scientist suggest, Wash. Post (Aug. 13, 2015), https://www.washingtonpost.com/news/energy-environment/wp/2015/08/13/drones-could-be-stressingout-wildlife-scientists-suggest/?utm term=.aa1641eb2269; Alexander Stimpson, et al., Understanding How Drone Noise May Affect Wildlife Studies, Unmanned Systems, pp. 20-21 (Jan.-Feb. 2018) (higher frequency range of some UAS with potential similarities to honeybees could create distress in elephants); Horse put down after drone causes accident in Zermatt, The Local (Jan. 31, 2017),

https://www.thelocal.ch/20170131/horse-put-down-after-drone-causes-accident-in-zermatt (domesticated animals stress: horses panicked, took flight, suffered several fractures, and had to be put down); The Final Rule, Discussion, p. 520, et seq. (recognizing interference or harassment of wildlife is prohibited by law); Migratory Bird Treaty Act, 16 U.S.C. \& 703, available at https://www.law.cornell.edu/uscode/text/16/703; Endangered Species Act (ESA), 50 C.F.R. Part 21, available at https://www.fws.gov/endangered/esalibrary/pdf/ESAall.pdf; Marine Mammal Protection Act (MMPA), 18 U.S.C. § 21, available at http://www.nmfs.noaa.gov/pr/laws/mmpa/; and Bald and Golden Eagle Protection Act, 50 C.F.R. Part 22 


\section{UAS Pilots Code -Annotated Version 1.0}

(prohibiting disturbing, agitating or bothering bald or golden eagles-which includes injuring, or interfering with breeding, feeding, sheltering, or leading to nest abandonment, "killing, injuring, inflicting harm, or harassing protected wildlife," impairing wildlife behavior patterns, or annoying wildlife by disrupting their normal behavior). See also Oceans Unmanned, ECO Initiative, http://oceansunmanned.org/eco-drone/ (Best practices "to advance and encourage Environmentally Conscious Operations of drones to protect and limit disturbances to marine resources.").

Recognize your obligation to report wildlife strikes. See FAA, Report a Wildlife Strike Report, https://wildlife.faa.gov/strikenew.aspx; and FAA, Advisory Circular, AC 150/5200-32B, Subj. Reporting Wildlife Aircraft Strikes (May 31, 2013), https://www.faa.gov/documentLibrary/media/Advisory Circular/150 5200 32b.pdf.

${ }^{178}$ See The Nat'I Environmental Policy Act (NEPA), pp. 511-513, https://ceq.doe.gov/; and FAA, Order 1050.1F, Subj. Environmental Impacts: Policies and Procedures (July 16, 2015), g 5-6.5(f), https://www.faa.gov/documentLibrary/media/Order/FAA_Order_1050_1F.pdf.

${ }^{179}$ Technologies required to make UAS pervasive "are not just in the realm of aeronautics but also information technology, computer science, perception, autonomy ..." Juan J. Alonso, PhD, Prof. of Aeronautics and Astronautics, Stanford U., Testimony before the House Subcomm. on Aviation, Unmanned Aircraft Systems Integration: Emerging Uses in a Changing National Airspace (Nov. 29, 2017), https://transportation.house.gov/calendar/eventsingle.aspx?EventID=402013.

${ }^{180}$ See ICAO, Manual on RPAS, §§ 11.4.7-11.4.9 (addressing considerations for redundant C2 link); and UASPC, n.183, (addressing graceful degradation).

${ }^{181}$ For example, where applicable, use a transponder with altitude encoding and keep it operable unless otherwise authorized or directed by ATC. Confirm that UAS "ID Settings" are accurately set. 14 C.F.R. $\S$ 91.215, ATC transponder and altitude reporting equipment and use.

${ }^{182}$ Where implemented, ensure all DAA equipment is functional, that there is proper annunciation, and that such annunciation is acted upon timely. See generally FAA ATO, Literature Review on Detect, Sense, and Avoid Technology for Unmanned Aircraft Systems, DOT/FAA/AR-08/41 (Sept. 2009), available at http://www.tc.faa.gov/its/worldpac/techrpt/ar0841.pdf; https://www.faa.gov/uas/research/reports/. See UASPC, n.204 (regarding DAA).

${ }^{183}$ See, e.g., Oscar González, et al., Adaptive Fault Tolerance and Graceful Degradation Under Dynamic Hard Real-time Scheduling, Comp. Sci. Dept. Faculty Pub. Series. 188 (1997), available at http://scholarworks.umass.edu/cs faculty pubs/188?utm source=scholarworks.umass.edu\%2Fcs faculty pubs\%2F188\&utm medium=PDF\&utm campaign=PDFCoverPages. Observe that Dronecode Project, Inc., the influential open source software has adopted this approach in flight controllers. Dronecode, www.Dronecode.org. See also UASPC, § IV.d (regarding fault tolerance).

${ }^{184}$ See NASA, UTM, https://utm.arc.nasa.gov/; Parimal Kopardekar, et al., NASA Ames Research Center, Unmanned Aircraft System Traffic Management (UTM) Concept of Operations, $16^{\text {th }}$ AIAA Aviation Tech., Integration, and Ops. Conf., Wash., DC., p. 3 (June 2016), available at https://utm.arc.nasa.gov/docs/Kopardekar 2016-3292 ATIO.pdf ("The safety of existing traditional [manned] operations cannot be reduced by the introduction of these new UAS operations."). Cf., SESAR, Uspace Blueprint (2017), http://www.sesarju.eu/sites/default/files/documents/reports/U-

space\%20Blueprint\%20brochure\%20final.PDF (describing the low-altitude ATM initiatives by the Single European Sky ATM Research Joint Undertaking (SESAR JU)). 


\section{UAS Pilots Code -Annotated Version 1.0}

${ }^{185}$ UTM includes recognition of and support for certain VLOS sUAS operations. As such, it contributes to general VLOS (rather than only BVLOS) operational safety. Similarly, selected BVLOS standards and guidelines have informed the UASPC to the extent such standards and guidelines are extensible to VLOS operations. See, e.g., Unmanned Systems Canada, Small RPAS Best Practices for BVLOS, v1.1 (Feb. 16, 2017), https://www.unmannedsystems.ca/download/usc-small-rpas-bvlos-best-practices/.

${ }^{186}$ See ICAO, Manual on RPAS, § 11.1.3 (“C2 link should support a range of data link health monitoring functions, including a heartbeat, or positive and negative acknowledgements of messages exchanged in either direction."); and UASPC, n.72 (addressing preflight).

${ }^{187}$ See ICAO, Manual on RPAS, § 11.6.11 (listing possible causes of C2 link loss, including: obstacles, ground clutter, natural (weather) interference, unintentional interference such as by television broadcast, intentional interference such as by jamming, out of range, equipment failure, human error, and aircraft maneuvers), § 11.3.10-11.3.15 (addressing C2 link spectrum protection from interference and available bands), and $\S 11.3 .18$ (identifying performance parameters, including: communications transaction time, continuity, availability, and integrity); NOAA, Space Weather Prediction Center, http://www.swpc.noaa.gov/ (indicating impact of solar storms on GPS and radio communications); UASPC, n.196 (addressing GPS interference); and FAA, ORDER 8130.34D, SUBJ. Airworthiness Certification of Unmanned Aircraft Systems and Optionally Piloted Aircraft, p. D-3 (Sept. 8, 2017), available at https://www.faa.gov/documentLibrary/media/Order/FAA Order 8130.34D.pdf (requiring manufacturer to disclose: ". . . how the radio signal strength, signal error rate, or similar information is computed and displayed to the pilot. Identify the threshold values that represent a critically degraded signal."). Also, recognize the possibility of interference between two UAS operating in close proximity. See UASPC, n.207 (address GPS anomaly reporting).

See 47 C.F.R. Part 15, Subpart D-Unlicensed Personal Communications Service Devices, https://www.ecfr.gov/cgi-bin/textidx?SID=5e2a156ecddf773e7c470324e2b7df7e\&mc=true\&node=sp47.1.15.d\&rgn=div6 (requirements for use of unlicensed spectrum); and Letter to Ricardo Durham, Acting Chief, Spectrum Enforcement Div., FCC, from Christopher D. Imlay, General Counsel, ARRL (Jan. 11, 2017), available at https://tinyurl.com/y9ol3unp (drones illegally transmitting on licensed spectrum, causing interference and "representing a significant hazard to public safety").

188 "Generally speaking, electromagnetic interference (EMI) should not be a factor for flights greater than 30 $\mathrm{ft}(10 \mathrm{~m})$ from energized equipment; however, flights at 6-12 ft (2-4 $\mathrm{m}$ ) have been observed to experience EMI issues." Richard M. Lusk, et al., An Early Survey of Best Practices for the Use of Small Unmanned Aerial Systems by the Electric Utility Industry, Oak Ridge Nat'I Lab., ORNL/TM-2017/93 (Feb. 2017), available at http://nias-uas.com/wp-content/uploads/2017/02/An-Early-Survey-of-Best-Practices-for-the-Use-of-SmallUnmanned-Aerial-Systems-by-the-Electric-Utility-Industry-RM-Lusk-Feb-2017.pdf.

${ }^{189}$ See ICAO, Manual on RPAS, §§ 9.4.3, -5 (Impacts on radio frequencies), \& § 11.6.24 (C2 link contingency options); Harrison Wolf, Drones: Safety Risk Management for the Next Evolution of Flight, p. 120

(Routledge, 2017) ("Electro-magnetic interference that can cause lost-link procedures when coming close to transformers or towers of different sizes provide a need for policies, procedures, and training that consider such environmental issues."); and FCC, Accessing Spectrum, https://www.fcc.gov/general/accessingspectrum (addressing, in part, Licensed Spectrum for Commercial Services). See UASPC, n.207 (address GPS anomaly reporting). 


\section{UAS Pilots Code -Annotated Version 1.0}

${ }^{190}$ L. Han, et al,. Research on compass error compensation of certain UAS, 2013 IEEE Int'I Conf. on Info and Automation (ICIA), Yinchuan, pp. 811-815, available at http://doi.org/10.1109/ICInfA.2013.6720405. See UASPC, n.189.

${ }^{191}$ See 14 C.F.R. $§ 107.49$, Preflight familiarization, inspection, and actions for aircraft operation (requiring RP to evaluate local weather conditions during preflight assessment and satisfy requirements of 14 C.F.R. $\S$ 107.51(c) \& (d), addressing flight visibility and distance from clouds, respectively). Particularly for longerduration missions, weather resources are essential-in addition to complying with applicable regulations. See generally NOAA, Aviation Weather Center, https://www.aviationweather.gov/ (comprehensive aviation weather resources); and NOAA, Helicopter Emergency Medical Services (HEMS) Tool, https://new.aviationweather.gov/hems (providing low-altitude aviation weather information).

192 See, e.g., Drone Complier, available at https://www.youtube.com/watch?v=3Wz-dBPdxpg\&t=4s; Skyward Fleet Management, https://skyward.io/commercial-drone-software/ (UAS planning and compliance tools); and Jonathan Edwards, CEO, Skyward, https://www.youtube.com/watch?v=jvG7MGkcmLg (discussion).

${ }^{193}$ See, e.g., FAA, B4UFLY Mobile App., https://www.faa.gov/uas/where to fly/b4ufly/ (app for airspace and other services); AIRMAP, https://www.airmap.com (airspace compliance tool providing situational awareness and real-time traffic notifications); Skyward, https://skyward.io (UAS mission planning, compliance, and task management software); FAA, FAADroneZone, https://faadronezone.faa.gov/\#/ (provides for waiver requests); FAA, UAS Facility Maps, https://faa.maps.arcgis.com/apps/webappviewer/index.html?id=9c2e4406710048e19806ebf6a06754ad (UAS Facility Maps); FAA, UAS, https://www.faa.gov/uas/; and FAA Safety Team, https://www.faasafety.gov/.

${ }^{194}$ See FCC, Licensing, https://www.fcc.gov/licensing-databases/licensing; Robert J. Kerczewski, et al., NASA Glenn Research Center, Frequency Spectrum for Integration of Unmanned Aircraft (Oct. 2013),

https://ntrs.nasa.gov/archive/nasa/casi.ntrs.nasa.gov/20140011093.pdf; Drones, UTM and Spectrum - A review, Drone Alliance Europe (2016), http://dronealliance.eu/wp-content/uploads/2016/06/SpectrumAllocation-White-Paper-Drone-Alliance-Europe-fin.pdf; and Alan Hobbs, PhD., San José State U. Research Found., NASA Ames Research Ctr., Human Factors Guidelines For Remotely Piloted Aircraft System Remote Pilot Stations, TN-34128, § T_1.5.1, p. 36 (July 2016), https://human-

factors.arc.nasa.gov/publications/PS 02219 Human Factors Guidelines web.pdf ("The RPS should enable the pilot to confirm spectrum availability before selecting link" and, maintain selected communications mode.).

195 See Unmanned Systems Canada, Small RPAS Best Practices for BVLOS, v1.1, App. 2, § 5XX.114.2., p. 54 (Oct. 2016), https://www.unmannedsystems.ca/download/usc-small-rpas-bvlos-best-practices/

("Throughout the RPA flight envelope, the pressure altitude presented to the pilot must have an overall altitude error of less than 30 feet.").

${ }^{196}$ GPS Accuracy - GPS-based navigation aid precision can be improved by using the Wide Area Augmentation System (WAAS) or employing Real-Time Kinematics (RTK) technology. WAAS is a highly accurate navigation system developed for civil aviation covering the NAS. Precisely surveyed Wide Area Reference Sites compare, correct, and transmit augmented information to GPS receivers to enhance the accuracy and reliability of position estimates. A tool is available to predict the performance (including outages) of the WAAS signal at airports for a particular date. http://www.nstb.tc.faa.gov/AirportSchedules/. A localized variant of WAAS for other GNSS, RTK, exploits signal phase-shift rather than only GPS time data 


\section{UAS Pilots Code -Annotated Version 1.0}

in concert with a static base station within a limited geographical area. FAA, Satellite Navigation - Wide Area Augmentation System (WAAS), https://www.faa.gov/about/office org/headquarters offices/ato/service units/techops/navservices/gnss/ waas/.

GPS Interference - See Muhammad Darwish, Did Russia make this ship disappear?, CNN (Nov. 3, 2017), http://money.cnn.com/2017/11/03/technology/gps-spoofing-russia/index.html (presenting a survey of GPS spoofing and other vulnerabilities). See also UASPC, n.203 (address GPS anomaly reporting). Additionally, tall buildings may cause multipath reflections resulting in large position errors. See NovAtel, An introduction to GNSS, Ch. 4. GNSS Error Sources, https://www.novatel.com/an-introduction-to-gnss/chapter-4-gnsserror-sources/error-sources/(explaining multipath); Paul D Groves, et al., Intelligent Urban Positioning using Multi-Constellation GNSS with 3D Mapping and NLOS Signal Detection, 25th Int'I Meeting of the Sat. Div., Inst. of Nav., Nashville (Sept. 17-21, 2012), http://discovery.ucl.ac.uk/1394444/1/0681.pdf; and Gianluca Falco, et al., Loose and Tight GNSS/INS Integrations: Comparison of Performance Assessed in Real Urban Scenarios, (Jan. 29, 2017), https://www.ncbi.nlm.nih.gov/pmc/articles/PMC5335985/ (in particular, consider the error described in § 4.2. Zone 2: Urban Canyon, and § 4.3. Zone 3: Straight Avenue of Trees).

${ }^{197}$ Many systems are equipped with multifunction controls that permit reconfiguration in flight. Inflight reconfiguration can potentially compromise platform controllability or lead to loss of situational awareness. Refer to manufacturer's guidance addressing use in different flight modes. See Alan Hobbs, PhD., San José State U. Research Found., NASA Ames Research Ctr., Human Factors Guidelines For Remotely Piloted Aircraft System Remote Pilot Stations, TN-34128, § G_5, p. 36 (July 2016), https://humanfactors.arc.nasa.gov/publications/PS 02219 Human Factors Guidelines web.pdf.

${ }^{198}$ See, e.g., R. J. Stone, et al., Standard Operating Procedures Small Unmanned Aerial Vehicles (sUAVs) and Small Unmanned Surveillance Vehicle (sUSVs), Human Interface Technologies Team School of Electronics, Electrical \& Systems Engineering U. of Birmingham, v. 1.2 (Nov. 2014) available at https://www.birmingham.ac.uk/Documents/college-eps/eece/research/bob-stone/sUAV-standardoperating-procedures.pdf ("Propeller guards, if available, should be used at all times."). Also, ASTM Int'I, Comm. F38 is developing a new specification for sUAS parachutes. See https://www.astm.org/COMMITTEE/F38.htm.

199 See UASPC, n.58 (addressing the sterile cockpit and distractions).

200 "Complex Functions are defined as software functions or algorithms that may cause the UAS to operate in a manner that is difficult to predict due to compounded implications from factors such as sensor measurement precision, algorithm complexity, environmental variables, multi-core processing, probabilistic algorithms, fuzzy logic, machine learning, genetic algorithms, resource availability, and aircraft system state. These functions may contain algorithms that are sometimes referred to as 'autonomous', 'non-

deterministic', 'artificial intelligence', 'adaptive', or 'intelligent' algorithms, and there is an industry demand to employ these technologies in UAS. And, an acceptable level of flight safety maintained through use of a 'run-time assurance (RTA) architecture'." ASTM Int'I, F3269, Standard Practice for Methods to Safety Bound Flight Behavior of Unmanned Aircraft Systems (UAS) Containing Complex Functions, available (fee) at https://www.astm.org/Standards/F3269.htm?A\&utm_source=tracker\&utm_campaign=20171005\&utm_me dium=email\&utm content=standards.

${ }^{201}$ This may include backup or alternative control stations, as well as integrating the functional status of such devices into standard preflight checks. See Alan Hobbs, PhD., San José State U. Research Found., NASA Ames Research Ctr., Human Factors Guidelines For Remotely Piloted Aircraft System Remote Pilot Stations, 


\section{UAS Pilots Code -Annotated Version 1.0}

TN-34128, § T_1.3.2, p. 22 (July 2016), https://human-

factors.arc.nasa.gov/publications/PS 02219 Human Factors Guidelines web.pdf.

${ }^{202}$ Keep appraised of the useful life of each battery for both the UAS and control stations, taking into consideration use in both normal and emergency conditions. Understand any load-shedding capabilities of the equipment. Additionally, understand the combustibility and other safety risks and corresponding mitigations associated with each type of battery deployed, including storage conditions, charging and discharge limitations, thermal thresholds, handling and inspection, adherence to manufacturer's instructions / technical data sheet, testing, and firmware updates. See, e.g., FAA, SAFO 09013, Subj. Fighting Fires Caused By Lithium Type Batteries in Portable Electronic Devices (June 23, 2009), available at https://www.faa.gov/other visit/aviation industry/airline operators/airline safety/safo/all safos/media/2 009/SAF009013.pdf; ASTM Int'I, F3005, Standard Specification for Batteries for Use in Small Unmanned Aircraft Systems (sUAS), available (fee) at https://www.astm.org/Standards/F3005.htm; RTCA SC-225, Rechargeable Lithium Batteries and Battery Systems Committee, [draft] RTCA/DO-331A, Minimum Operational Performance Standards for Rechargeable Lithium Battery Systems (Mar. 2008); and Steve Summer, FAA Fire Safety Branch, RTCA SC-225: Rechargeable Lithium Batteries and Battery Systems, Int'I Aircraft Systems Fire Protection Working Group, Dresden, (May 12 - 13, 2015), available at https://www.fire.tc.faa.gov/pdf/systems/May15Meeting/Summer-0515-RTCAandEUROCAE-SAE.pdf (summarizing battery safety standards initiatives).

${ }^{203}$ Drafting Considerations: While the UASPC makes primary reference to GPS, the same limitations apply to all Global Navigation Satellite Systems (GNSS), which include GPS, GLONAS, Galileo, Beidou, and other systems. Also, because the term "GPS" is more familiar than "GNSS" to a broader audience, "GPS" is presented throughout the UASPC to represent all GNSS systems. Implementers are free to substitute "GNSS" or specific GNSS systems.

GPS Anomaly Reporting - Aviation-related GPS anomalies, including degradations, disruptions, or other incidents should be reported to the FAA at GPS Anomaly Reporting Form,

https://www.faa.gov/air traffic/nas/gps reports/. See US Coast Guard Navigation Center, GPS Problem Reporting, https://www.navcen.uscg.gov/?pageName=gpsUserInput. The NASA Aviation Safety Reporting System also solicits GPS anomaly reports.

${ }^{204}$ Well Clear - The limitations, in part, should be understood in terms of their objectives and parameters to resolve "well clear" requirements. While there are no universally accepted criteria that establish aeronautical standards for "well clear," pilots are required to adhere to 14 C.F.R. § 91.111 that state "(a) no person may operate an aircraft so close to another aircraft as to create a collision hazard; (b) no person may operate an aircraft in formation flight except by arrangement with the pilot in command of each aircraft in the formation." Additionally, pilots should consider the potential risk associated with the proximity of operations to other aircraft, which may constitute a violation of 14 C.F.R. $\S 91.13$, Careless or reckless operations: "No person may operate an aircraft in a careless or reckless manner so as to endanger the life or property of another." Finally, specific guidance regarding UAS operations is contained in 14 C.F.R. Part 107, which states, "No person may operate a small unmanned aircraft in a manner that interferes with operations and traffic patterns at any airport, heliport, or seaplane base. Additional guidance is available in FAA, Order 7110.65X, Air Traffic Control (Oct. 12, 2017),

https://www.faa.gov/documentLibrary/media/Order/JO 7110.65X Air Traffic Control.pdf (defining minimally acceptable vertical and lateral separation distance between aircraft).

Right-of way protocols should also be understood. See 14 C.F.R. § 91.113(b): “General ... When a rule of this section gives another aircraft the right-of-way, the pilot shall give way to that aircraft and may not pass 


\section{UAS Pilots Code -Annotated Version 1.0}

over, under, or ahead of it unless well clear." (emphasis added) And, 14 C.F.R. § 91.181(b): "On any other route ... this section does not prohibit maneuvering the aircraft to pass well clear of other air traffic ..." (emphasis added); Andrew Weinert, et al., A Well Clear Recommendation for Small Unmanned - Aircraft Systems based on Unmitigated Collision Risk, Lincoln Lab (2016) (copy on file with Drafting team); Dallas Brooks, et al., UAS Excom, Science and Research Panel (SARP) Update, Presentation at AUVSI, XPONENTIAL (April 2017) (recommending 2000' horizontal, and 250' vertical distance for safe separation between sUAS and manned aircraft).

See also RTCA, DO-365, Minimum Operational Performance Standards for Detect and Avoid Systems (May 31, 2017), available (fee) at www.rtca.org; Kevin W. Williams, et al., An Investigation Of Minimum Information Requirements For An Unmanned Aircraft System Detect And Avoid Traffic Display, FAA Office of Aerospace Medicine, DOT/FAA/AM-17/14 (June 2017), available at http://libraryonline.erau.edu/onlinefull-text/faa-aviation-medicine-reports/AM17-14.pdf; ICAO, Manual on RPAS, § 10.2.4 (“One or more DAA capabilities may be needed to meet requirements to address the [DAA] hazards."); Unmanned Systems Canada, Small RPAS Best Practices for BVLOS, v1.1, § 5XX.8.4.d, p. 51 (Oct. 2016),

https://www.unmannedsystems.ca/download/usc-small-rpas-bvlos-best-practices/ ("System Reliability The probability of failure of the system to avoid a conflicting aircraft shall be less than $10^{-3}$ per flight hour. ."); RTCA, Program Management Committee Meeting Summary (June 22, 2017),

https://www.rtca.org/sites/default/files/pmc june 2017 summary.pdf; and Doug Davis, CANSO, RPAS \& ET Co-Chair, \& Northrop Grumman, Presentation at ICAO, RPAS 2017, Montréal (Sept. 17, 2017) ("When we get a mature RPAS collision avoidance system - that should shock the aviation world.").

${ }^{205}$ See generally ACl, Commentary to AMCC VII.e., Promote Ethical Behavior within the GA Community (Mar. 16, 2006), http://www.secureav.com/Comment-AMCC-VII.e-Ethics.pdf; and Ass'n of Remotely Piloted Aircraft Systems UK, Code of Conduct, https://www.arpas.uk/mem-code-of-conduct/ ("As an industry, it is incumbent upon us to hold ourselves and each other to a high professional and ethical standard."). See also, Email from Parimal Kopardekal ("PK"), Sr. Tech. Air Transport, NASA (Jan 17, 2018) ("The overall theme [of the UASPC] could be "share and care" share information about your intent and care about safety all airspace users and assets on the ground.").

${ }^{206}$ See ACl, Recent Developments, http://www.secureav.com/newdevelopments.html (presenting, in part, noteworthy code of conduct implementations).

${ }^{207}$ See AUVSI, Code of Conduct, http://www.auvsi.org/code-conduct (“We will respect the rights of other users of the airspace.").

${ }^{208}$ See Joerg Lamprecht, It starts at the park: Local governments lead the way in drone advocacy and regulation, GovFresh (March 30, 2017), http://govfresh.com/2017/03/starts-park-local-governments-leadway-drone-advocacy-regulation/ (highlighting the increasing role of local government in regulating UAS);

Reggie Govan, FAA Chief Counsel, Presentation at the FAA UAS Symposium, Daytona Beach (Apr. 20, 2016) ("The FAA has had a hard time enforcing manned aviation. ... It is virtually impossible for us to enforce unmanned aviation."); FAA, Law Enforcement Guidance for Suspected Unauthorized UAS Operations, ver. 4 (June 6, 2017), https://www.faa.gov/uas/resources/law enforcement/media/FAA UAS-

PO LEA Guidance.pdf; FAA, Law Enforcement Engagement with Suspected Unauthorized UAS Operations, https://www.faa.gov/uas/resources/law enforcement/; UASPC, n.31 (addressing regulations, compliance philosophy, and enforcement); and UASPC, n.82 (addressing state, local, and tribal rules).

${ }^{209}$ See AOPA, Five Questions for Dallas Brooks (June 12, 2017), https://www.aopa.org/news-and-media/allnews//2017/June/12/Five-questions-for-Dallas- 


\section{UAS Pilots Code -Annotated Version 1.0}

Brooks?utm source=drone\&utm medium=email\&utm campaign=170613drone (urging participation in local unmanned clubs):

What you lose [in online communities], however, is the discipline-you can take the information you want without caveats, without conditions, and apply it instantly. Sometimes that makes it easy for people to do irresponsible things. Not because they are irresponsible people, but because they could get to the information on how to do something without having to truly understand the context and the consequences of what they are doing....

[Y]ou don't have to be a manned pilot to understand and embrace a safety culture. We all share the same sky, and we must all consider the impact of what we do on everyone. That's what a community does-they look out for one another.

See Additional Resources (for a nonexclusive list of recognized UAS associations).

${ }^{210}$ Facility Map errors can be submitted to the FAA at: 9-AJV-115-EmergTech@faa.gov.

${ }^{211}$ FAA, FAA Safety Team (FAASTeam), www.faasafety.gov/about/mission.aspx.

${ }^{212}$ See ACl, Commentary to AMCC VII.e - Advancement And Promotion of GA (Mar. 16, 2016), http://www.secureav.com/Comment-AMCC-VII.e-Ethics.pdf. See also NBAA, Ethical Business Aviation

Transactions (Dec. 2017), https://www.nbaa.org/admin/registration/ethical-business-aviationtransactions/nbaa-ethical-business-aviation-transactions-statement.pdf (best practices for ethical transactions between buyers and sellers of business aircraft products and services); and NTIA, Voluntary Best Practices for UAS Privacy, Transparency, and Accountability, § 1 (May 18, 2016), https://www.ntia.doc.gov/files/ntia/publications/uas privacy best practices 6-21-16.pdf ("In order to ensure that UAS and the exciting possibilities that come with them live up to their full potential, operators should use this technology in a responsible, ethical, and respectful way.") (emphasis added).

${ }^{213}$ See generally NTIA, Voluntary Best Practices for UAS Privacy, Transparency, and Accountability. See Australian Ass'n for Unmanned Systems, Code of Conduct, v1.0, p. 3 (Aug. 19, 2016), http://aaus.org.au/resources/Documents/Documents/AAUS\%20Code\%200f\%20Conduct.pdf ("Where possible, you will seek to share your safety experiences and provide any data to support safety initiatives that aim to raise the safety knowledge of the community.").

${ }^{214}$ See Ethical Issues in Aviation (Elizabeth A. Hoppe, ed., Ashgate, 2011), p. xxviii ("If you as a student or business professional believe in core values that center around "Integrity, Honesty, and Accountability," you must also be an example of them 24-7."). In the absence of established UAS instructor standards, more experienced operators should seek ways to embody the principles and behaviors described in the FAA's Aviation Instructor's Handbook, FAA-H-8083-9A (2008), https://www.faa.gov/regulations policies/handbooks manuals/aviation/aviation instructors handbook/m edia/FAA-H-8083-9A.pdf, and the ACl, Flight Instructors Model Code of Conduct, http://www.secureav.com/FIMCC-v1.0.htm.

${ }^{215}$ AOPA, https://www.aopa.org/go-fly/aircraft-and-ownership/drones.

${ }^{216}$ ASTM Int'l, Comm. F38 on Unmanned Aircraft Systems, https://www.astm.org/COMMITTEE/F38.htm.

${ }^{217}$ See EASA, NPA 2017-05, Introduction of a regulatory framework for the operation of drones Unmanned aircraft system operations in the open and specific category (May 4, 2017), https://www.easa.europa.eu/document-library/notices-of-proposed-amendment/npa-2017-05. 


\section{UAS Pilots Code-Annotated Version 1.0}

${ }^{218}$ EUROCAE WG-105, WG-73 on UAS, and WG-93 on Light UAS, https://www.eurocae.net/aboutus/working-groups/ ("WG-105 is tasked to develop standards and guidance documents that will allow the safe operation of UAS in all types of airspace, at all times and for all types of operations."); see CANSO and EUROCAE, Press Release, Canso And Eurocae Commit To Jointly Develop Standards On Air Traffic Management Issues Including Integration Of Uas And Cyber-security (Oct. 10, 2018), https://www.canso.org/civicrm/mailing/view?reset=1\&id=709 (CANSO will join the EUROCAE Working Group on Aeronautical Systems Security).

${ }^{219}$ See ICAO, RPAS Toolkit, https://www4.icao.int/uastoolkit/Home/UAS2. See Mike Lissone, UAS ATM Integration Manager, Eurocontrol, Presentation at ICAO, RPAS2017 (Sept. 17, 2017) (observing that "18 of 19 ICAO Annexes are affected [by UAS]").

${ }^{220}$ ISO, TC 20/WG 16, https://www.iso.org/committee/5336224.html ("Standardization in the field of unmanned aircraft systems (UAS) including, but not limited to, classification, design, manufacture, operation (including maintenance) and safety management of UAS operations.").

${ }^{221}$ Source documents for this appendix include, but are not limited to:

- ASTM Int'l, Committee F38, https://www.astm.org/COMMITTEE/F38.htm,

- U.S. Navy, Introduction to Operational Risk Management, OPNAVINST 3500.39, Operational Risk Management, https://www.netc.navy.mil/sobt/web/orm.html, https://doni.documentservices.dla.mil/Directives/03000\%20Naval\%200perations\%20and\%20Readin ess/03-500\%20Training\%20and\%20Readiness\%20Services/3500.39C.pdf,

- FAA, 14 C.F.R. Part 107,

- FAA, AIM, available at http://www.faa.gov/air traffic/publications/,

- ICAO, Manual on Remotely Piloted Aircraft Systems (RPAS), Doc. 10019 (2015), available (fee) at https://store.icao.int/manual-on-remotely-piloted-aircraft-systems-rpas-doc-10019-english-printed12792.html; and

- JARUS guidelines on SORA, Annex 1, glossary of terms, Doc. JAR-DEL-WG6-D.04 ("JARUS SORA"), http://jarus-rpas.org/sites/iarus-rpas.org/files/jar doc 06 jarus sora annex i v1.0.pdf.

222 JARUS, SORA, Annex I Glossary of Terms.

${ }^{223}$ See FAA, Advisory Circular, AC 60-22, Subj. Aeronautical Decision Making (Dec. 13, 1991), https://www.faa.gov/regulations policies/advisory circulars/index.cfm/go/document.information/docume ntID/22624.

${ }^{224}$ See FAA, Pilot's Handbook of Aeronautical Knowledge, FAA-H-8030-25B, Ch. 2, Aeronautical DecisionMaking.

${ }^{225} 14$ C.F.R. § 1.1, General definitions.

${ }^{226} 14$ C.F.R. § 1.1, General definitions.

${ }^{227} 14$ C.F.R. § 1.1, General definitions.

228 JARUS-SORA.

${ }^{229}$ UAS Requiring Airworthiness Certificate - See 14 C.F.R. § 21.

Small UAS - Noncertificated - See FAA, FSIMS 8900.1, Vol. 16, Unmanned Aircraft Systems, § 2(A), Definitions ("The FAA has determined that small Unmanned Aircraft Systems (sUAS) (less than 55 lbs.) will not be required to obtain airworthiness certification if satisfying the regulatory requirements of part 107 . 


\section{UAS Pilots Code -Annotated Version 1.0}

However, in the absence of an airworthiness certification process, the FAA was still required to establish maintenance and inspection criteria that support safe operations. In establishing these criteria the FAA took into consideration the significantly reduced risk posed by sUAS operations as compared to that of typical manned aircraft."); FAA, Advisory Circular, AC 107-2, Subj. Small Unmanned Aircraft Systems (sUAS) (providing guidance to determine sUAS condition for safe operation); and 14 C.F.R. § 107.15, Condition for safe operation.

${ }^{230}$ ICAO, Unmanned Aircraft Systems (UAS), Cir 328 AN/190 (2011), https://www.icao.int/Meetings/UAS/Documents/Circular\%20328 en.pdf.

${ }^{231}$ ICAO; JARUS-SORA. Cf., UK, Unmanned Aircraft System Operations in UK Airspace - Guidance, CAP 722, Ch. 2 (Mar. 2016), http://publicapps.caa.co.uk/modalapplication.aspx?appid=11\&mode=detail\&id=415 ("Autonomy is the capability of the system to make decisions based upon an evaluation of the current situation (often referred to as situation awareness). The system must take account of situational awareness data that is pertinent to the decision about to be made. Autonomous systems should make a rational evaluation of the choices available and the possible courses of action that could be taken, in light of this situation awareness in order to make its decision. We expect such a rational system to then make "good" decisions in terms of a human's assessment of those available choices."). See UASPC, n.133.

${ }^{232}$ Cf., JARUS-SORA; and see ASTM Int'l, Comm. F38.

233 JARUS, RPAS “Required C2 Performance" (RLP) concept, JAR_DEL_WG5_D.04 (Jan. 5, 2016), http://jarusrpas.org/sites/jarus-rpas.org/files/storage/Library-Documents/iar doc $13 \mathrm{rpl}$ concept upgraded.pdf; and JARUS-SORA.

${ }^{234}$ ICAO, Manual on RPAS, § 11.6.4.

${ }^{235} 14$ C.F.R. § 1.1, and JARUS-SORA.

${ }^{236}$ See UASPC, n.233.

${ }^{237}$ Cf., UAS-ID ARC Final Report, "the process by which the owner/operator sets up a device to communicate the appropriate unique ID."

${ }^{238}$ JARUS-SORA.

${ }^{239} 14$ C.F.R. § 1.1.

${ }^{240}$ NTIA, Voluntary Best Practices for UAS Privacy, Transparency, and Accountability, § 3 (May 18, 2016), https://www.ntia.doc.gov/files/ntia/publications/uas privacy best practices 6-21-16.pdf.

${ }^{241}$ Adapted from FAA, Advisory Circular, AC 107-2, Subj. Small unmanned aircraft systems, p. 5-10 (2016), https://www.faa.gov/documentLibrary/media/Advisory Circular/AC 107-2.pdf.

242 USA Patriot Act of 2001, Pub. L. 107-56, 115 STAT. 272 (Oct. 26, 2001), available at https://www.congress.gov/bill/107th-congress/house-bill/3162.

${ }^{243}$ ICAO, Annex 2.

244 "Hazards are often mischaracterized as errors or events, neither of which are useful for development of effective interventions. Telling people not to make errors or sanctioning them for making them won't prevent them. Addressing the conditions under which they are performing will reduce the likelihood of these failures or errors. We want to get people to focus on the conditions that can affect performance, 


\section{UAS Pilots Code-Annotated Version 1.0}

understand why they have these effects, and what they can do about them." Email from Don Arendt, PhD, PEB Member, ACl (Sept. 12, 2017).

245 ICAO, Human Factors Digest, No. 1, Circular 216-AN/131, p. 1.2 (1989), https://www.icao.int/safety/airnavigation/OPS/Pages/flsmanual.aspx.

24614 C.F.R. § 1.1.

24714 C.F.R. $\S 1.1$.

${ }^{248} 14$ C.F.R. § 1.1; FAA Modernization and Reform Act of 2012, Pub. L. 112-95, § 336(c) (Feb. 14, 2012), available at https://www.faa.gov/uas/media/Sec 331336 UAS.pdf.

${ }^{249} 14$ C.F.R. § 1.1.

${ }^{250}$ FAA, FAA Near Midair Collision System (NMACS), http://www.asias.faa.gov/pls/apex/f?p=100:35:0::NO::P35 REGION VAR:1.

251 14 C.F.R. § 1.1.

252 U.S. Navy, Introduction to Operational Risk Management, OPNAVINST 3500.39, Operational Risk Management, https://www.netc.navy.mil/sobt/web/orm.html. See ASTM Int'l, F3178, Standard Practice for Operational Risk Assessment of Small Unmanned Aircraft Systems (sUAS), available (fee) at https://www.astm.org/COMMITTEE/F38.htm; and JARUS-SORA.

${ }^{253}$ ICAO, Manual on RPAS, Definitions. Cf., UAS-ID ARC Final Report, "the person or organization responsible for ensuring compliance with the ID and tracking regulation."

${ }^{254}$ Unmanned Systems Canada, Small RPAS Best Practices for BVLOS, v1.1, App. 2 Proposed Small RPAS Design Standard, § 5XX.1 Definitions (Feb. 16, 2017), https://www.unmannedsystems.ca/download/uscsmall-rpas-bvlos-best-practices/.

${ }^{255}$ Cf., NTIA, Voluntary Best Practices for UAS Privacy, Transparency, and Accountability, § III. Definitions (May 18, 2016), https://www.ntia.doc.gov/files/ntia/publications/uas privacy best practices 6-21-16.pdf.

${ }^{256}$ Adapted from 14 C.F.R. § 1.1.

257 14 C.F.R. $\S 1.1$.

258 ICAO, Manual on RPAS, § 1.1.1 (“Remotely piloted aircraft are one type of unmanned aircraft. All unmanned aircraft, whether remotely piloted, fully autonomous or combinations thereof, are subject to the provisions of Article 8 of the Convention on International Civil Aviation (Doc 7300), signed at Chicago on 7 Dec. 1944 and amended by the ICAO Assembly.").

259 JARUS, RPAS “Required C2 Performance" (RLP) concept, Doc JAR_DEL_WG5_D.04, http://jarusrpas.org/sites/jarus-rpas.org/files/storage/Library-Documents/jar doc 13 rpl concept upgraded.pdf.

${ }^{260}$ FAA, Order 8040.4B Safety Risk Management Policy, Appx. A, g X.1. (May 2, 2017), https://www.faa.gov/documentLibrary/media/Order/FAA Order 8040.4B.pdf.

${ }^{261}$ ICAO, Safety Management Manual, Doc. 9859 AN/474 (3d. ed. 2013), www.icao.int/safety/SafetyManagement/Documents/Doc.9859.3rd\%20Edition.alltext.en.pdf.

${ }^{262}$ Per 14 C.F.R. Part 5.5, Definitions. 


\section{UAS Pilots Code -Annotated Version 1.0}

${ }^{263}$ FAA, Safety Management System Components, https://www.faa.gov/about/initiatives/sms/explained/components/.

${ }^{264}$ JARUS-SORA, in accordance with 14 C.F.R. 91.113, SERA 3201, and ICAO Annex 2, § 3.2. Consider - "[T]he state of maintaining a safe distance from other aircraft that would not normally cause the initiation of a collision avoidance (CA) maneuver by either aircraft. A well clear separation standard should be large enough to (1) avoid corrective maneuvers by intruders (i.e., any aircraft detected in range of the RPAS's surveillance system) that are equipped with a CA system (e.g., Traffic Alert and Collision Avoidance System (TCAS) - or Airborne Collision Avoidance System (ACAS)), (2) minimize traffic alert issuances by air traffic control (ATC), and (3) avoid excessive concern for pilots of proximate piloted aircraft. However, a well clear separation standard also should be small enough to prevent the need for large deviations that potentially disrupt traffic flow and ATC separation management plans." R. Jay Shively, NASA Ames Research Center, et al., Human Performance Considerations for Remotely Piloted Aircraft Systems (RPAS), ICAO, Remotely Piloted Aircraft Systems Panel (RPASP), Second Mtg. (RPASP/2), Montreal (June 15-19, 2015), § 2.5, p. 51, available at https://ntrs.nasa.gov/archive/nasa/casi.ntrs.nasa.gov/20150011435.pdf.

${ }^{265}$ FAA, Risk Management Handbook, FAA-H-8083-2, p. 5-8.

${ }^{266} 14$ C.F.R. $\S 1.1$.

${ }^{267} 14$ C.F.R. § 1.1, and 14 C.F.R. § 107.3.

${ }^{268}$ FAA, Pilot/Controller Glossary (Aug. 25, 2011), available at http://tfmlearning.faa.gov/Publications/atpubs/PCG/S.HTM.

${ }^{269}$ FAA, Pilot/Controller Glossary (Aug. 25, 2011), available at http://tfmlearning.faa.gov/Publications/atpubs/PCG/S.HTM.

${ }^{270}$ ICAO, Annex 1. Note that as here defined, threats may result from errors committed by actors other than flight crewmembers. In the threat and error management model (TEM), errors committed by crewmembers are considered distinct from threats.

${ }^{271}$ European Helicopter Safety Team (EHEST), The Principles of Threat and Error Management (TEM) for Helicopter Pilots, Instructors and Training Organizations, § 4, p. 18 (Dec. 2014), available at https://www.easa.europa.eu/system/files/dfu/HE8.pdf (also, categorizing UAS as an "unanticipated threat", § 1.2, p. 6).

${ }^{272}$ Uncontrolled airspace may include Class $\mathrm{G}$ and, where applicable, Class F.

${ }^{273} 14$ C.F.R. § 1.1, and 14 C.F.R. § 107.3.

${ }^{274}$ FAA, Pilot Handbook of Aeronautical Knowledge, FAA-H-8083-25B, p. G33 (2016), https://www.faa.gov/regulations policies/handbooks manuals/aviation/phak/media/pilot handbook.pdf.

${ }^{275}$ See FAA, FSIMS 8900.1, Vol. 16, Unmanned Aircraft Systems, § 2, Definitions; 14 C.F.R. § 107.31, Visual line of sight aircraft operation. 